Teste de mutação aplicado a programas concorrentes em MPI

Rodolfo Adamshuk Silva 

SERVIÇO DE PÓS-GRADUAÇÃO DO ICMC-USP

Data de Depósito:

Assinatura:

\title{
Teste de mutação aplicado a programas concorrentes em MPI
}

\author{
Rodolfo Adamshuk Silva
}

Orientadora: Profa. Dra. Simone do Rocio Senger de Souza

Dissertação apresentada ao Instituto de Ciências Matemáticas e de Computação - ICMC-USP, como parte dos requisitos para obtenção do título de Mestre em Ciências - Ciências de Computação e Matemática Computacional. VERSÃO REVISADA 
Ficha catalográfica elaborada pela Biblioteca Prof. Achille Bassi e Seção Técnica de Informática, ICMC/USP, com os dados fornecidos pelo(a) autor(a)

Silva, Rodolfo Adamshuk

S586t Teste de mutação aplicado a programas

concorrentes em MPI / Rodolfo Adamshuk Silva;

orientadora Simone do Rocio Senger de Souza. -- São

Carlos, 2013.

$107 \mathrm{p}$.

Dissertação (Mestrado - Programa de Pós-Graduação em Ciências de Computação e Matemática

Computacional) -- Instituto de Ciências Matemáticas

e de Computação, Universidade de São Paulo, 2013.

1. Teste de software. 2. Teste de mutação. 3. Programação concorrente. I. Souza, Simone do Rocio Senger de, orient. II. Título. 


\section{Agradecimentos}

Agradeço a Deus por, a cada dia, dar-me o melhor dia da minha vida: o hoje. Agradeço também por fazer-me forte e perseverante frente aos desafios de cada dia.

À minha família, em especial aos meus pais, pelo apoio que me deram e por acreditarem que eu estou fazendo um bom trabalho aqui, mesmo longe deles. Obrigado por entenderem a minha ausência e por sempre oferecerem palavras de apoio quando as coisas apertavam por aqui.

À minha orientadora, Prof. ${ }^{a}$ Simone e ao Prof. Paulo, que aqui na USP costumamos dar o título de Mãe e Pai e que, de fato, foram minhas figuras materna e paterna aqui em São Carlos e que, sem dúvida, merecem receber esse título. Obrigado pela atenção, disponibilidade, ajuda e, principalmente, pela paciência que tiveram comigo. Obrigado pelos conselhos e pelas chamadas de atenção sempre que necessários.

Aos meus amigos de Ponta Grossa, por entenderem que não é fácil voltar para Ponta Grossa com tanta frequência quanto todos gostaríamos.

Ao pessoal do Laboratório de Engenharia de Software - LabES pela ajuda e convivência durante esse período e, em especial ao nosso "grupo": Arineiza, Draylson, Eduardo, Eliana, Harry, Joice, Juliana e Silvana. Agradeço também a todos que me ajudaram de alguma forma com a ferramenta ValiMPI.

À Universidade de São Paulo.

À FAPESP pelo apoio financeiro. 

A Programação Concorrente tornou-se uma forma popular de desenvolvimento de software. Este paradigma de desenvolvimento é essencial para construir aplicações com o intuito de reduzir o tempo computacional em muitos domínios como, por exemplo, previsão do tempo, processamento de imagem, entre outros. Estes programas têm novas características como a comunicação, a sincronização e o não determinismo, que precisam ser considerados durante a atividade de teste. O teste de software é uma atividade que busca garantir a qualidade por meio da identificação de falhas no produto. O Teste de Mutação é um critério de teste que se baseia nos enganos que podem ser cometidos pelos desenvolvedores de software. Porém, o teste de mutação não pode ser aplicado em programas concorrentes da mesma maneira como é aplicado em programas sequenciais por causa das particularidades presentes nos programas concorrentes. Um problema de aplicar o teste de mutação nesse contexto é o comportamento não determinístico das aplicações. Este trabalho investiga a definição do teste de mutação para programas concorrentes implementados em MPI (Message Passing Interface), os quais realizam comunicação e sincronização por meio de troca de mensagens. Para isso, defeitos típicos nesse domínio foram considerados, buscando modelar operadores de mutação para tratar os aspectos de comunicação e sincronização dessas aplicações. Também foi proposto um procedimento para dar suporte à análise comportamental dos mutantes. As ideias foram implementadas em uma ferramenta de teste chamada ValiMPI_Mut. 

Concurrent programming became a popular paradigm for software development. This paradigm is essential to build applications which aim to reduce the computational time in many areas, such as, weather forecast, image processing, among others. These programs present new features such as communication, synchronization, and nondeterminism, which must be considered during the testing activity. Software testing is an activity that looks to ensure quality by identifying faults in the product. Mutation Testing is a criterion based on the most common mistakes that might be made by software developers. However, the mutation testing cannot be applied in concurrent programs the same way as applied in sequential ones due to the peculiarities present in concurrent programs. One of the problems in applying mutation testing in this context is the non-deterministic behavior. This work investigates the definition of mutation testing for concurrent programs implemented in MPI (Message Passing Interface), which perform communication and synchronization using message passing. For this, typical faults in this area were considered in order to model mutation operators addressing the aspects of communication and synchronization of these applications. Also, we are proposing a new procedure to support the behavioral analysis of the mutants. The ideas were implemented in a testing tool called ValiMPI_Mut. 

1 Introdução 1

1.1 Contextualização . . . . . . . . . . . . . . . . . . . . . . 1

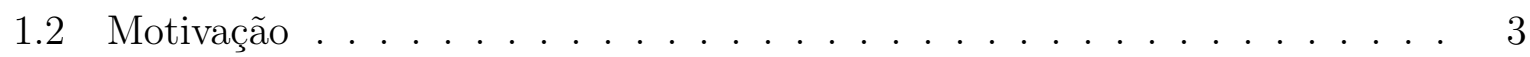

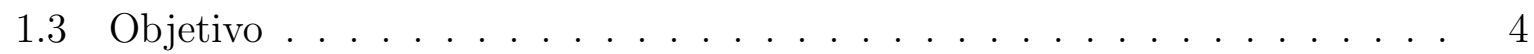

1.4 Organização . . . . . . . . . . . . . . . . . . 4

2 Programação Concorrente 5

2.1 Considerações Iniciais . . . . . . . . . . . . . . . . . . . . . . . 5

2.2 Arquiteturas Paralelas . . . . . . . . . . . . . . . . . . . . . . . . . . . . .

2.3 Geração de Processos Concorrentes . . . . . . . . . . . . . . . . . . . . . . . . . . .

2.3.1 Modelos de Programação Concorrente . . . . . . . . . . . . . . . . 9

2.3.2 Memória Compartilhada . . . . . . . . . . . . . . . . . 10

2.3.3 Passagem de Mensagens . . . . . . . . . . . . . . . . . . . . . . . . 12

2.4 Ferramentas de Apoio à Programação Concorrente . . . . . . . . . . . . . . 14

2.5 O Padrão MPI . . . . . . . . . . . . . . . . . . . . . . 16

2.5.1 Tipos Básicos de Dados e Constantes do Padrão MPI . . . . . . . . 17

2.5.2 Funções MPI . . . . . . . . . . . . . . . . . . . . . . . . . . . . . . . . . . . . . .

2.6 Considerações Finais . . . . . . . . . . . . . . . . . . . . . 24

3 Teste de Software 25

3.1 Considerações Iniciais . . . . . . . . . . . . . . . . . . . . 25

3.2 Terminologia e Conceitos Básicos . . . . . . . . . . . . . . . 26

3.3 Técnicas e Critérios de Teste . . . . . . . . . . . . . . . . . . . 28

3.3 .1 Teste de Mutação . . . . . . . . . . . . . . . . . . . . 30

3.4 Teste Estrutural Aplicado a Programas Concorrentes . . . . . . . . . . . . 34

3.5 Teste de Mutação Aplicado a Programas Concorrentes . . . . . . . . . . . 35

3.5.1 Taxonomia de Erros e Defeitos . . . . . . . . . . . . . . 36

3.5.2 Operadores de Mutação . . . . . . . . . . . . . . . . . . 44

3.5.3 Procedimentos para a Aplicação do Teste de Mutação . . . . . . . . 49

3.6 Ferramenta de Teste ValiMPI . . . . . . . . . . . . . . . . . . 53

3.7 Considerações Finais . . . . . . . . . . . . . . . . . . . 55 
4 Teste de Mutação para Programas em MPI $\quad 57$

4.1 Considerações Iniciais . . . . . . . . . . . . . . . . . . 57

4.2 Operadores de Mutação para MPI . . . . . . . . . . . . . . . . . 57

4.2.1 Constantes Requeridas . . . . . . . . . . . . . . . . 58

4.2 .2 Operadores de Mutação . . . . . . . . . . . . . . . . . . . 59

4.2.2.1 Operadores de Mutação para Funções Coletivas . . . . . . 60

4.2.2.2 Operadores de Mutação para Funções Ponto a ponto . . . 63

4.2.2.3 Operadores de Mutação para Todas as Funções MPI . . . 70

4.3 Comparação dos Operadores para MPI com os Definidos para C . . . . . . 72

4.4 Classificação dos Operadores . . . . . . . . . . . . . . . . . . 73

4.5 Procedimento para a Análise Comportamental de Mutantes . . . . . . . . 76

4.5.1 Procedimento DEMT adaptado . . . . . . . . . . . . . . 76

4.5.2 Procedimento MET adaptado . . . . . . . . . . . . . . . 78

4.6 Considerações Finais . . . . . . . . . . . . . . . . . . . . . . 80

5 Ferramenta de Apoio ao Teste de Mutação $\quad 81$

5.1 Considerações Iniciais . . . . . . . . . . . . . . . . . . . . . . . . 81

5.2 Arquitetura da Ferramenta ValiMPI_Mut . . . . . . . . . . . . . . . 82

5.3 Exemplo de Uso da Ferramenta . . . . . . . . . . . . . . . . . . . . 88

5.4 Considerações Finais . . . . . . . . . . . . . . . . . . . . . . . . . 92

6 Conclusão $\quad 95$

6.1 Caracterização da Pesquisa Realizada . . . . . . . . . . . . . . . . . . . . . 95

6.2 Contribuições . . . . . . . . . . . . . . . . . . . . 96

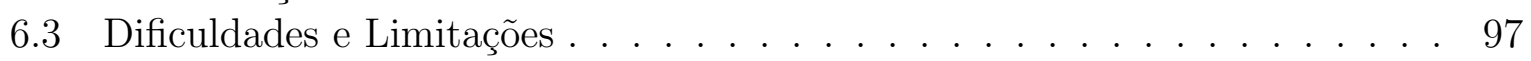

6.4 Trabalhos Futuros . . . . . . . . . . . . . . . . . . . 97

$\begin{array}{ll}\text { Referências } & 107\end{array}$ 
2.1 Taxonomia de arquiteturas com processadores paralelos (Stallings, 2010). . 6

2.2 Arquitetura multiprocessador (a) e multicomputador (b) . . . . . . . . . 7

2.3 Exemplo de como ocorre a comunicação por passagem de mensagens. . . . 13

2.4 Constantes definidas no padrão MPI. . . . . . . . . . . . . . . . . . 18

2.5 Código do programa gcd.c. . . . . . . . . . . . . . . . 23

3.1 Código do programa exemplo. (Delamaro et al., 2007) . . . . . . . . . . 31

3.2 Relacionamento entre os trabalhos encontrados. . . . . . . . . . . . . 44

3.3 Procedimento DEMT. . . . . . . . . . . . . . . . . . . 50

3.4 Fluxo de trabalho da ValiMPI. (Hausen, 2005) . . . . . . . . . . . . 54

4.1 Programa original. . . . . . . . . . . . . . . . . . . . . 62

4.2 Programa mutante. . . . . . . . . . . . . . . . . . . 62

4.3 Classificação dos operadores seguindo a taxonomia de DeSouza et al. (2005). 75

4.4 Procedimento DEMT adaptado. . . . . . . . . . . . . . . . . 77

4.5 Procedimento MET modificado. . . . . . . . . . . . . . . . . . . . 79

5.1 Arquitetura da ferramenta ValiMPI_Mut. . . . . . . . . . . . . . . 83

5.2 Diagrama de classes do módulo "Código Original". . . . . . . . . . . . . . 84

5.3 Diagrama de classes do módulo "Caso de Teste". . . . . . . . . . . . . . . 85

5.4 Diagrama de classes do módulo "Mutantes". . . . . . . . . . . . . . . . 86

5.5 Diagrama de classes do módulo "Teste de Mutação". . . . . . . . . . . . . . 87

5.6 Tela inicial e opções do menu. . . . . . . . . . . . . . . . . . . . . . . . . . 88

5.7 Tela para criar um novo projeto. . . . . . . . . . . . . . 88

5.8 Tela para adicionar um código a ser testado. . . . . . . . . . . . . . 89

5.9 Arquivos gerados quando um novo projeto de teste é criado. . . . . . . . . 89

5.10 Tela para adicionar um caso de teste. . . . . . . . . . . . . . . . . . . 89

5.11 Arquivos gerados a partir da execução do caso de teste 1. . . . . . . . . . . 90

5.12 Aba para visualizar as entradas dos casos de teste. . . . . . . . . . . . . 90

5.13 Aba para visualizar as saídas dos casos de teste. . . . . . . . . . . . . . . 91

5.14 Tela para criar mutantes. . . . . . . . . . . . . . . . . . . . . . 91

5.15 Tela para visualizar mutante. . . . . . . . . . . . . . . . . . 92

5.16 Informações sobre o resultado da execução de um mutante morto. . . . . . . 93 
5.17 Informações sobre um mutante vivo. . . . . . . . . . . . . . . . . . 93

5.18 Informações sobre a aplicação do teste de mutação . . . . . . . . . . . . . . 93 


\section{Lista de Tabelas}

2.1 Tipos básicos no padrão MPI e sua correspondência com a linguagem C. . 17

3.1 Mutantes gerados pelo operador ORRN. (Delamaro et al., 2007) . . . . . . 32

4.1 Conjunto de constantes requeridas (Delamaro, 1997) . . . . . . . . . . . 59

4.2 Operadores de mutação para programas em MPI. . . . . . . . . . . . . 60

4.3 Operadores de mutação para o padrão MPI e sua correspondência para com os operadores para a linguagem C . . . . . . . . . . . . . 73

5.1 Funcionalidades do módulo "Código Original". . . . . . . . . . . . . . . . . 84

5.2 Funcionalidades do módulo "Caso de Teste". . . . . . . . . . . . . . . . . 85

5.3 Funcionalidades do módulo "Mutantes". . . . . . . . . . . . . . . . . . . . 87

5.4 Funcionalidades do módulo "Teste de Mutação". . . . . . . . . . . . . . . . 87 


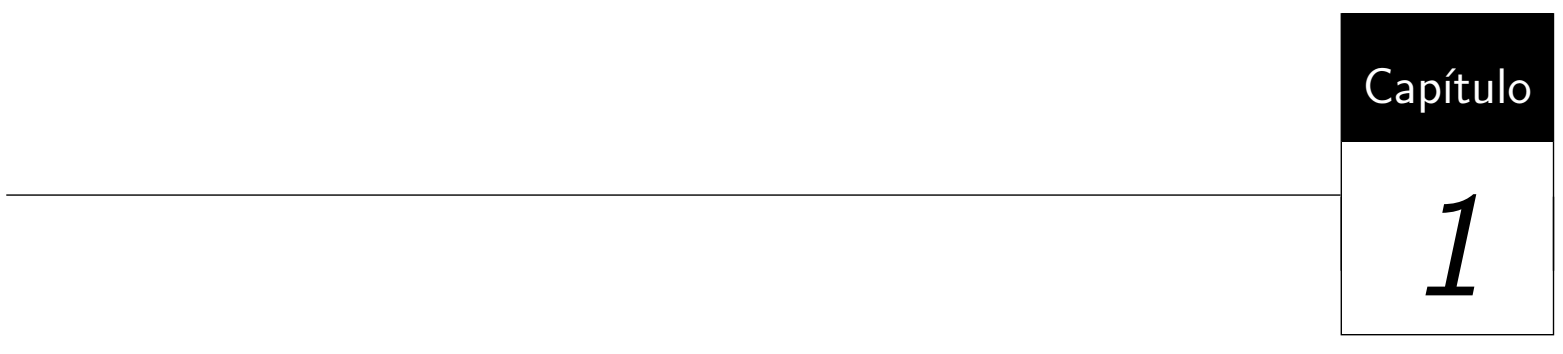

Introdução

\subsection{Contextualização}

Como um resultado dos avanços tecnológicos na área de hardware, como por exemplo processadores multicore, a computação distribuída faz-se cada vez mais presente nos sistemas atuais. Com isso, a programação concorrente está tornando-se cada vez mais popular no desenvolvimento de softwares modernos. Pode-se citar como exemplo um servidor Web que cria processos (ou threads) separados para atender as requisições dos clientes, aumentando o desempenho da aplicação. Esse paradigma de desenvolvimento é essencial para a construção de aplicações capazes de reduzir o tempo computacional em vários domínios, como é o caso de softwares para previsão de tempo, dinâmica de fluídos, processamento de imagens, química quântica, entre outros. Esses programas apresentam novas características como comunicação, sincronização e, como consequência, o não determinismo. Essas características devem ser consideradas durante a proposição de mecanismos de apoio para o desenvolvimento dessas aplicações concorrentes. Nesse contexto, a atividade de teste de software apresenta-se com desafiadora, pois novas questões precisam ser exploradas.

Teste de software é uma atividade de garantia de qualidade que visa a identificar defeitos no produto em teste. A atividade de teste consiste em uma análise dinâmica do produto e é uma atividade relevante para a identificação e eliminação de defeitos que persistem. O teste de produtos de software envolve basicamente quatro etapas: planejamento de testes, projeto de casos de teste, execução e avaliação dos resultados dos testes (Dela- 
maro et al., 2007; Myers et al., 2011). Essas atividades devem ser desenvolvidas ao longo do próprio processo de desenvolvimento de software, e, para isso, um ponto crucial é a seleção dos casos de teste que serão utilizados. Sabe-se que executar todos os casos de teste possíveis a partir do domínio de entrada do produto em teste é impraticável e, portanto, critérios de teste são definidos. Os critérios de teste procuram estabelecer como selecionar casos de teste que possuam alta probabilidade de encontrar a maioria dos defeitos com um mínimo de tempo e esforço. Portanto, o teste bem sucedido é aquele que consegue determinar casos de teste para os quais o programa em teste falhe. Tem-se observado que a própria atividade de projeto de casos de teste é bastante efetiva em evidenciar a presença de defeitos de software.

No contexto de programas tradicionais (ou programas com características sequenciais), foram identificadas ao longo dos anos várias iniciativas de técnicas e critérios para a validação, as quais consideram duas questões importantes em relação à atividade de teste: 1) seleção de casos de teste e 2) avaliação da adequação dos casos de testes em relação ao programa em teste (DeMillo et al., 1978; Maldonado, 1991; Myers et al., 2011). Esses trabalhos oferecem a base fundamental para que novos critérios e novos modelos de teste sejam propostos, considerando os paradigmas e metodologias atuais de desenvolvimento de software como, por exemplo, orientação a objetos, a aspectos e processos ágeis. Outra tendência é explorar e adaptar esses conceitos de teste para outros domínios de aplicação, tais como: sistemas de informação, aplicações concorrentes/distribuídas, sistemas de tempo real e sistemas embarcados.

Diferentemente dos programas tradicionais, a computação distribuída envolve programas (ou processos) concorrentes (ou paralelos) que interagem para resolver um determinado problema. Essa interação pode ocorrer de forma sincronizada ou não, sendo que esses programas podem ou não concorrerem pelos mesmos recursos computacionais. A construção de processos concorrentes requer o uso de algumas primitivas fundamentais, necessárias para permitir: 1) a definição de quais processos serão executados em paralelo; 2) a inicialização e finalização dos processos concorrentes e; 3) a coordenação entre os processos concorrentes enquanto estes estiverem executando (Almasi e Gottlieb, 1989). Desses três tipos de primitivas, destacam-se as primitivas necessárias à interação (comunicação e sincronização) entre os processos, devido à sua frequência de utilização bem como impacto no desempenho final do programa concorrente.

A atividade de teste no contexto de programas concorrentes é considerada mais complexa quando comparada com a atividade de teste de programas sequenciais. Além das dificuldades inerentes à atividade de teste, outras ocorrem devido, principalmente, ao comportamento não determinístico dessas aplicações, no qual múltiplas execuções de um programa concorrente com a mesma entrada podem executar diferentes sequências de 
sincronização e podem produzir diferentes resultados. Cabe à atividade de teste, nesse cenário, identificar se todas as sequências de sincronização possíveis foram executadas e se as saídas obtidas estão corretas. Essa característica difere os programas concorrentes dos programas sequenciais e precisa ser considerada durante a atividade de teste de software.

Um dos critérios de testes da técnica baseada em defeitos é o teste de mutação. Este critério utiliza informações sobre os enganos típicos que podem ser cometidos no processo de desenvolvimento para derivar casos de teste (Delamaro et al., 2001). Assim, os defeitos típicos de um domínio ou paradigma de desenvolvimento são caracterizados e implementados como operadores de mutação que, durante a atividade de teste, geram versões modificadas (mutantes) do produto em teste (especificação ou implementação, por exemplo). A intenção é auxiliar a seleção de casos de teste que demonstrem que os defeitos modelados pelos operadores de mutação não estão presentes no produto em teste. Essa técnica é dependente dos defeitos típicos do domínio e, desse modo, esses defeitos precisam ser caracterizados para que os critérios possam ser aplicados.

Assim como os demais critérios de teste, o teste de mutação tem sido investigado para programas concorrentes (Bradbury et al., 2006; Delamaro et al., 2001; Ghosh, 2002; Giacometti et al., 2003; Jagannath et al., 2010; Offutt et al., 1996; Sen, 2009; Silva-Barradas, 1998; Wu e Kaiser, 2011). No contexto de programas concorrentes com passagem de mensagem, existem poucas inciativas, o que motivou o desenvolvimento deste trabalho, visto que esse é um paradigma amplamente utilizado para o desenvolvimento de aplicações concorrentes.

\subsection{Motivação}

As seguintes constatações serviram de motivação para a proposição deste trabalho:

1. Teste de software é reconhecido como uma atividade fundamental, independentemente do domínio de aplicação do programa a ser testado;

2. O teste de mutação tem demonstrado ser um critério bastante eficaz para revelar defeitos;

3. Não existe uma ferramenta de apoio ao teste de mutação no contexto de programas concorrentes com paradigma de troca de mensagens;

4. Falta de um mecanismo automatizado para injetar defeitos em programas concorrentes, importante para a condução de estudos experimentais para a avaliação da eficácia em revelar defeitos de critérios de teste nesse contexto. 


\subsection{Objetivo}

Este projeto de mestrado tem como objetivo investigar a definição do teste de mutação para o contexto de programas concorrentes. Diferentemente dos trabalhos anteriores, este projeto investigou a definição desse critério considerando programas concorrentes com memória distribuída, desenvolvidos utilizando o ambiente MPI (Message Passing Interface). O padrão MPI (Forum, 1995) surgiu como uma tentativa de padronização dos ambientes de passagem de mensagem por meio de uma especificação para o desenvolvimento de aplicações paralelas.

Além de explorar a definição de operadores de mutação, este trabalho tem como objetivo a caracterização de uma abordagem para a execução dos programas mutantes, uma vez que o não determinismo é um fator que influencia a execução dos mutantes. Isso ocorre porque, dependendo da sequência de comandos e sincronizações executadas, a saída obtida pode variar, comprometendo, assim, a avaliação do comportamento dos programas mutantes. Por fim, este trabalho tem como objetivo de apresentar uma ferramenta para dar suporte à utilização do teste de mutação no contexto de programas concorrentes em MPI.

\subsection{Organização}

No Capítulo 2 são apresentados conceitos sobre programas concorrentes, definições e suas principais características. Nesse capítulo é apresentada uma visão geral sobre algumas funções do padrão MPI nas quais alguns operadores de mutação definidos são aplicados.

No Capítulo 3 são apresentados conceitos sobre teste de software, as técnicas e os critérios para a realização dos testes, dando maior destaque ao critério de teste de mutação, uma vez que este é o tema deste projeto de mestrado.

No Capítulo 4 são apresentadas as principais contribuições na área de teste para programas concorrentes. Primeiramente são apresentados os operadores de mutação definidos para programas em MPI, em seguida é feita uma comparação desses operadores com os operadores de mutação definidos para a linguagem C. Após isso, é apresentada a classificação dos operadores definidos com relação à taxonomia de defeitos escolhida. Por fim, são apresentados dois procedimentos para a aplicação da análise comportamental dos mutantes.

No Capítulo 5 é apresentada a ferramenta ValiMPI_Mut, mostrando as classes que compõem cada módulo da ferramenta. Em seguida é mostrada a utilização da ferramenta para criar uma sessão de teste.

Por fim, o último capítulo apresenta as conclusões deste trabalho de mestrado. 


\section{Programação Concorrente}

\subsection{Considerações Iniciais}

A programação concorrente agrega novos conceitos, modelos e primitivas à programação sequencial, permitindo o desenvolvimento de algoritmos que, quando executados, dão origem a processos que podem executar concorrentemente e que interagem na solução de problemas. Dessa forma, a programação concorrente permite que uma tarefa seja dividida em porções menores para, assim, aumentar o desempenho da aplicação, melhorar a tolerância a falhas ou otimizar o uso de recursos como processadores, memória e dispositivos de entrada e saída (E/S).

Neste capítulo são apresentados conceitos sobre programas concorrentes, definições e suas principais características. Na Seção 2.2 são apresentadas as arquiteturas paralelas segundo Flynn (1972) e descritas as principais características de cada uma. Na Seção 2.3 é descrito como ocorre a geração de processos correntes, os modelos de programação concorrente e os paradigmas que podem ser utilizados. A Seção 2.4 apresenta ferramentas de apoio à programação concorrente. A Seção 2.5 descreve o padrão MPI, apresentando algumas funções presentes no padrão. Por fim, na Seção 2.6 são apresentas as considerações finais deste capítulo. 


\subsection{Arquiteturas Paralelas}

A arquitetura de um sistema diz respeito a como o hardware está organizado, levando em consideração as interconexões entre os processadores e como ocorre a comunicação entre eles. Algumas taxonomias foram desenvolvidas para agrupar arquiteturas paralelas com características similares. A taxonomia de Flynn (1972), que pode ser vista na Figura 2.1 identificou quatro modelos de processamento baseados no fluxo de instruções e de dados:

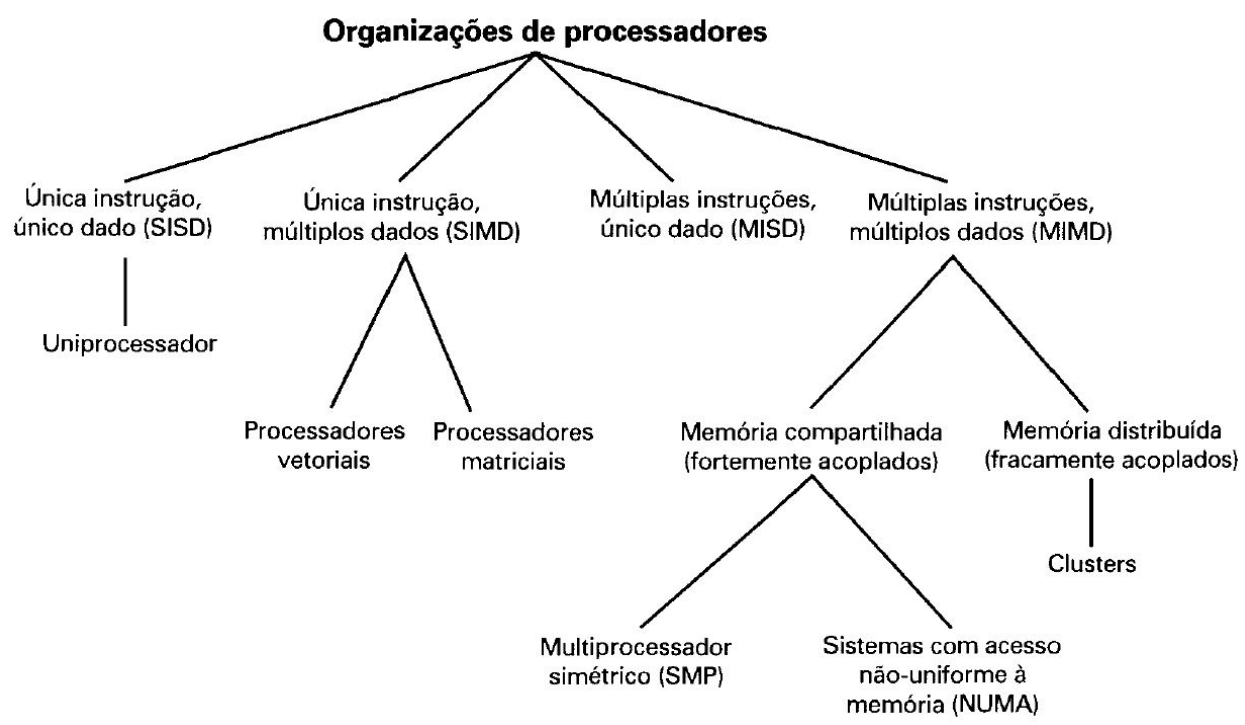

Figura 2.1: Taxonomia de arquiteturas com processadores paralelos (Stallings, 2010).

- SISD (Single Instruction stream, Single Data stream): Esse modelo corresponde ao processamento convencional obtido com a arquitetura de Von Neumann que consiste em uma única Unidade de Controle (UC) determinando um fluxo de instruções operando sobre um único fluxo de dados. O nível de microarquitetura, abaixo da arquitetura do conjunto de instruções do processador, permite a execução paralela por meio de pipeline, no qual há diferentes instruções executando diferentes estágios do pipeline.

- SIMD (Single Instruction stream, Multiple data Stream): Esse modelo corresponde ao uso de vários elementos de processamento controlados por uma única UC que gera o mesmo fluxo de instruções operando sobre múltiplos fluxos de dados. Processadores matriciais e vetoriais são exemplos de arquiteturas desta categoria.

- MISD (Multiple Instruction stream, Single Data stream): Esse modelo corresponde à execução em paralelo de diferentes instruções, obtidas de diferentes UCs, operando 
sobre um único fluxo de dados. É considerada por alguns autores como uma classe de arquitetura sem produtos comerciais.

- MIMD (Multiple Instruction stream, Multiple Data stream): Nesse modelo, vários elementos de processamento recebem diferentes fluxos de instrução vindos de UCs distintas e operam sobre diferentes fluxos de dados. Processadores executam diferentes códigos em diferentes conjuntos de dados. Este é o modelo de operação em sistemas distribuídos e na maioria dos sistemas paralelos atuais. Máquinas MIMD são classificadas de acordo com a organização de memória, organização essa, que afeta diretamente o modo de como os processos vão realizar a interação durante a execução. As máquinas MIMD podem possuir memória compartilhada (multiprocessador) ou distribuída (multicomputador).

- Sistema multiprocessador é um sistema paralelo no qual vários processadores possuem acesso direto à memória compartilhada que forma um espaço de endereçamento comum. A arquitetura multiprocessador pode ser vista na Figura 2.2 (a). Os processadores estão muito próximos fisicamente e estão conectados por uma rede interconectada. A comunicação entre processos é tradicionalmente feita por meio de operações de escrita e leitura na memória compartilhada. Todos os processadores geralmente executam o mesmo sistema operacional.

- Sistema multicomputador é um sistema paralelo no qual os múltiplos processadores não possuem acesso direto à memória compartilhada. Esta arquitetura pode ser vista na Figura 2.2 (b). A memória dos multicomputadores pode ou não formar um espaço de endereçamento comum. A comunicação é feita por meio de espaço de endereçamento comum ou via passagem de mensagem.

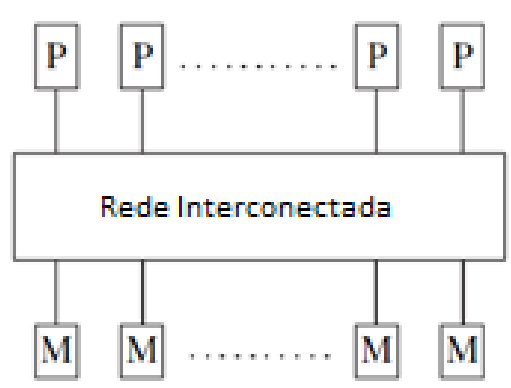

(a)

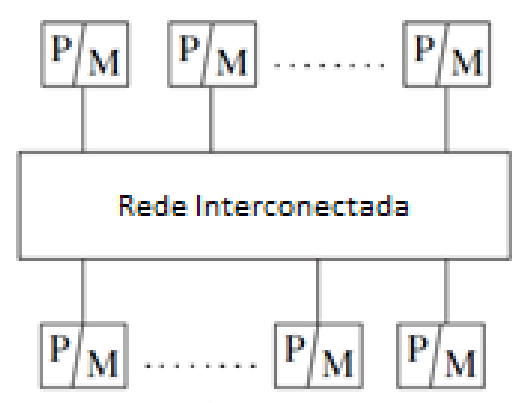

(b)

$M$ memória $\quad$ p processador

Figura 2.2: Arquitetura multiprocessador (a) e multicomputador (b).

É importante observar que o uso do paradigma de programação baseado em passagem de mensagens ou variáveis compartilhadas pode ser determinado tanto pelo hardware 
quanto pelo software. Mesmo que a arquitetura não disponibilize o paradigma desejado, este pode ser simulado em software, no nível do Sistema Operacional, da linguagem de programação ou na aplicação (Tanenbaum, 2007).

O foco deste trabalho está em estudar aplicações concorrentes desenvolvidas para serem executadas em máquinas MIMD e sob o paradigma de passagem de mensagens.

\subsection{Geração de Processos Concorrentes}

A programação concorrente tem como objetivo o desenvolvimento de programas concorrentes. Segundo Andrews (2001), um programa concorrente contém dois ou mais processos ou threads que trabalham juntos para realizar uma tarefa. Esse estilo de programação se difere da programação sequencial, pois esta última é utilizada nas arquiteturas de Von Neumman e possui basicamente: instruções executadas sequencialmente, desvios condicionais, desvios incondicionais ou chamadas a procedimentos e estruturas de repetição. Já a programação concorrente permite otimizar o desempenho dessas aplicações, explorando a concorrência em diferentes arquiteturas, permitindo assim uma melhor utilização dos recursos disponíveis.

A ideia básica da programação concorrente, portanto, é que determinadas aplicações sejam divididas em processos concorrentes, sendo cada um responsável pela resolução de um pedaço do problema. Essa divisão em processos concorrentes é obtida por meio de recursos de software adicionais, esses responsáveis, por exemplo, pela ativação e finalização de processos concorrentes e que não estão disponíveis para programas sequenciais.

No contexto deste trabalho, uma aplicação é composta por um ou mais processos. Um programa é uma sequência de instruções. Um processo é um programa em execução, composto pelo programa, um conjunto de dados e um registro descritor (área da memória que armazena o conteúdo dos registradores quando o processo não está executando). Uma thread (ou processo leve) é uma linha de controle independente dentro do processo (Tanenbaum, 2007).

Segundo Almasi e Gottlieb (1989), processos concorrentes são processos que começaram a sua execução e, em um determinado instante do tempo, ainda não a finalizaram. Esses processos concorrem por recursos como processadores, memória e dispositivos de E/S. Processos paralelos, por sua vez, representam um tipo especial de processos concorrentes, pois há a garantia que eles estejam executando em diferentes processadores e no mesmo intervalo de tempo.

Para obter-se um ganho de velocidade por meio do uso de paralelismo é necessário dividir a computação em tarefas ou processos que possam executar simultaneamente (Wilkinson e Allen, 1999). O número e o tamanho de cada tarefa em que um problema 
é decomposto determina a granularidade da decomposição. Segundo Grama et al. (2003) uma decomposição em um grande número de pequenas tarefas é chamada de granularidade fina. Já a decomposição em um pequeno número de grandes tarefas é chamado de granularidade grossa. Uma granularidade fina requer um número maior de processadores, uma vez que há mais processos para serem executados, enquanto uma granularidade mais grossa, comparativamente, precisa de um número menor de processadores. Um conceito que possui relação com a granularidade é o grau de concorrência. O número máximo de tarefas que podem ser executadas simultaneamente em um programa concorrente em um mesmo tempo é chamado de grau de concorrência máximo.

Um programa concorrente é composto por processos ou threads conforme o contexto no qual está inserido. Quando a programação segue o paradigma de passagem de mensagem os programas normalmente são compostos por processos. Em ambientes de memória compartilhada são compostos por threads (Tanenbaum, 2007).

\subsubsection{Modelos de Programação Concorrente}

No desenvolvimento de programas concorrentes há diferentes modelos que podem ser utilizados. Esses modelos são maneiras de estruturar o algoritmo paralelo selecionando uma decomposição, mapeando uma técnica e aplicando a estratégia apropriada com a intenção de minimizar o número de interações entre as tarefas. Há 8 tipos principais de modelos que podem ser empregados para o desenvolvimento de programas concorrentes (Grama et al., 2003).

1. Pipeline: No modelo pipeline, um fluxo de dados passa por uma sequência de processos, cada um executando uma tarefa diferente. O pipeline pode ser visto como uma cadeia de produtores-consumidores. Cada processo inicia a execução de sua tarefa ao receber os dados do processo anterior na cadeia e produz os dados para o processo seguinte. Os processos não precisam necessariamente ser organizados de forma linear; pode-se construir pipelines com estrutura multidimensional, árvores ou grafos direcionais.

2. Mestre-Escravo: No modelo mestre-escravo, um ou mais processos mestres alocam tarefas para os processos escravos. Ao utilizar-se esse modelo, deve-se tomar cuidado para que o processo mestre não se torne um gargalo, caso as tarefas sejam muito pequenas, ou os escravos sejam muitos rápidos. Assim, a granularidade deve ser escolhida de modo que o custo de atribuir tarefas e de sincronização seja menor que o custo de executar as tarefas.

3. Modelo de Grafo de Tarefas: Nesse modelo, a relação entre as tarefas é utilizada para reduzir os custos de interação. Esse modelo é tipicamente empregado para 
solucionar problemas nos quais a quantidade de dados associado com as tarefas é maior do que a quantidade de computação associada a eles, favorecendo a localidade dos dados.

4. Modelo de Dados Paralelos: O mais simples dos modelos, no qual as tarefas são mapeadas estaticamente ou semi-estaticamente em processos e cada tarefa desenvolve uma operação similar em dados diferentes. Esse tipo de paralelismo é resultado de operações iguais sendo executadas concorrentemente em dados diferentes. Também é conhecido como paralelismo de dados.

5. SPMD (Single Program Multiple Data): Nesse modelo uma cópia do mesmo programa é executada em cada processador, com dados diferentes. Esse modelo é amplamente usado por diversas plataformas paralelas e requer suporte arquitetural mínimo.

6. MPMD (Multiple Program Multiple Data): Nesse modelo cada processador tem seu próprio programa, executando sobre dados diferentes.

7. Work Pool: No modelo work pool ou task pool é utilizado um mapeamento dinâmico da computação a ser feita, visando o balanceamento de carga, no qual cada tarefa possui o mesmo potencial de ser executada por qualquer processo.

8. Híbrido: Em alguns casos, mais de um modelo pode ser aplicado para o problema em questão, resultando em um modelo híbrido. Um modelo híbrido pode ser composto por vários modelos aplicados hierarquicamente ou sequencialmente em diferentes fases do algoritmo. Em alguns casos a formulação do algoritmo pode apresentar características de mais de um modelo.

Levando em consideração como os processos irão interagir com relação à comunicação e sincronização, os paradigmas de desenvolvimento podem ser de duas formas: 1) Espaço de endereçamento compartilhado (variáveis compartilhadas) e 2) Passagem de mensagens. Quando variáveis compartilhadas são usadas, um processo escreve em uma variável que pode ser lida e/ou atualizada por outro processo ou thread que compartilha o mesmo espaço de endereçamento. Quando a passagem de mensagens é usada, um processo envia uma mensagem que é recebida por outro, por meio do uso das primitivas básicas send() (envio) e recv() (recebimento).

\subsubsection{Memória Compartilhada}

Segundo Scott et al. (2005), de uma maneira geral, programação com memória compartilhada permite um acesso uniforme a variáveis. Enquanto isso parece ser um benefício, 
muitos agentes irão acessar esse recurso compartilhado, então há a necessidade de mecanismos que assegurem a corretude dos resultados. O ponto chave nesse contexto é a utilização de ações para a sincronização de processos como, por exemplo, os semáforos. Outras abstrações também permitem a sincronização de processos com memória compartilhada como é o caso das barreiras, monitores e variáveis de condição (Grama et al., 2003; Tanenbaum, 2007).

A sincronização entre os processos pode ser feita utilizando-se Semáforos e/ou Barreiras. O semáforo é um tipo de dado abstrato composto por uma variável inteira, normalmente iniciada com o valor 1 , e uma lista de processos, inicialmente vazia. Um semáforo é formado por uma variável controlada pelo Sistema Operacional e manipulada por duas operações atômicas conhecidas como: lock (var_sem) ou p (var_sem) e unlock (var_sem) ou v (var_sem) (Tanenbaum, 2007). Essas operações são necessárias para o bloqueio e o desbloqueio de um semáforo.

Basicamente a operação lock () tenta decrementar o valor de var_sem caso esta tenha um valor superior a zero. Caso a variável seja 0 , o processo que executou a primitiva é retirado de execução e colocado para dormir (fila de bloqueado esperando por E/S). A operação unlock incrementa var_sem e caso algum processo esteja dormindo devido ao valor anterior como zero dessa variável, tal processo é colocado na fila de pronto para execução, a fim de disputar novamente o semáforo no operação unlock ().

Geralmente, declara-se um semáforo diferente para cada lugar onde há a necessidade de coordenação precedida de uma região crítica, ou seja, uma região onde há acesso de escrita em dados compartilhados.

Semáforos podem apresentar diferentes valores acima de 0. Há um caso especial de semáforo que assume apenas valores 0 e 1 . Tais semáforos binários também são conhecidos como MUTEX, por serem aplicados fundamentalmente em operações de exclusão mútua.

A barreira é outra estrutura normalmente usada para sincronização de threads ou processos paralelos. A barreira é usada para parar a execução de uma thread até que todas as outras threads participantes da barreira tenham alcançado a barreira (Grama et al., 2003). Barreiras podem ser implementadas usando um contador, um MUTEX ou variável de condição. Uma única variável do tipo inteiro é usada para controlar o número de threads que chegam à barreira. Caso o contador seja menor que o total de threads, elas executam a função de espera. A última thread entra na barreira, fazendo o valor do contador igualar ao número de threads e com isso, acordando todas as outras threads usando a função de broadcast. 


\subsubsection{Passagem de Mensagens}

O paradigma de programação baseado em passagem de mensagens permite a interação entre processos que não compartilham o mesmo espaço de endereçamento. O termo passagem de mensagem refere-se a um modelo de programação baseado em CSP (Processos de Comunicação Sequencial) (Roscoe et al., 1997). No CSP essa comunicação ocorre por meio de canais que conectam processos separados. Esses canais são declarados estaticamente no código. O problema com a utilização de canais está na necessidade de haver muitos canais para que não haja ambiguidade na comunicação. Os canais não proviam a flexibilidade necessária para uma comunicação com um grande número de processos em diferentes tempos com diferentes intenções.

Os dois elementos chave no modelo de passagem de mensagem são: Send - uma mensagem contendo dados para um determinado processador; Receive - uma mensagem contendo dados de um determinado processador. As operações básicas de send e receive vão variar de um sistema para outro, mas geralmente vão seguir o seguinte modelo:

$$
\begin{aligned}
& \text { snd(tag, memlocat, type, procwich, size) } \\
& \text { rcv(tag, memlocat, type, procwich, size) }
\end{aligned}
$$

Aqui, tag corresponde a um identificador para a mensagem que está sendo enviada ou recebida, memlocat é o início do espaço de memória da mensagem a ser enviada está, no caso do send ou para onde ela será copiada, no caso do receive. Size significa o tamanho do array que será enviado ou recebido e type diz quantos bytes há por item no array. A variável procwich indica o processo de destino da mensagem, no caso do send e o transmissor, no caso do receive.

Um mecanismo de sincronização utilizado em programas desenvolvidos no modelo de passagem de mensagem é o rendezvous synchronization que é um ponto de execução onde duas tarefas se encontram. A diferença entre uma barreira e um rendezvous é que a barreira permite a atividade de sincronização entre duas ou mais tarefas, enquanto que no rendezvous a sincronização é feita entre duas tarefas.

A Figura 2.3 apresenta uma representação de como ocorre a comunicação utilizando o paradigma de passagem de mensagens. Na figura é mostrado um programa que possui 4 processos (P0, P1, P2 e P3) cooperando para realizar uma determinada tarefa. As linhas verticais representam a sequência de execução do processo e os retângulos representam os pontos onde há o envio (send) ou recebimento (recv) de mensagens. As setas contínuas representam o fluxo da mensagem entre os processos e as setas tracejadas representam um possível fluxo de mensagem e não se pode ter certeza de qual fluxo irá acontecer durante a execução do programa. 


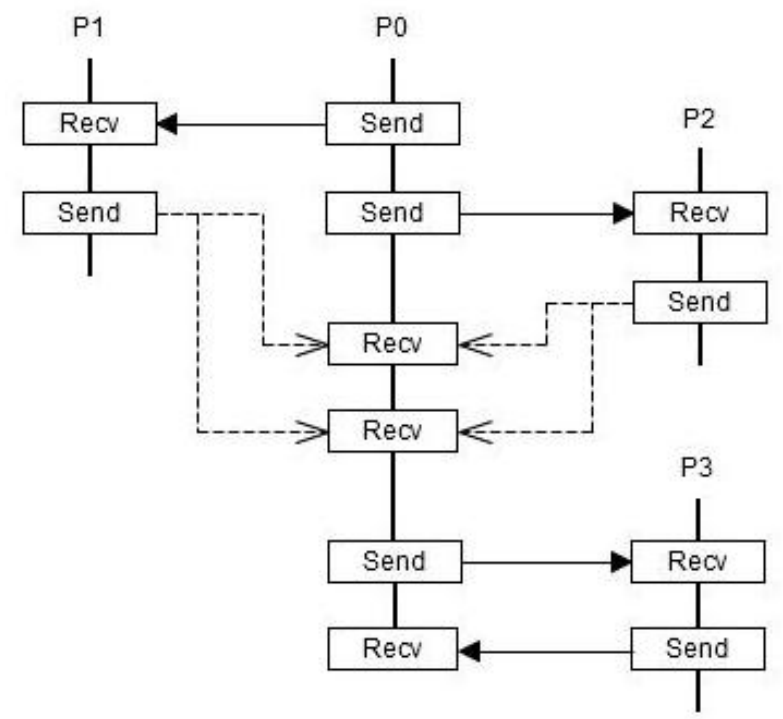

Figura 2.3: Exemplo de como ocorre a comunicação por passagem de mensagens.

Segundo Ben-Ari (1990) em um rendezvous, dois processos encontram-se e sincronizam por um pequeno período de tempo. Nesse contexto, identificam-se dois tipos de processos. O accepting process é o processo que define um lugar de encontro entre os dois processos. Esse processo não precisa saber quem é o processo que faz a chamada para o rendezvous. O calling process é o processo que faz a chamada para o rendezvous. Esse processo precisa saber a identidade do accepting process e a identidade do rendezvous. A sincronização funciona da seguinte forma: Primeiramente o calling process faz uma chamada para o accepting process e bloqueia até que o accepting process esteja pronto para aceitar a chamada. Durante o rendezvous, o accepting process produz um resultado usando parâmetros fornecidos pelo calling process. Ao final do rendezvous, o calling process recebe o resultado e é desbloqueado.

Existem algumas alternativas disponibilizadas aos programadores, as quais são abstrações construídas sobre as primitivas send e receive. Pode-se citar como exemplos dessas alternativas a RPC (Remote Procedure Call) e a RMI (Remote Method Invocation). A RPC é um mecanismo de comunicação alto nível para aplicações distribuídas. É baseada na noção convencional de uma chamada local, de modo que o procedimento chamado não precisa existir no mesmo espaço de endereço como um procedimento de chamada. Os dois processos podem estar no mesmo sistema ou podem estar em sistemas diferentes com uma rede conectando-os ( $\mathrm{Li}, 2000)$. Já a RMI fornece um modelo simples e direto para a computação distribuída com objetos Java. Esses objetos podem ser objetos Java ou pode ser simples invólucros em torno de uma API Java já existente.

O modelo de passagem de mensagem apresenta algumas vantagens com relação ao modelo de espaço de endereçamento compartilhado. Gropp et al. (1999) apresentam algumas dessas vantagens. 
- Universalidade - O modelo de passagem de mensagem encaixa-se bem em processadores conectados por uma comunicação de rede, seja ela rápida ou lenta. Assim, pode ser executado na maioria dos supercomputadores paralelos atuais, assim como nos clusters de PCs.

- Expressividade - Passagem de mensagem foi criada para ser um modelo de fácil utilização e completo para desenvolver algoritmos paralelos, fornecendo o controle local dos dados.

- Fácil Depuração - O processo de depuração é mais fácil de ser realizado nos programas desenvolvidos usando o paradigma de passagem de mensagem. Isso acontece porque uma das causas mais comuns de erros não esperados é quando ocorre a sobreposição de dados na memória. O modelo de passagem de mensagens, controlando mais explicitamente as referências de memória do que os outros modelos (apenas um processo possui acesso direto a qualquer local de memória), deixa fácil a localização de erros de leitura e escrita de memória.

- Desempenho - Uma das vantagens principais deste modelo é com relação ao desempenho. Como as CPUs modernas estão cada vez mais rápidas, gerenciar cache e hierarquia de memória em geral tem tornado-se um ponto chave quando se quer aproveitar o máximo dessas máquinas. Passagem de mensagem provê uma forma para o programador deixar explícita a associação entre os dados e os processos e, assim, permitir que o compilador e o gerenciador de cache funcionem completamente. De fato, uma vantagem que os computadores com memória distribuída possuem em relação aos computadores com um processador é que eles proveem mais memória e mais cache.

\subsection{Ferramentas de Apoio à Programação Concorrente}

Programas concorrentes podem ser implementados basicamente de três maneiras: utilizando compiladores que paralelizam o código sequencial, utilizando linguagens específicas para aplicações paralelas ou utilizando extensões de linguagens. Segundo Quinn (2003), dezenas de linguagens para programação paralela foram introduzidas nos últimos 40 anos. Muitas delas eram de alto nível o que tornava o desenvolvimento mais simples para o usuário.

A linguagem de programação Ada permite a implementação de programas concorrentes baseados em dois diferentes paradigmas. O primeiro consiste na sincronização de tarefas baseado em rendezvous e outro consiste na comunicação por meio de objetos de dados. A comunicação entre as tarefas é provida por chamadas de entradas e a subprogramas 
protegidos. Chamadas a subprogramas protegidos permitem coordenar os acessos a dados protegidos. Chamadas de entrada permitem o bloqueio do processo que realiza a chamada até que uma determinada condição seja satisfeita (Silva-Barradas, 1998).

Occam é uma linguagem de programação baseada na CSP (Communicating Sequential Processes) (Roscoe et al., 1997). Em occam, os processos são conectados para a formação de sistemas concorrentes, podendo cada um deles ser visto como uma "caixa preta" com seu próprio estado interno e estabelecendo comunicação com os demais pelo uso de canais de comunicação ponto a ponto. Processos podem modelar o comportamento de muitas coisas, como uma porta lógica, um microprocessador, etc. Um processo inicia, efetua ações e termina. Uma ação pode ser um conjunto de processos sequenciais, um executado após o outro, ou um conjunto de processos paralelos, a serem executados de forma concorrente. Uma vez que um processo pode conter outros processos, os quais podem ser executados simultaneamente, pode-se observar um certo grau de concorrência intraprocesso, variando à medida que a execução evolui (Hyde, 1995).

Python é uma linguagem de programação e um conjunto de ferramentas de software e bibliotecas. Python foi criada para ser de fácil leitura e desenvolvimento. A programação concorrente em Python é realizada utilizando-se threads por meio de um módulo que tem como função prover uma interface que suporte a programação com threads. Esse módulo provê uma classe Thread que gerencia as suas threads e também os objetos de sincronização necessários nas aplicações com threads (Lutz, 2011).

A linguagem Java também permite a programação concorrente por meio da criação de threads. Os mecanismos básicos de sincronização das threads são os blocos e os métodos sincronizados. Cada objeto em Java possui um monitor associado a ele. A garantia do monitor é que no máximo uma thread pode ser executada dentro dele em um certo momento (Coulouris et al., 2007).

A versão concorrente de Java (J2SE 5.0) provê um maior suporte para programas concorrentes do que as versões anteriores. Como exemplo, programadores usando J2SE 5.0 podem alcançar sincronização entre threads concorrentes usando explicitamente locks, semaphores, barries, latches ou exchangers. Essa versão também oferece estruturas concorrentes de dados, além de variáveis atômicas (Bradbury et al., 2006).

Quando se fala em extensões de linguagens, leva-se em consideração o uso de bibliotecas. Essas bibliotecas têm como função permitir o desenvolvimento de programas concorrentes em linguagens de programação sequenciais.

Dentre as extensões das linguagens C e Fortran, a mais usada para o paradigma de passagem de mensagem é o MPI (Message Passing Interface) (Forum, 1995). O padrão MPI é a especificação mais popular de passagem de mensagens que oferece suporte à programação paralela. 
Para o paradigma de memória compartilhada, pode-se citar como exemplo Pthreads, que implementa o uso de threads em C, e o OpenMP. O OpenMP (Open Multi-Processing) é um padrão para API (Aplication Programming Interface) constituído por um conjunto de diretivas, rotinas de biblioteca e variáveis de ambiente que influenciam na execução de um programa (Quinn, 2003).

Na próxima seção serão apresentadas mais detalhadamente as características do padrão MPI, pois este trabalho está envolvido neste contexto.

\subsection{O Padrão MPI}

O desenvolvimento do MPI (Message Passing Interface) começou com um esforço comunitário. O MPI surgiu como uma tentativa de padronização dos ambientes de passagem de mensagem por meio de uma especificação para o desenvolvimento de aplicações paralelas.

Sabe-se que a maior parte dos programas paralelos continua sendo desenvolvida em Fortran ou C com funções que realizam a comunicação entre os processos (Quinn, 2003). O padrão MPI especifica sintaxe e semântica de uma biblioteca de funções disponíveis ao programador de aplicações paralelas nas linguagens sequenciais C, Fortran e C++ (Pacheco, 1997).

O MPI 1.1 especifica, para as linguagens C e Fortran, comunicação ponto a ponto, comunicação coletiva, grupos de processos e contexto de comunicação, topologia de processos e interface para profiling (Forum, 1995). O MPI 2 estende a especificação anterior com novas operações coletivas, comunicação unilateral, E/S, criação e gerência de processos, interfaces externas, além de adicionar suporte à linguagem $\mathrm{C}++$ (Forum, 1997). A versão mais recente é o MPI 3 (Forum, 2012), que estende as especificações anteriores. As atualizações dessa versão compreendem a extensão das operações coletivas, incluindo versões não bloqueantes, a extensão de operações one-sided e a ligação feita com a linguagem Fortran 2008. Além disso, foram removidas ligações com $\mathrm{C}++$ que estavam obsoletas, além de muitas outras rotinas MPI obsoletas (como MPI_UNdatatype).

O padrão MPI permite duas formas de comunicação entre os processos: one-sided e two-sided. A comunicação one-sided permite que um processo acesse o endereço de memória de outro processo sem que esse possua participação explicita na operação. Já na comunicação two-sided há a necessidade de que em ambos os processos haja a especificação da comunicação. A comunicação two-sided pode ocorrer tanto com a utilização de funções ponto-a-ponto, quanto com a utilização de funções coletivas.

Em MPI uma computação é formada por um ou mais processos que se comunicam por meio de chamadas de sub-rotinas de envio e recebimento de mensagens. A comunicação é realizada de duas formas. A primeira utiliza operadores send e receive e é conhecida 
como comunicação ponto-a-ponto. A segunda, que utiliza funções como broadcast, barrier, gather, entre outras, é chamada de comunicação coletiva.

\subsubsection{Tipos Básicos de Dados e Constantes do Padrão MPI}

Ao declarar uma variável é necessário explicitar de qual tipo ela será, para que o compilador possa realizar operações nessas variáveis de forma correta. O padrão MPI possui os tipos básicos apresentados na Tabela 2.1, onde é apresentado o tipo de dado no padrão MPI e sua respectiva correspondência na linguagem C.

Tabela 2.1: Tipos básicos no padrão MPI e sua correspondência com a linguagem C.

\begin{tabular}{|l|l|}
\hline MPI & C \\
\hline MPI_CHAR & signed char \\
MPI_SHORT & signed short int \\
MPI_INT & signed int \\
MPI_LONG & signed long int \\
MPI_UNSIGNED_CHAR & unsigned char \\
MPI_UNSIGNED_SHORT & unsigned short int \\
MPI_UNSIGNED & unsigned int \\
MPI_UNSIGNED_LONG & unsigned long int \\
MPI_FLOAT & Float \\
MPI_DOUBLE & Double \\
MPI_LONG_DOUBLE & long double \\
MPI_BYTE & - \\
MPI_PACKED & - \\
\hline
\end{tabular}

A Figura 2.4 apresenta as constantes definidas no MPI. Essas constantes foram retiradas do arquivo mpi.h, que é o arquivo onde estão as especificações de todo o padrão MPI. Cada constante é representada por uma macro, que é uma palavra reservada que representa esta constante dentro do programa.

\subsubsection{Funções MPI}

Uma função MPI é uma função em $\mathrm{C}$ ou procedimento em Fortran que realiza uma determinada atividade. Existem várias funções MPI. Quando se necessita utilizar uma função MPI, deve-se sinalizar que uma determinada parte do sistema será executada em paralelo (Quinn, 2003).

A função MPI_Init é a primeira função que todo processo MPI deve chamar. Ela permite que o sistema possa acessar a biblioteca MPI quando necessário ao decorrer da execução do programa. Esta função possui a seguinte sintaxe: 
CAPÍTULO 2. PROGRAMAÇÃO CONCORRENTE

\begin{tabular}{|c|c|}
\hline Constante & Valor \\
\hline MPI_UNDEFINED & -32766 \\
\hline MPI_ROOT & -4 \\
\hline MPI_PROC_NULL & -2 \\
\hline MPI_ANY_SOURCE & -1 \\
\hline MPI_ANY_TAG & -1 \\
\hline MPI_KEYVAL_INVALID & -1 \\
\hline MPI_DISTRIBUTE_DFLT_DARG & -1 \\
\hline MPI_IDENT & 0 \\
\hline MPI_TAG_UB & 0 \\
\hline MPI_BOTTOM & 0 \\
\hline MPI_COMBINER_NAMED & 0 \\
\hline MPI_ORDER_C & 0 \\
\hline MPI_DISTRIBUTE_BLOCK & 0 \\
\hline MPI_STATUS_IGNORE & 0 \\
\hline MPI_STATUSES_IGNORE & 0 \\
\hline MPI_THREAD_SINGLE & 0 \\
\hline MPI_SUCCESS & 0 \\
\hline MPI_CONGRUENT & 1 \\
\hline MPI_HOST & 1 \\
\hline MPI_CART & 1 \\
\hline MPI_ORDER_FORTRAN & 1 \\
\hline MPI_DISTRIBUTE_CYCLIC & 1 \\
\hline MPI_SUBVERSION & 1 \\
\hline MPI_THREAD_FUNNELED & 1 \\
\hline MPI_ERR_BUFFER & 1 \\
\hline MPI_SIMILAR & 2 \\
\hline MPI_IO & 2 \\
\hline MPI_GRAPH & 2 \\
\hline MPI_VERSION & 2 \\
\hline MPI_COMBINER_CONTIGUOUS & 2 \\
\hline MPI_DISTRIBUTE_NONE & 2 \\
\hline MPI_THREAD_SERIALIZED & 2 \\
\hline MPI_ERR_COUNT & 2 \\
\hline MPI_UNEQUAL & 3 \\
\hline MPI_WTIME_IS_GLOBAL & 3 \\
\hline MPI_COMBINER_VECTOR & 3 \\
\hline MPI_THREAD_MULTIPLE & 3 \\
\hline MPI_ERR_TYPE & 3 \\
\hline
\end{tabular}

\begin{tabular}{|c|c|}
\hline Constante & Valor \\
\hline MPI_ERR_TAG & 4 \\
\hline MPI_COMBINER_HVECTOR & 5 \\
\hline MPI_ERR_COMM & 5 \\
\hline MPI_COMBINER_INDEXED & 6 \\
\hline MPI_ERR_RANK & 6 \\
\hline MPI_ERR_REQUEST & 7 \\
\hline MPI_COMBINER_HINDEXED & 8 \\
\hline MPI_ERR_ROOT & 8 \\
\hline MPI_ERR_GROUP & 9 \\
\hline MPI_ERR_OP & 10 \\
\hline MPI_ERR_TOPOLOGY & 11 \\
\hline MPI_COMBINER_STRUCT & 11 \\
\hline MPI_ERR_DIMS & 12 \\
\hline MPI_ERR_ARG & 13 \\
\hline MPI_ERR_UNKNOWN & 14 \\
\hline MPI_ERR_TRUNCATE & 15 \\
\hline MPI_ERR_OTHER & 16 \\
\hline MPI_ERR_INTERN & 17 \\
\hline MPI_ERR_IN_STATUS & 18 \\
\hline MPI_ERR_PENDING & 19 \\
\hline MPI_MAX_INFO_KEY & 36 \\
\hline MPI_ERR_LASTCODE & 54 \\
\hline MPI_BSEND_OVERHEAD & 128 \\
\hline MPI_MAX_PROCESSOR_NAME & 256 \\
\hline MPI_MAX_ERROR_STRING & 256 \\
\hline MPI_MAX_INFO_VAL & 256 \\
\hline MPI_MAX_PORT_NAME & 1024 \\
\hline MPI_CHAR & 134529056 \\
\hline MPI_INFO_NULL & 134529568 \\
\hline MPI_SHORT & 134529696 \\
\hline MPI_ERRHANDLER_NULL & 134530208 \\
\hline MPI_OP_NULL & 134531232 \\
\hline MPI_LONG_DOUBLE_INT & 134532256 \\
\hline MPI_REQUEST_NULL & 134532768 \\
\hline MPI_PACKED & 134532896 \\
\hline MPI_ERRORS_ARE_FATAL & 134533408 \\
\hline MPI_INT & 134534432 \\
\hline MPI_MIN & 134534944 \\
\hline
\end{tabular}

\begin{tabular}{|l|c|}
\hline \multicolumn{1}{|c|}{ Constante } & Valor \\
\hline MPI_DOUBLE_INT & 134535968 \\
\hline MPI_UNSIGNED_SHORT & 134536480 \\
\hline MPI_COMM_NULL & 134536992 \\
\hline MPI_ERRORS_RETURN & 134537504 \\
\hline MPI_UB & 134538528 \\
\hline MPI_BOR & 134539040 \\
\hline MPI_2INT & 134540064 \\
\hline MPI_LONG_DOUBLE & 134540576 \\
\hline MPI_PROD & 134541088 \\
\hline MPI_LONG_LONG_INT & 134542112 \\
\hline MPI_LONG_LONG & 134542112 \\
\hline MPI_MINLOC & 134542624 \\
\hline MPI_MAX & 134543648 \\
\hline MPI_BAND & 134544672 \\
\hline MPI_FLOAT_INT & 134545696 \\
\hline MPI_LOR & 134546208 \\
\hline MPI_SHORT_INT & 134547232 \\
\hline MPI_UNSIGNED_CHAR & 134547744 \\
\hline MPI_LAND & 134548256 \\
\hline MPI_UNSIGNED & 134549280 \\
\hline MPI_LB & 134549792 \\
\hline MPI_DATATYPE_NULL & 134550304 \\
\hline MPI_COMM_SELF & 134550816 \\
\hline MPI_DOUBLE & 134551328 \\
\hline MPI_BXOR & 134551840 \\
\hline MPI_LONG_INT & 134552864 \\
\hline MPI_COMM_WORLD & 134553376 \\
\hline MPI_UNSIGNED_LONG & 134553888 \\
\hline MPI_GROUP_NULL & 1345555457500 \\
\hline MPI_SUM & 134555552 \\
\hline MPI_MAXLOC & \\
\hline MPI_FLOAT & 1345676 \\
\hline MPI_GROUP_EMPTY & \\
\hline MPI_BYTE & \\
\hline MPI_LONG & \\
\hline MPI_LXOR & \\
\hline
\end{tabular}

Figura 2.4: Constantes definidas no padrão MPI.

$$
\text { MPI_Init(\&argc, \&argv); }
$$

Quando o MPI é inicializado, cada processo ativo torna-se membro de um comunicador chamado MPI_COMM_WORLD. Um comunicador é responsável por criar um ambiente para a passagem de mensagens entre os processos. Os processos dentro do comunicador são ordenados. O rank de um processo é a sua posição na ordenação dentro do comunicador. Cada processo tem um rank único que pode estar entre 0 e $p-1$, onde $p$ é o número de processos. O processo pode usar seu rank para determinar qual parte da tarefa ele é responsável. Um processo chama a função $M P I$ _Comm_rank para determinar seu rank dentro do comunicador. O processo chama a função MPI_Comm_size para determinar o número total de processos no comunicador. As funções MPI_Comm_rank e MPI_Comm_size possuem as seguintes sintaxes:

$$
\begin{gathered}
\text { MPI_Comm_rank }(\text { comm, rank }) ; \\
\text { MPI_Comm_size }(\text { comm }, \text { size }) ;
\end{gathered}
$$


Quando um processo necessita enviar uma mensagem para o outro são utilizadas funções para envio e recepção de mensagens. O MPI permite essa comunicação por meio das funções MPI_Send e MPI_Recv para envio e recebimento de mensagens, respectivamente. Em MPI, o envio de mensagens ponto a ponto entre os processos pode ser implementado de 4 modos diferentes:

Standard - no qual a implementação decide se a mensagem será "buferizada", ou seja, contará com a presença de um buffer para guardar a mensagem. Este modo é dito como não local, pois a operação de envio pode depender da postagem de um receive correspondente para completar.

Ready - no qual o envio da mensagem só é iniciado se um receive correspondente já tenha sido postado no processo destino, caso contrário um erro é gerado.

Synchronous - a operação de envio da mensagem completa quando um receive correspondente tiver sido postado. Esse modo é dito como não local, pois a operação de envio depende da postagem de um receive correspondente para completar.

Buffered - a operação de envio de mensagem completa independentemente da postagem de um receive correspondente. É necessário alocar um espaço suficiente para a mensagem em um buffer especial antes do envio. Este modo é dito local, pois somente a execução do processo local é suficiente para que a operação seja completada.

As diferentes funções de send e a função de receive possuem a seguinte sintaxe, respectivamente:

MPI_Send(\&sndbuf, sendcount, sendtype, dest, sendtag, comm);

MPI_Rsend(\&sndbuf, sendcount, sendtype, dest, sendtag, comm);

MPI_Ssend(\&sndbuf, sendcount, sendtype, dest, sendtag, comm);

MPI_Bsend(\&sndbuf, sendcount, sendtype, dest, sendtag, comm);

MPI_Recv(\&recvbuf, count, dtype, source, tag, comm, \&status);

Além dos modos de comunicação, é possível determinar se as operações de send e receive serão bloqueantes ou não bloqueantes, a fim de melhorar o desempenho e evitar deadlocks (Gropp e Lusk, 2002). Nas operações bloqueantes, a função chamada não poderá retornar até que os dados da mensagem tenham sido armazenados de maneira que o buffer de comunicação possa ser sobrescrito. Enquanto que nas operações não bloqueantes, uma função pode retornar antes de completar, tornando necessário chamar outra função para verificar se a operação foi completada. Um send bloqueante pode casar com um receive não bloqueante e vice-versa. As funções de send e receive não bloqueantes possuem a seguinte sintaxe, respectivamente:

MPI_Isend(\&sndbuf, count, dtype, dest, tag, comm, \&request); MPI_Irsend(\&sndbuf, count, dtype, dest, tag, comm, \&request); 
MPI_Issend(\&sndbuf, count, dtype, dest, tag, comm, \&request);

MPI_Ibsend(\&sndbuf, count, dtype, dest, tag, comm, \&request);

MPI_Irecv(\&recvbuf, count, dtype, source, tag, comm, \&status, \&request);

Com relação às funções de envio e recebimento de mensagens, o padrão MPI oferece a função MPI_Sendrecv que realiza o envio e o recebimento de uma mensagem em apenas uma chamada de função. A função MPI_Sendrecv_replace também realiza o envio e o recebimento de uma mensagem, porém utiliza apenas um buffer para realizar isso. Essas funções possuem as seguintes sintaxes:

MPI_Sendrecv(\&sendbuf, sendcount, sendtype, dest, sendtag, \&recvbuf, recvcount, recvtype, source, recvtag, comm, \&status);

MPI_Sendrecv_replace(\&buf, count, datatype, dest, sendtag, source, recvtag, comm, \&status);

O padrão MPI oferece também a utilização de funções de comunicação persistente, nas quais as funções de envio e/ou recebimento são definidas previamente e podem ser utilizadas em qualquer parte do código por meio das funções de MPI_Start e MPI_Startall. A função MPI_Start tem como objetivo realizar a inicialização de uma função de comunicação persistente usando uma requisição como parâmetro. A função MPI_Startall tem como objetivo realizar a inicialização de um conjunto de funções de comunicação persistente usando um conjunto de requisições como parâmetro. Essas funções seguem as seguintes sintaxes:

\section{MPI_Start(\&request); MPI_Startall(count, array_of_requests[]);}

Além das funções de envio e recebimento de mensagens, há outras funções ponto a ponto, como é o caso da função MPI_Probe, que tem como objetivo realizar uma checagem de uma mensagem que está chegando para verificar se ela pode ou não ser recebida por uma função de recebimento de mensagens. Esta função pode ser bloqueante ou não bloqueante que possuem as seguintes sintaxes:

\section{MPI_Probe(source, tag, comm, \&status); MPI_Iprobe(source, tag, comm, \&flag, \&status);}

Além das funções ponto a ponto, o MPI ainda possui funções coletivas, as quais envolvem três ou mais processos. Uma dessas funções é a função MPI_Reduce que tem como objetivo realizar uma determinada operação aritmética sobre os valores de todos os processos dentro de um determinado grupo e enviar o resultado a um determinado 
processo. A função MPI_Allreduce tem como objetivo de realizar uma determinada operação aritmética sobre os valores de todos os processos dentro de um determinado grupo gerando um vetor de resultados, o qual será enviado a todos os processos. A função MPI_Reduce_scatter tem como objetivo de realizar uma determinada operação aritmética sobre os valores de todos os processos dentro de um determinado grupo gerando um vetor de resultados, o qual será dividido entre os processos do grupo. Essas funções possuem as seguintes sintaxes:

MPI_Reduce(\&sendbuf, \&recvbuf, count, datatype, op, root, comm);

MPI_Allreduce(\&sendbuf, \&recvbuf, count, datatype, op, comm);

MPI_Reduce_scatter(\&sendbuf, \&recvbuf, \&recvcnts, datatype, op, comm);

Outra função coletiva é a MPI_Gather que tem como objetivo receber uma mensagem de todos os processos e concatená-las no processo destino. A função MPI_Allgather tem como objetivo receber uma mensagem de todos os processos e distribuir esses dados para todos os processos. A função MPI_Gatherv tem como objetivo receber mensagens de tamanho variado de todos os processos e concatená-las no processo destino. A função MPI_Allgatherv tem como objetivo receber mensagens de tamanho variado de todos os processos e distribuir esses dados para todos os processos. Essas funções possuem a seguinte sintaxe, respectivamente:

MPI_Gather (\&sendbuf, sendcnt, sendtype, \&recvbuf, recvcount, recvtype, root, comm);

MPI_Allgather (\&sendbuf, sendcnt, sendtype, \&recvbuf, recvcount, recvtype, comm);

MPI_Gatherv(\&sendbuf, sendcnt, sendtype, \&recvbuf, recvcnts, displs, recvtype, root, comm);

MPI_Allgatherv(\&sendbuf, sendcnt, sendtype, \&recvbuf, recvcnts, displs, recvtype, comm);

O padrão MPI oferece funções para esperar uma requisição ser completada. A função MPI_Wait tem como objetivo esperar até que uma requisição seja completada. A função MPI_Waitall tem como objetivo esperar um conjunto de requisições até que todas sejam completadas. A função MPI_Waitany tem como objetivo bloquear até que uma das operações associadas às requisições presentes no array seja completada. Caso mais de uma operação seja ativada e possa terminar, uma é escolhida arbitrariamente. Retorna o índice da requisição e retorna o status da comunicação completada. A função MPI_Waitsome tem como objetivo bloquear até que ao menos uma das operações associadas às requisições presentes no array seja completada. Retorana o número de requisições que foram completadas e os índices das operações e os status das operações completadas. A sintaxe de cada uma dessas funções é a seguinte:

\section{MPI_Wait(\&request, \&status);}


MPI_Waitall(count, array_of_requests, array_of_statuses);

MPI_Waitany(count, array_of_requests, \&index, \&status);

MPI_Waitsome(incount, array_of_requests, \&outcount, array_of_indices,

array_of_statuses);

Em MPI exitem funções que realizam a criação de tipo derivados de dados. Em MPI, as funções que realizam a criação de dados são: MPI_Type_contiguous, MPI_Type_vector, MPI_Type_struct, MPI_Type_indexed, MPI_Type_hvector, MPI_Type_hindexed. A sintaxe de cada uma dessas funções é a seguinte:

MPI_Type_contiguous (count, old_type, \&new_type_p);

MPI_Type_vector (count, blocklength, stride, old_type, \&newtype_p);

MPI_Type_struct(count, blocklens[], indices[], old_types[], \&newtype);

MPI_Type_indexed(count, blocklens[], indices[], old_type, \&newtype);

MPI_Type_hvector (count, blocklen, stride, old_type, \&newtype_p);

MPI_Type_hindexed(count, blocklens [], indices[], old_type, \&newtype);

O padrão MPI possui a função MPI_Buffer_detach que realiza a desalocação de memória alocada, por exemplo, para a utilização de um MPI_Bsend. Há também uma função para liberar um request que não será mais utilizado, por meio da função MPI_Request_free. A sintaxe dessas funções são as seguintes:

\section{MPI_Buffer_detach(\&buffer, \&size); \\ MPI_Request_free(\&request);}

A função MPI_Barrier bloqueia os processos até que todos os processos dentro de um comunicador executem esta função. Esta função possui a seguinte sintaxe:

\section{MPI_Barrier(comm);}

Para realizar a finalização de processos em MPI, há duas funções que podem ser utilizadas. A função MPI_Abort realiza o término dos processos pertencentes a um determinado comunicador. A função MPI_Finalize realiza a finalização do ambiente MPI e permite que o sistema libere os recursos, como por exemplo memória, que foram alocadas para o MPI. Essa função deve ser executada pelo processo que iniciou o ambiente MPI, ou seja, que chamou a função MPI_Init. A sintaxe dessas funções é a seguinte:

$$
\begin{gathered}
\text { MPI_Abort(comm, errorcode); } \\
\text { MPI_Finalize }() ;
\end{gathered}
$$

Na Figura 2.5 pode-se ver um exemplo da implementação do algoritmo do máximo divisor comum entre três números. No código apresentado, pode-se observar as funções 
de inicialização (linha 18) e finalização (linha 31) do código paralelo. Pode-se também observar as funções de envio de mensagens (linha 41) e recebimento (linha 45). Além disso, pode-se observar a função para determinar o rank do processo (linha 19).

A função main realiza a verificação de quantos processos foram definidos no momento da execução uma vez que, para o programa funcionar corretamente, o número de argumentos passados ao executar o programa precisa ser 4 (número de processos, nome do executável, parâmetro 1, parâmetro2 e parâmetro 3) como, por exemplo mpirun -np 4 gcd 1020 30. Caso o número de processos for igual a 4, inicia-se o código concorrente com a declaração da função MPI_Init. Após isso, cada processo determina seu rank dentro do comunicador utilizando a função $M P I \_C o m m \_r a n k$.

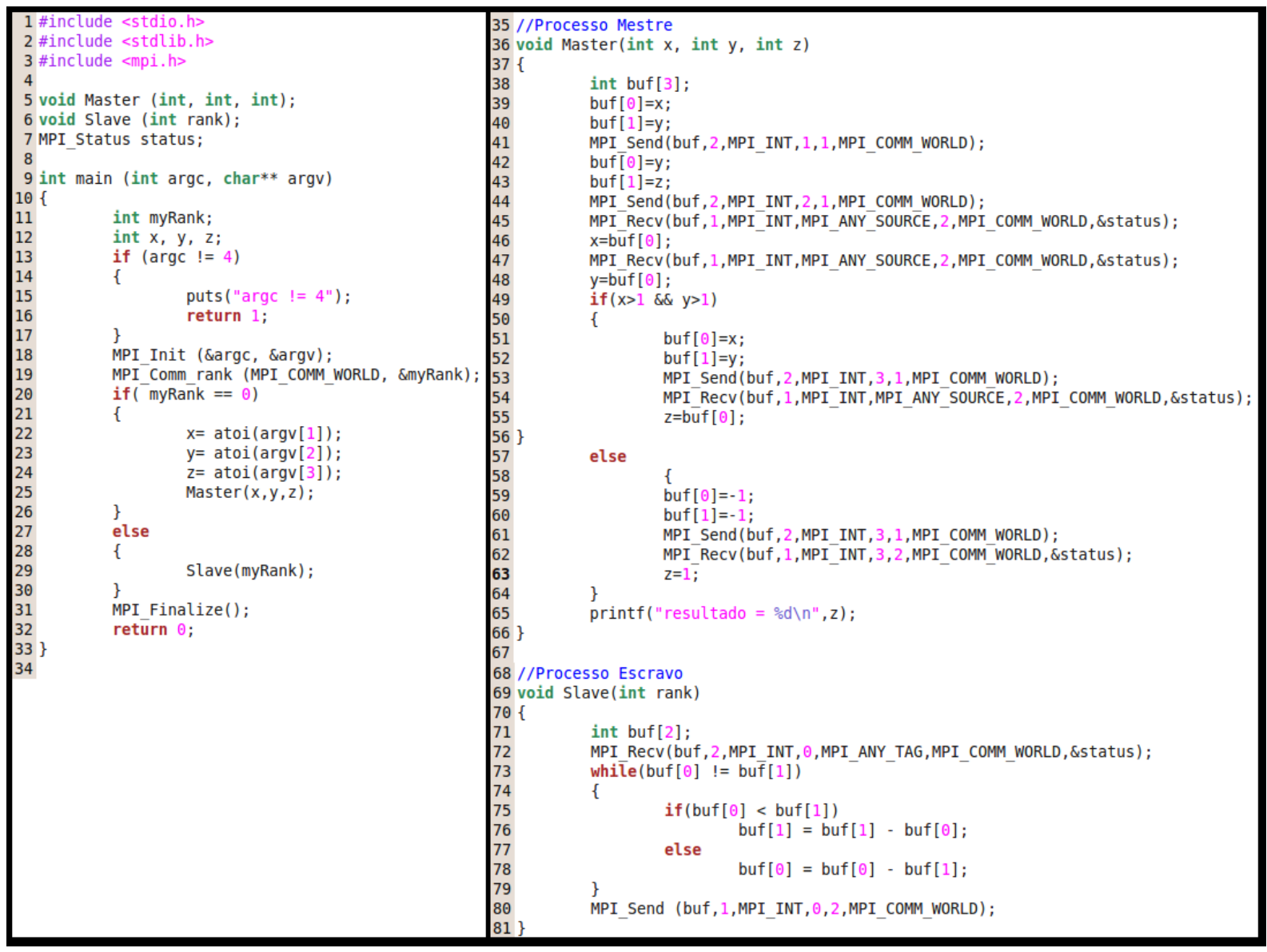

Figura 2.5: Código do programa gcd.c.

O processo de rank 0 é o processo que executará o código do processo Mestre e os demais executarão o trecho de código corresponde ao processo Escravo. O processo Mestre pega os dois primeiros números e envia para o processo 1 (linha 41) e os dois últimos para o processo 2 (linha 44). Os dois processos Escravos recebem os valores enviados pelo processo Mestre, encontram o máximo divisor comum entre os dois valores, utilizando a técnica de sucessivas subtrações, e enviam o resultado para o processo Mestre (linha 80). 
Se um dos valores retornados ao Mestre for 1, então o Escravo 3 não recebe nada e é finalizado. Se esses valores não têm um valor como 1, então esse par de valores retornados é enviado ao Escravo 3 (linha 53) para que ele determine o MDC dos mesmos. O resultado é retornado ao mestre que imprime o resultado final (linha 65).

\subsection{Considerações Finais}

Neste capítulo foram apresentados os principais conceitos sobre programação paralela. Foi descrito como ocorre a geração de processos concorrentes e paralelos e também quais são as arquiteturas de hardware nas quais os programas paralelos são executados. Em seguida foram listadas algumas ferramentas de apoio à programação concorrente como linguagens de programação e bibliotecas. Por fim, foi descrito mais detalhadamente o padrão MPI, o qual está inserido no contexto deste trabalho.

Este capítulo mostrou o contexto de desenvolvimento de um programa concorrente. Como nos programas sequenciais, erros de programação ocorrem e há a necessidade que a atividade de teste seja realizada. Porém, a realização de testes em programas concorrentes não é uma tarefa simples de ser realizada. Características como o não determinismo dos programas concorrentes faz com que novas técnicas de testes sejam criadas ou as técnicas usadas para programas sequenciais sejam adaptadas para esse contexto de programação concorrente.

No próximo capítulo serão apresentados trabalhos que objetivam a criação ou adaptação de critérios de teste para programas concorrentes. Também serão apresentadas algumas taxonomias de defeitos para programas paralelos assim como ferramentas que ajudam na aplicação de testes para programas concorrentes. 


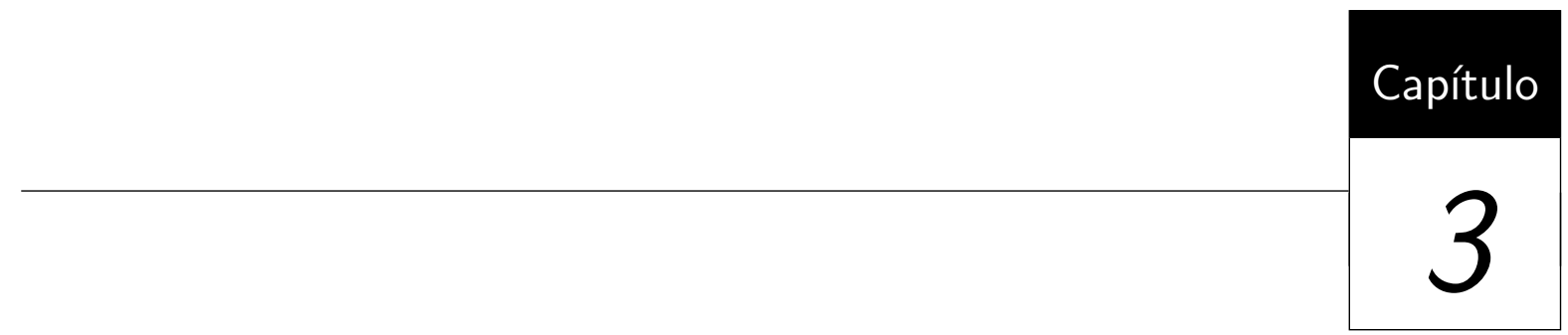

Teste de Software

\subsection{Considerações Iniciais}

A busca por qualidade nos softwares desenvolvidos fez com que uma série de atividades fossem criadas com o objetivo de descobrir problemas antes da liberação do software para a utilização. Essas atividades chamadas de "Validação, Verificação" ou pela sigla "V\&V" possuem como finalidade garantir que tanto o modo pelo qual o software está sendo construído quanto o produto em si estejam em conformidade com o especificado. Durante o processo do desenvolvimento de software diferentes atividades devem ser realizadas, empregando técnicas, métodos e ferramentas para obter-se a melhor qualidade do produto. Por mais bem aplicadas e executadas essas atividades, erros ocorrem. Desta forma, os testes de software têm como objetivo diminuir a quantidade de defeitos e aumentar a aceitação do produto. Teste de software é uma atividade de garantia de qualidade que procura identificar defeitos ainda não descobertos.

Neste capítulo são apresentados conceitos sobre teste de software, as técnicas e critérios para a realização dos testes, dando maior destaque ao critério de teste de mutação, que é tema deste projeto de mestrado. Também são mostradas algumas taxonomias de defeitos para programas concorrentes e procedimentos para a análise comportamental de mutantes. Para isso, a Seção 3.2 apresenta os conceitos principais sobre teste de software. Na Seção 3.3 são mostradas as técnicas de teste e seus principais critérios para programas sequenciais, dando destaque ao critério teste de mutação. Na Seção 3.4 são apresenta- 
dos os critérios de teste estrutural definidos para programas concorrentes. A Seção 3.5 apresenta o teste de mutação para programas concorrentes, mostrando as taxonomias de defeitos existentes, operadores de mutação e procedimento para a aplicação do teste em programas concorrentes. Na Seção 3.6 a ferramenta ValiMPI é brevemente apresentada. Por fim, na Seção 3.7 são apresentas as considerações finais deste capítulo.

\subsection{Terminologia e Conceitos Básicos}

No contexto de teste de software, há alguns termos utilizados que possuem diferentes conceituações. Define-se "defeito" (fault) como sendo um passo, processo ou definição de dados incorretos e "engano" (mistake) como a ação humana que produz um defeito. Assim, esses dois conceitos são estáticos, pois estão associados a um determinado programa ou modelo e não dependem de uma execução particular (Delamaro et al., 2007; IEEE, 1990).

O estado da execução de um programa em determinado instante é dado pelo valor da memória (ou das variáveis do programa) e do apontador de instruções. A existência de um defeito pode ocasionar a ocorrência de um "erro" (error) durante a execução de um programa, que se caracteriza por um estado inconsistente ou inesperado. Tal estado pode levar a uma "falha" (failure), ou seja, pode fazer com que o resultado produzido pela execução seja diferente do resultado esperado (Delamaro et al., 2007; IEEE, 1990).

Myers et al. (2011) definem teste de software como sendo um processo, ou uma série de processos, designados para garantir que produto de software realiza o que deveria, conforme sua especificação, e não realize algo que não foi especificado. A atividade de teste é uma atividade dinâmica, ou seja, necessita de um programa ou modelo para ser executada. Um teste, quando bem-sucedido, expõe um defeito existente, pois faz com que o sistema opere de maneira inesperada (Sommerville, 2007).

O teste de software envolve basicamente quatro etapas: planejamento de testes, projeto de casos de teste, execução e avaliação dos resultados dos testes (Delamaro et al., 2007; Myers et al., 2011; Pressman, 2010). Essas atividades devem ser desenvolvidas ao longo do próprio processo de desenvolvimento do software, e em geral, concretizam-se em três fases de teste: de unidade, de integração e de sistema.

Na fase de unidade testam-se as menores partes executáveis de um sistema, procurando por pequenos erros de lógica e defeitos em seu funcionamento. Essa menor parte do software pode ser considerada como procedimentos, sub-rotinas ou no caso de orientação a objetos, os métodos ou as classes. Técnicas funcionais, estruturais e baseadas em defeitos podem ser utilizadas nesta fase (Delamaro et al., 2007; Myers et al., 2011). 
A fase de integração caracteriza-se pela união dessas menores partes do sistema visando partes cada vez maiores, com o objetivo de encontrar erros de comunicação entre os módulos associados à interface de cada um em relação ao outro (Pressman, 2010).

A fase de testes de sistema, já com o sistema todo integrado e completo, visa identificar defeitos do mesmo através de suas características e funções baseadas nas especificações. O objetivo é verificar se as funcionalidades foram implementadas corretamente e se os requisitos não funcionais satisfazem a especificação.

Após a realização do teste, este pode apresentar dois resultados: o esperado é aquele em que o software se comporta como deveria conforme a sua especificação, e o não esperado, aquele em que o software se comporta de maneira inesperada. A partir destes testes que apresentaram um resultado inesperado pode-se realizar a correção dos defeitos. Quando se está testando um software, o ideal seria que ele fosse testado com todo o domínio de entrada, certificando-se assim que o programa não possui nenhum defeito. O domínio de entrada de um programa $P$, denotado por $D(P)$, é o conjunto de todos os possíveis valores que podem ser utilizados para executar $P$. Porém, não é viável testar $P$ com o conjunto $D(P)$, pois isso necessitaria tempo e um grande processamento.

Para tentar solucionar esse problema, estudos foram conduzidos com a finalidade de encontrar uma forma de utilizar apenas um subconjunto reduzido de $D(P)$ para a execução de $P$. A ideia central para isso é a criação de subdomínios. Um subdomínio de $D(P)$ é um subconjunto do domínio de entrada que contém dados de testes semelhantes. Casos de teste são considerados semelhantes quando espera-se que $P$ se comporte igualmente para qualquer um deles, sendo assim do mesmo subdomínio de $D(P)$. Então pode-se testar $P$ com apenas um deles. Fazendo isso para todos os subdomínios de $D(P)$, consegue-se um conjunto de teste $T$ bastante reduzido, mas que, de certa forma, representa cada um dos elementos de $D(P)$ (Delamaro et al., 2007; Myers et al., 2011; Pezzè e Young, 2008).

Essencialmente, há duas maneiras de selecionar os elementos de cada um dos subdomínios de teste. A primeira é selecionado aleatoriamente os casos de teste. O segundo é o teste de partição ou teste de subdomínios, no qual se procura estabelecer quais são os subdomínios a serem utilizados e, então, selecionam-se os casos de teste em cada subdomínio. Em relação ao teste de subdomínios, são estabelecidas "regras" para identificar quando os dados de teste pertencem ao mesmo subdomínio ou não. Dependendo do tipo de regra que se utiliza, obtém-se subdomínios diferentes, e, portanto, conjuntos de teste diferentes. Tais regras são chamadas critérios de teste que podem ser de três tipos: Estruturais, Funcionais ou Baseados em Defeitos (ou erros). 


\subsection{Técnicas e Critérios de Teste}

Em geral, os critérios de teste de software são estabelecidos, basicamente, a partir de três técnicas: a funcional, a estrutural e a baseada em defeitos. A diferença entre as técnicas está na informação de origem utilizada para testar o produto de software.

Na técnica Funcional o testador avalia o software sem conhecimento sobre sua implementação e suas operações internas, concentrando-se apenas nas especificações do mesmo e, a partir dessas, são determinados certos resultados de saída para algumas entradas de dados. Esse tipo de teste reflete de certa forma, a ótica do usuário, que está interessado em usar o programa sem considerar os detalhes de sua construção. Comparando a outros tipos de teste, este é relativamente mais simples (Koscianski e Soares, 2007). O principal problema para o responsável pelos testes é selecionar entradas que tenham grande probabilidade de encontrar defeitos (Sommerville, 2007). Para tal, o comum é serem utilizados seus próprios conhecimentos sobre o domínio e pode-se também usar de uma abordagem sistêmica para seleção de dados. Os critérios e requisitos de teste são estabelecidos a partir da função de especificação do software. Os critérios mais conhecidos da técnica de teste funcional são (Myers et al., 2011): Particionamento de equivalência, Análise do Valor Limite e Grafo Causa-Efeito.

$\mathrm{Na}$ técnica Estrutural os critérios e requisitos são derivados essencialmente a partir das características de uma particular implementação em teste, permitindo uma verificação mais elaborada do seu comportamento. Esse tipo de teste possibilita que uma maior atenção seja dada aos pontos mais importantes ou "perigosos" do código (Koscianski e Soares, 2007). Geralmente, a técnica é aplicada a pequenas partes do código, como sub-rotinas, ou operações relacionadas a um objeto. Assim, o testador pode analisar o código antes de iniciar os testes e buscar dados que possivelmente possam ser tratados de forma inesperada. A partir do código fonte é definido um conjunto de elementos de software que deve ser executado para que se atinja uma cobertura mínima do critério. Esses elementos são os componentes do programa requeridos pelo critério e que devem ser testados (Maldonado, 1991). Em geral, a maioria dos critérios de teste dessa técnica utiliza o GFC (Grafo de Fluxo de Controle) composto por nós que representam conjuntos de instruções executadas sequencialmente e arestas que representam uma transferência de controle entre instruções (Myers et al., 2011).

Os critérios estruturais que são aplicados em programas sequenciais são, em geral, classificados em:

1. Critérios baseados na complexidade, nos quais os critérios utilizam informações sobre a complexidade do programa para derivar os requisitos de teste. Como exemplo, o 
critério de McCabe (ou teste de caminho básico) (McCabe, 1976), que utiliza a complexidade ciclomática do GFC para derivar os requisitos de teste;

2. Critérios baseados em fluxo de controle, nos quais são utilizadas apenas características de controle da execução do programa, como comandos de desvios, para determinar quais estruturas são necessárias. Alguns critérios dessa técnica são: Todos-Nós, Todas-Arestas (ou Todos-Arcos) e Todos-Caminhos;

3. Critérios baseados em fluxo de dados, nos quais é utilizada a análise de fluxo de dados como fonte de informação para derivar os requisitos de teste. Para a derivação de casos de teste, esses critérios baseiam-se nas associações entre a definição de uma variável e seus possíveis usos subsequentes. Rapps e Weyuker (1985) definem uma família de critérios de fluxo de dados, sendo que o critério Todos-Usos é o mais conhecido. Tendo como base esses critérios, Maldonado (1991) define uma família de critérios, chamada Potenciais-Usos, que requerem associações independentemente da ocorrência explícita de uma referência ou uso a uma determinada definição. Os critérios que fazem parte da família de critérios Potencial-Usos são: Todos-Potenciais-Usos, Todos-Potenciais-Usos-Du e Todos-Potenciais-Du-Caminhos.

A técnica Baseada em Defeitos usa de forma direta um modelo de defeitos para criar hipóteses sobre falhas potenciais no programa que está sendo testado, bem como criar ou avaliar conjuntos de testes baseado na sua eficácia em detectar os defeitos hipotéticos. Esses defeitos são enganos típicos cometidos pelos desenvolvedores de software durante o processo de implementação de software e é a partir desses defeitos que são derivados os requisitos de teste. Na maioria das vezes, quem cria ou adapta o modelo de defeito é o testador e, para não tornar a técnica ineficaz, deve-se inserir apenas defeitos plausíveis. No entanto, se o modelo de análise e de projeto puderem prover conhecimento sobre os possíveis defeitos que podem ser inseridos, então essa técnica pode achar uma quantidade de defeitos significativos com um menor esforço (Pezzè e Young, 2008; Pressman, 2010). Nessa técnica de teste a corretude de um programa $P$ leva em consideração um conjunto $\Phi$ de programas alternativos, que depende de $P$ e do qual $P$ é membro. Tal conjunto $\Phi(P)$ é chamado de vizinhança de $P$. A corretude de $P$ é dada através de um processo de eliminação que mostra que nenhum programa da vizinhança de $P$, não equivalente a $P$, é correto. Isso é feito utilizando um conjunto de teste $T$ em que todos os membros de $\Phi(P)$, não equivalentes a $P$, falhem em pelo menos um caso de teste. Porém, isso não é possível de ser alcançado quando se tem um conjunto de $\Phi$ infinito. Por isso é necessário restringir a vizinhança, demonstrando assim que existe um conjunto $T$ adequado para $P$ em relação à $\Phi$. Com isso, precisa-se abandonar a ideia inicial de provar que $P$ está 
correto e procura-se demonstrar uma correção relativa de $P$ sobre um pequeno conjunto de programas.

O Teste baseado em defeitos pode garantir a detecção de defeitos apenas se a hipótese do programador competente e a hipótese do efeito do acoplamento se aplicam (Delamaro et al., 2007; DeMillo et al., 1978; Pezzè e Young, 2008). A hipótese do Programador Competente diz que os programadores, em geral, são competentes e desenvolvem programas próximo do considerado correto. A hipótese do Efeito de Acoplamento diz que os casos de teste que distinguem programas com diferenças mínimas entre eles, podem distinguir programas com diferenças mais complexas. Essas duas hipóteses sugerem que pequenas mudanças nos programas são adequadas para ajudar a revelar defeitos complexos. Os principais critérios dessa técnica são: injeção de falhas e o teste de mutação, que é o foco deste trabalho, sendo detalhado na próxima seção.

\subsubsection{Teste de Mutação}

O Teste de Mutação ou Análise de Mutantes é um dos critérios mais comumente aplicados da técnica baseada em defeitos (Pezzè e Young, 2008). Esse critério tem como objetivo principal avaliar a qualidade de um conjunto de casos de teste. Para isso, pequenas mudanças sintáticas, que não geram erros sintáticos, são introduzidas no programa, gerando mutantes. Essas mudanças representam possíveis defeitos que poderiam estar presentes no programa original. O objetivo desse critério é apoiar a geração de um conjunto de teste capaz de indicar que os defeitos inseridos não estão presentes no programa em teste, aumentando a confiança sobre a corretude desse programa. Para aplicar esse critério algumas etapas são necessárias: 1) Geração dos mutantes; 2) Execução do programa em teste; 3) Execução dos mutantes e 4) Análise dos mutantes.

A primeira etapa consiste em criar os mutantes. Para criar os mutantes é necessário ter um modelo contendo defeitos hipotéticos que são cometidos durante a implementação do programa ou erros que podem ocorrer durante a execução do programa. Cada defeito presente neste modelo se torna um operador de mutação. Aplicando esses operadores de mutação no programa $P$ consegue-se os programas que formam a vizinhança de $P$ chamados de mutantes.

O modelo precisa conter defeitos plausíveis, uma vez que programas mutantes que são rejeitados pelo compilador ou que falham em quase todos os testes não são bons modelos das falhas que se procura descobrir com o teste. Um mutante válido é aquele que está sintaticamente correto. Um mutante obtido a partir de uma troca de um if por um for não é válido, pois resultará em um erro de compilação. Diz-se que um mutante é útil se, além de válido, seu comportamento difere do comportamento do programa original por não mais do que um pequeno subconjunto dos casos de teste do programa (Pezzè e 
Young, 2008). Caso uma constante em uma condição de laço de repetição seja trocada de 1 para 1000 esse mutante será válido, mas não útil, pois não agrega nenhuma informação útil sobre a efetividade do conjunto de testes.

Além dos defeitos e erros os quais se desejam revelar, a escolha do conjunto de operadores de mutação depende da linguagem de programação em que os programas estão implementados. Budd (1981) apresenta em seu trabalho a definição de 22 operadores de mutação para Fortran que são utilizados pelo sistema de mutação EXPER (Experimental Mutation System). Acree (1980) define 27 operadores para Cobol e são utilizados pelo sistema CMS. Na linguagem C, Agrawal et al. (1989) definem um conjunto de 77 operadores de mutação. Kim et al. (1999) propõem um conjunto de 13 operadores de mutação de classes em Java.

A Figura 3.1 apresenta um código em C que será utilizado como exemplo para a criação de alguns mutantes. A Tabela 3.1 apresenta os mutantes gerados pela aplicação do operador ORRN que tem como função trocar os operadores relacionais.

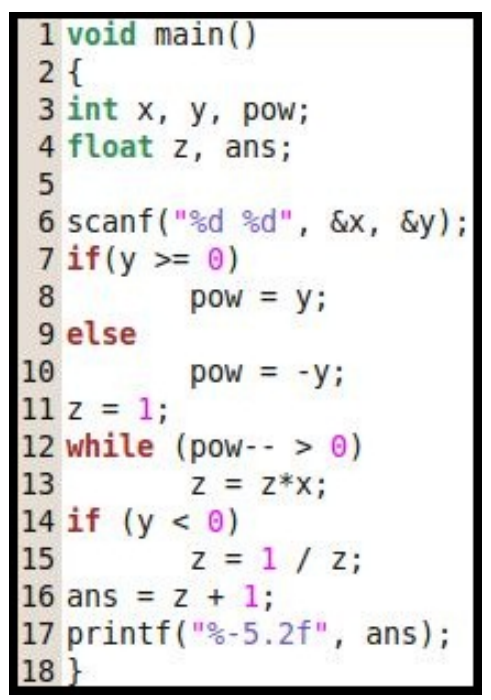

Figura 3.1: Código do programa exemplo. (Delamaro et al., 2007)

A segunda etapa não é muito diferente do que ocorre com os outros critérios de teste, na qual se executa o conjunto de caso de teste $T$ no programa $P$ e verifica se o resultado esperado é igual ao resultado obtido. Caso isso não ocorra, o programa possui um defeito, o qual deve ser corrigido antes de prosseguir com o processo de teste.

Na terceira etapa cada um dos mutantes é executado usando os casos de teste de $T$. Se um mutante $M$ apresentar um resultado diferente do resultado apresentado por $P$, isso significa que os casos de testes utilizados são efetivos e conseguiram fazer com que houvesse uma diferença entre a saída de $P$ e de $M$. Com isso, pode-se considerar este mutante como um mutante morto. 
Tabela 3.1: Mutantes gerados pelo operador ORRN. (Delamaro et al., 2007)

\begin{tabular}{ll}
\hline Número & Linha mutante \\
\hline 1 & if $(\mathrm{y}>0)$ \\
2 & if $(\mathrm{y}<0)$ \\
3 & if $(\mathrm{y}==0)$ \\
4 & if $(\mathrm{y}<=0)$ \\
5 & if $(\mathrm{y} !=0)$ \\
6 & while $($ pow $-<0)$ \\
7 & while $($ pow $-==0)$ \\
8 & while $($ pow $->=0)$ \\
9 & while $($ pow $-<=0)$ \\
10 & while $($ pow $-!=0)$ \\
11 & if $(\mathrm{y}>0)$ \\
12 & if $(\mathrm{y}==0)$ \\
13 & if $(\mathrm{y}>=0)$ \\
14 & if $(\mathrm{y}<=0)$ \\
15 & if $(\mathrm{y} !=0)$ \\
\hline
\end{tabular}

Após a análise dos mutantes pode-se calcular o quão adequado o conjunto de caso de teste $T$ é para $P$ utilizando-se do "escore de mutação". Este escore pode variar entre 0 e 1 e é calculado pela seguinte fórmula:

$$
m_{s}=\frac{D M(P, T)}{M(P)-E M(P)}
$$

Onde: $\mathrm{DM}(\mathrm{P}, \mathrm{T})$ : número de mutantes mortos pelo conjunto de casos de teste $T ; \mathrm{M}(\mathrm{P})$ : número total de mutantes gerados a partir do programa $P ; \operatorname{EM}(\mathrm{P})$ : número de mutantes gerados que são equivalentes, obtidos a partir do momento em que o testador decide marcar um mutante vivo como equivalente.

A última etapa consiste em analisar os mutantes vivos e decidir se o teste continua ou não. Se o escore de mutação for 1,0 ou bem perto de 1,0, então pode-se encerrar o teste e considerar o conjunto de teste $T$ adequado para $P$. Caso o teste continue, há a necessidade de criar novos casos de teste para matar os mutantes vivos e/ou decidir se os mutantes são equivalentes. Um mutante equivalente é aquele que não pode ser distinguido do programa original por nenhum caso de teste.

O principal problema associado à Análise de Mutantes está no número de mutantes gerados. Muitas vezes esse número é muito alto, fazendo com o que o custo computacional para executar todos os mutantes também seja alto. Além disso, há o problema com relação a identificar os mutantes equivalentes. Essa é uma tarefa realizada pelo testador e leva um certo tempo para ser realizada, pois deve-se analisar o programa mutante, comparar com o programa original, para então decidir se o mutante é equivalente ou não. Então, quanto mais mutantes forem gerados, mais mutantes terão que ser analisados para identificar os equivalentes. 
Muitos trabalhos têm sido desenvolvidos no contexto de Teste de Mutação. Inúmeros aspectos, tais como estudos teóricos e experimentais, extensões ou adaptações do critério, definição de operadores de mutação, construção de ferramentas, entre outros, têm sido explorados. Alguns trabalhos procuram diminuir o custo desse critério propondo alternativas para sua utilização como é o caso da Mutação Seletiva (Offutt et al., 1993), Mutação Aleatória (Acree et al., 1979) e Operadores Essenciais (Barbosa et al., 1998).

Alguns trabalhos têm utilizado o Teste de Mutação para validar modelos de software descritos por técnicas como Redes de Petri (Fabbri et al., 1996), Máquinas de Estados Finitos (Fabbri et al., 1999a) e Statecharts (Fabbri et al., 1999b). A aplicação do teste de mutação para programas Orientados a Aspectos (OA) escritos na linguagem AspectJ foi desenvolvido por Ferrari (2010).

Com o objetivo de apoiar a atividade do teste de mutação, algumas ferramentas foram desenvolvidas. Na literatura, encontra-se que a FMS.1 (Fortran Mutation System) é a primeira ferramenta a apoiar o teste de mutação, porém ela somente tratava um conjunto restrito de programas em Fortran. Essa ferramenta motivou a construção de ferramentas mais elaboradas como a FMS.2 e a CMS (Cobol Mutation System) (Acree, 1980).

A ferramenta Mothra (Choi et al., 1989) é um ambiente de testes para programas em Fortran 77. e, segundo seus criadores, as principais vantagens com relação às outras desenvolvidas são a utilização de uma interface em janelas, nenhuma restrição de tamanho do programa a ser testado e a fácil incorporação de ferramentas como gerador de casos de teste, verificador de equivalência e oráculo.

A ferramenta Proteum (Delamaro, 1993) foi inicialmente projetada para teste de mutação em programas em C na fase de unidade. Delamaro (1997) estendeu as funcionalidades da ferramenta para tratar também teste de integração, dando origem a versão Proteum/IM.

Algumas características que diferem a Proteum das demais ferramentas são:

- Grande flexibilidade na geração de mutantes, pois para cada operador de mutação é possível escolher a porcentagem de mutantes que será criada, além da possibilidade de posteriores gerações de mutantes.

- Abordagem compilada em vez de interpretada, onde a ferramenta cria uma nova versão do programa, o compila e o executa com os casos de teste sendo, assim, mais rápido que uma possível interpretação do programa.

- Utilização de informação de fluxo de controle para evitar a execução de certos mutantes, uma vez que o mutante só precisa ser executado quando o caso de teste passa pelo trecho de código no qual houve a mutação. 
- Facilidade de importação de conjuntos de teste, permitindo assim a execução de teste em modo batch, não sendo necessária a inserção dos testes interativamente.

- Modo "teste" ou "pesquisa" de execução dos mutantes, sendo que no modo "pesquisa" todos os mutantes são executados com todos os casos de teste, retirando assim, informações como o quão fácil um mutante é de ser morto contando quantos casos de testes matam o mutante.

- Operações para habilitar/desabilitar casos de teste sem a necessidade de modificar o conjunto de teste e possibilitando assim que o testador possa utilizar diversas combinações de casos de teste.

- Operações para selecionar/desselecionar conjunto de mutantes, podendo observar assim o efeito de um determinado conjunto de teste em conjuntos diferentes de mutantes.

A Proteum implementa 71 operadores de mutação divididos em quatro classes (Delamaro, 1993): mutação de comandos (statement mutations), mutação de operadores (operator mutations), mutação de variáveis (variable mutations) e mutação de constantes (constant mutations).

\subsection{Teste Estrutural Aplicado a Programas Concorrentes}

Programas concorrentes possuem alguns aspectos não presentes em sistemas sequenciais, como comunicação, sincronização e não determinismo, que devem ser considerados durante a definição de mecanismos de apoio à atividade de teste. Esses aspectos tornam o teste nesse contexto mais complexo, porém, observa-se que é possível aproveitar e adaptar com sucesso critérios de teste definidos para programas sequenciais.

O teste estrutural, amplamente utilizado em programas sequenciais, teve uma de suas primeiras adaptações para o contexto de programas paralelos através do trabalho de Taylor et al. (1992). Os autores propõem a criação de um grafo de concorrência (ou grafo de alcançabilidade). Esse grafo é obtido a partir da análise estática dos programas concorrentes. No trabalho desenvolvido por Yang e Chung (1992) é criada uma abordagem de teste para programas concorrentes na qual o comportamento da execução de um programa é formado pela computação, que consiste na saída produzida junto com o caminho executado pelo processo, e pela comunicação, que consiste na sequência de sincronização junto com os dados trocados em cada sincronização. Alguns critérios de teste utilizados em programas sequenciais tiveram sua adaptação para que pudessem ser aplicados em programas concorrentes como é apresentado no trabalho de Yang et al. (1998), com foco 
em programas concorrentes que utilizam memória compartilhada, e os trabalhos de Vergilio et al. (2005) e Souza et al. (2008), com foco em programas concorrentes que utilizam o paradigma de passagem de mensagens. Sarmanho et al. (2008) estendem os critérios estruturais definindo um modelo de teste para programas concorrentes com memória compartilhada implementados em Pthreads.

Lei e Carver (2006) apresentam o teste de alcançabilidade de programas concorrentes. Nesta técnica, primeiramente é realizada uma execução não controlada (não determinística) do programa gerando uma sequência de sincronização $Q_{0}$ que é gravada durante a execução por meio de timestamp. A partir do trace obtido da execução de $Q_{0}$, identificam-se "condições de disputa" nos eventos receive, gerando variantes da sequência de sincronização executada sem construir nenhum modelo estático. Em seguida, essas variantes são utilizadas para realizar execuções controladas baseadas em prefixo com a mesma entrada, exercitando as sincronizações da variante. Como as sequências são derivadas a partir de uma execução do programa, essa abordagem não apresenta o problema da não executabilidade. Um problema encontrado nesse modelo é o mesmo que ocorre no grafo de concorrência de Taylor et al. (1992) que é a explosão de estados de concorrência, uma vez que o número de estados cresce exponencialmente com o número de threads e o número de sincronizações a serem executadas.

Com base nos conceitos de teste de alcançabilidade, Souza et al. (2011) apresentam uma proposta de utilização dessa abordagem em conjunto com os critérios estruturais para programas com passagem de mensagens. Essa proposta apresenta a vantagem de reduzir o custo do teste de alcançabilidade, como também guiar a avaliação dos critérios de cobertura.

\subsection{Teste de Mutação Aplicado a Programas Concorren- tes}

A definição do teste de mutação para o contexto de programas concorrentes apresenta alguns desafios. Isso se deve ao não determinismo presente nos programas concorrentes, permitindo assim, o programa possuir mais de uma resposta diferente e correta. Uma vez que isso acontece, o fato da execução do mutante gerar um resultado diferente do resultado gerado pela execução do programa original não é o suficiente para matar o mutante, uma vez que a discrepância dos resultados pode ter ocorrida pela ação do não determinismo e não por causa da mutação implementada.

A ideia principal do teste de mutação é que um mutante executado com um caso de teste $t$ deve ser morto caso seu comportamento seja diferente do comportamento do programa $P$ do qual o mutante foi derivado. Em programas concorrentes seria necessário 
comparar o conjunto de todos os resultados possíveis de um mutante $M$ quando executado com um caso de teste $t$ em relação ao conjunto de todos os resultados possíveis do programa original $P$ com o caso de teste $t$. Se $M$ apresentar um comportamento diferente, ele foi distinguido de $P$ (Souza et al., 2007). Entretanto, em geral, não é possível conhecer todo o comportamento possível de um programa concorrente para determinada entrada. Apesar disso, algumas soluções são propostas, visando permitir que o teste de mutação seja aplicado nesse contexto.

\subsubsection{Taxonomia de Erros e Defeitos}

Durante a definição de novos critérios de teste é importante levar em consideração os tipos de erros e defeitos que devem ser evidenciados pelos critérios, de preferência que sejam defeitos típicos no contexto explorado (Souza et al., 2007).

Segundo Krawczyk et al. (1995), há dois tipos de erros relacionados a programas concorrentes. O erro de observabilidade (observability error) e erro de travamento (locking error). Dado um caminho $p_{x}, \mathrm{D}\left(p_{x}\right)$ representa o domínio de entrada, formado pelas entradas que exercitam $p_{x}$ e $\mathrm{C}\left(p_{x}\right)$ é a computação de $p_{x}$, formado pelas saídas produzidas pela execução de $p_{x}$. Os dois tipos de erros são definidos como:

- Erro de observabilidade: ocorre em um programa $P$ se para algum caminho $p_{i}$ $\in P$ existe outro caminho $p_{j} \in P$ tal que $D\left(p_{i}\right)=D\left(p_{j}\right)$ e $C\left(p_{i}\right) \neq C\left(p_{j}\right)$. Este erro está relacionado ao ambiente de teste, quando o testador não pode controlar o comportamento do programa em paralelo e, desse modo, pode ser impossível exercitar uma sequência do programa que apresente o erro.

- Erro de travamento: ocorre em um programa $P$ se para algum caminho $p \in P$, formado pelo conjunto de nós $p=q_{0}, q_{1}, \ldots q_{j}$, existe um nó $q_{i}$ em $p$ tal que no subcaminho $p_{s}=q_{0}, q_{1}, \ldots q_{i}$ contendo um domínio $D\left(p_{s}\right)$, existe pelo menos um elemento de $D\left(p_{s}\right)$ em que todos os predicados avaliados a partir de $q_{i}$ são falsos. Este erro relaciona-se quando, por exemplo, um processo não se comunica com outro de maneira correta. Isso fará com que um processo fique travado esperando algum tipo de comunicação que nunca ocorrerá.

Offutt et al. (1996) ao criarem operadores de mutação para programas em Ada não definem uma taxonomia de defeitos, porém levam em consideração para a criação dos operadores os seguintes defeitos:

- Troca de um operando por outro, sendo que um operando pode ser Variables, Constants, Array References, Record References ou Pointer References. 
- Modificação de instruções, sendo que as instruções podem ser Block, Case, Exit, For, Goto, If, Loop, Raise, Return ou While.

- Modificação de expressões.

- Modificação ou troca de operadores de tarefas, sendo que os operadores de tarefas são Entry, Accept e Select. Estes operadores de tarefas são utilizados para tratar o aspecto de concorrência da linguagem Ada.

Choi e Lewis (2000) realizaram um experimento no qual foram analisados 180 programas multithread desenvolvidos por estudantes. Os programas observados foram: semaphore, mutex, bounded buffer e cigarret smoker. Com base na análise realizada, os autores apresentam os defeitos comuns cometidos pelos estudantes durante o desenvolvimento dos programas. Como resultado, os autores classificaram os defeitos da seguinte forma:

- Condição de corrida: a) Variável compartilhada não protegida, b) Lock não adquirido para proteger um acesso, c) Compartilhamento acidental, d) Liberação do Lock prematuramente, e) Inicialização redundante de variável desprotegida e f) Múltiplos locks em uma única variável.

- Deadlocks: a) Múltiplos locks para uma única variável, b) Primitivas de test-and-set confundidas com mutex, c) Locks nunca liberados e d) Threads tentando readquirir locks que já possuem.

- Diversos: a) Uso desnecessário de desabilitar interrupções, b) Único lock para todas as variáveis, c) Assumir que a rotina unlock-and-stop retorna com o lock do test-and-set e d) Desbloquear o mesmo lock repetidamente sem necessidade.

Vetter e Supinski (2000) apresentam a ferramenta Umpire. Esta ferramenta realiza a análise dinamicamente (sem modificar o código e em tempo de execução) de programas em MPI com o intuito de encontrar erros típicos de programação. O principal objetivo da ferramenta é tornar os usuários mais produtivos por meio da detecção automática de problemas de programação antes do usuário ser forçado a realizar a depuração da aplicação. A ferramenta tem como função realizar a checagem de um conjunto de erros definidos como sendo os que mais ocorrem durante o desenvolvimento de programas MPI. A taxonomia adotada consiste nos seguintes erros e os defeitos relacionados com cada erro:

- Deadlock: a) Uso incorreto de chamadas bloqueantes, b) Loops sobre chamadas de conclusão não bloqueantes, c) Ordem de chamadas coletivas, d) Uso de parâmetros coringa e e) Erro de configuração do tamanho do buffer. 
- Segmento de Recursos: a) Vazamento de recursos básicos: Sobrescrita de objetos opacos (tipos derivados de dados, comunicadores derivados, grupos, valores chave, objetos request) e Finalizar programa sem liberar objetos opacos, b) Requisição Perdida e c) Escritas erradas em buffer de envio.

Luecke et al. (2003) apresentam a ferramenta MPI-CHECK que permite a checagem automática em tempo de compilação e em tempo de execução de programas MPI desenvolvidos em Fortran 90 e Fortran 77. O modelo de defeitos que o programa detecta é baseado nos seguintes defeitos:

- Troca do padrão, tipo, grau ou número de argumentos.

- Mensagens que excedem o limite do array de origem ou destino.

- Mensagens de tamanho negativo.

- Chamada a funções MPI antes do MPI_Init ou depois do MPI_Finalize.

- Inconsistências entre o tipo de declaração da mensagem e o argumento datatype associado a ele.

- Violação da intenção de um atributo em uma função (entrada/saída).

Krammer et al. (2003) apresentam a ferramenta MARMOT que tem como finalidade verificar a conformidade padrão de um programa MPI automaticamente durante a execução e ajudar a depurar o programa em caso de problemas. A ferramenta tem como objetivo encontrar os seguintes defeitos e erros que podem aparecer durante o desenvolvimento de programas em MPI:

- Reprodução de condições de disputa.

- Gerenciamento de recursos: a) Comunicador inválido, b) Grupos inválidos, c) Datatype inválido, d) Operações inválidas.

- Diversas (envolvendo argumentos como tag e rank)

- Deadlock.

Farchi et al. (2003) também apresentam uma taxonomia de defeitos concorrentes para programas em Java. Contudo os autores citam que a maior parte dos defeitos presentes nesta taxonomia não é exclusiva de programas Java e pode ser encontrada em grande parte dos programas concorrentes independentemente da linguagem de programação. Segundo essa taxonomia, os defeitos possuem um padrão com relação a: 
- Código que deveria ter proteção encontrando-se desprotegido: a) Operação não atômica assumida como sendo atômica, b) Acesso em dois estágios, c) Lock errado ou ausência de lock e d) Bloqueio de dupla-checagem (inicialização).

- Interleavings previstos para nunca ocorrerem: a) Uso de método sleep para sincronização e b) Perda de um notify.

- Bloqueio ou morte de uma thread: a) Bloqueio de uma seção crítica e b) Thread orfã.

Long e Strooper (2003) apresentam uma classificação de defeitos que podem ocorrer em programas concorrentes em Java. Através de uma rede de Petri, os autores representam um programa concorrente no qual identificam como sendo a transição T1 o pedido de um objeto lock, T2 o bloqueio de um objeto, T3 a espera por um objeto, T4 a liberação um objeto lock e T5 a notificação da thread. Cada transição é analisada utilizando dois critérios: 1) Falha na execução da transição e 2) Início incorreto da transição. Com isso, os autores apresentam os seguintes erros:

- Falha em iniciar a transição T1 em que uma thread não acessa um bloco sincronizado quando requerido.

- Início incorreto da transição T1 em que uma thread acessa um bloco sincronizado quando não é necessário.

- Falha em iniciar a transição T2 em que o objeto lock a ser obtido já foi pego por outra thread.

- Falha em iniciar a transição T3 em que nenhuma chamada à função wait é feita.

- Início incorreto da transição T3 em que uma thread faz uma chamada incorreta à função wait.

- Falha em iniciar a transição T4 em que uma thread nunca libera o objeto lock ou em que uma thread executa a transição T3, ou seja, ele chama a função wait.

- Início incorreto da transição T4 em que a thread libera o objeto lock prematuramente.

- Falha em iniciar a transição T5 em que a thread não é notificada.

- Início incorreto da transição T5 em que a thread é notificada antes do que deveria. 
Levando em consideração os trabalhos de Vetter e Supinski (2000) Krammer et al. (2003) e Luecke et al. (2003), DeSouza et al. (2005) apresentam uma taxonomia de erros para programas desenvolvidos em MPI. A taxonomia apresentada divide os erros em três categorias principais:

1. Sincronização

Deadlock: Padrão e Dependente do tempo.

Condição de corrida: Interface e Entre processos.

2. Incompatibilidade

Tipo de chamada.

Argumentos.

Tamanho.

3. Recursos

Alocação.

Inicialização.

Desalocação.

Utilizando as contribuições do trabalho de DeSouza et al. (2005), Samofalov et al. (2005) apresentam uma taxonomia de mais alto nível de defeitos para programas concorrentes desenvolvidos em MPI. A taxonomia proposta possui 4 categorias:

1. Defeitos os quais requerem a informação da função MPI local.

2. Defeitos que podem ser detectados analisando apenas as informações locais do processo.

3. Defeitos relacionados a múltiplos processos em um mesmo comunicador: defeitos de operações ponto a ponto e defeitos de operações coletivas.

4. Defeitos os quais não requer informação sobre a comunicação interprocesso, mas requer informação sobre estados dos processos.

Com base nos trabalhos de Farchi et al. (2003), Long et al. (2004) e Long et al. (2005), Bradbury et al. (2006) estendem a taxonomia de erros para programas concorrentes em Java adicionando algumas características presente em Java (J2SE 5.0). São definidos quatro novos padrões de erros que podem ocorrer: 
1. Falta de sinais que podem ser enviados entre as threads: esse padrão generaliza a perda de um sinal como o notify() para todos os outro sinais como, por exemplo, em uma barreira o método await() precisa ser executado por um conjunto de threads para que o programa possa continuar e caso uma thread não execute esse método, todas as outra ficam paradas.

2. Erro de starvation, que ocorre quando uma thread nunca é escalonada para ser executada.

3. Erro de exaustão de recursos, que ocorre quando um grupo de threads mantém todos os recursos finitos juntos e uma thread que precisa de um recurso adicional fica parada, uma vez que este não é dado por nenhuma das outras threads.

4. Erro de inicialização de contagem incorreta, que ocorre quando, por exemplo, há uma inicialização incorreta do número de threads que devem ser esperadas para que então a barreira seja liberada, uma inicialização incorreta do número de threads requeridas para completar uma ação ou uma inicialização incorreta do número de permissões no semáforo.

Pedersen (2006) classificou os defeitos que podem ocorrer em programas concorrentes que usam o paradigma de passagem de mensagem. A classificação foi feita utilizando programas desenvolvidos por alunos da graduação. Como resultado ele chegou a 7 classes de defeitos:

1. Decomposição de dados: A causa do problema tem relação com a decomposição do conjunto de dados.

2. Decomposição funcional: A causa do problema tem relação com a decomposição das funcionalidades ao implementar o programa.

3. Utilização de API: A causa do problema está relacionada com o uso das chamadas a funções MPI.

4. Defeito sequencial: Defeitos que já são conhecidos dos programas sequenciais.

5. Problema de mensagem: A causa do problema é o envio incorreto de dados por meio de funções de envio e recebimento de mensagens.

6. Problema de protocolo: A causa do problema está relacionada com mensagens perdidas que violam o protocolo de comunicação do sistema paralelo.

7. Outros: Defeitos que não podem ser incluídos em nenhuma das classes anteriores. Esta classe inclui permissões erradas nos programas, falha em E/S paralela, entre outros. 
No trabalho de Lourenço e Cunha (2007), os autores apresentam uma taxonomia de defeitos encontrados em STM (Software Transactional Memory). Um STM é um mecanismo de controle de concorrência que tem como objetivo controlar acessos à memória compartilhada. Esses defeitos vieram da experiência dos autores no desenvolvimento deste tipo de software. O modelo de defeitos foi obtido após que os interleavings provocaram comportamentos errôneos no STM, os quais se relacionam à referência de memória não transacional, atualização perdida com pequena tabela de bloqueio, falta de descarte de uma leitura incorreta quando a transação é abortada e atualização perdida com bloqueio.

A partir de um estudo de quatro aplicações na arquitetura cliente-servidor desenvolvidas em $\mathrm{C}$ ou $\mathrm{C}++$ e levando em consideração a taxonomia proposta por Farchi et al. (2003), Lu et al. (2008) apresentam um estudo no qual houve a coleta dos defeitos dessas aplicações estudadas. Esses defeitos posteriormente foram divididos em dois grupos:

1. Defeitos relacionados a deadlock.

2. Defeitos de concorrência não relacionados a deadlock: Podendo ser defeitos relacionados à atomicidade, à ordem e defeitos relacionados a outras características.

Sen (2009) define operadores de mutação para programas concorrentes em SystemC. SystemC é a linguagem de modelagem de sistemas para projetar SoCs (System-on-a-Chip) na indústria. O conceito de SoC surgiu no fim da década de 1990, que possibilitava integrar um sistema computacional completo dentro de um chip (Wawrzyniak, 1999). O modelo de erros utilizado pelos autores consiste em nove erros comuns que envolvem concorrência em SystemC:

1. Deadlock: Dois ou mais processos são impossibilitados de continuar pois um fica esperando o outro.

2. Interference: Duas ou mais threads concorrentes acessam uma variável compartilhada e ao menos uma acesso é de escrita.

3. Lost notify: Se um notify() é executando antes do seu respectivo whait(), o notify() não fará efeito e será perdido.

4. Nondeterminism: Caso uma notificação imediata seja utilizada, isso pode causar não determinismo.

5. Starvation: Falha ao alocar tempo de CPU para um processo durante a política de sincronização.

6. Resource exhaustion: Um grupo de processos seguram todo o finito número de recursos. Um deles precisa de um recurso adicional, porém nenhum outro processo cede para ele. 
7. Incorrect count initialization: Número incorreto de entradas na inicialização de um semáforo.

8. Forgetting operators: Esquecer de chamar um put antes de uma função get.

9. Incorrect operators: Usar um read no lugar de write ou usar um operador bloqueante no lugar de um não bloqueante.

Levando em consideração os trabalhos de Choi e Lewis (2000), Farchi et al. (2003), Long e Strooper (2003) e Lu et al. (2008), Wu e Kaiser (2011) apresentam uma taxonomia de erros para programas concorrentes, a qual é usada para a criação de operadores de mutação de segunda ordem. O modelo de erros apresentado contém os seguintes erros:

- Condição de corrida: Acontece quando várias threads lêem e escrevem no mesmo dado e a saída da execução depende da ordem em que ocorreram os acessos ao dado. Isso também é chamado de interferência.

- Inconsistência de memória: Ocorre quando diferentes threads possuem visões diferentes de uma mesma variável.

- Violação de atomicidade: É causado pela execução concorrente de várias threads violando a atomicidade de uma região do código.

- Deadlock: Ocorre quando, por exemplo, quando duas ou mais threads estão bloqueadas para sempre esperando uma a outra.

- Livelock: Ocorre quando duas threads estão ocupadas respondendo uma a outra e, com isso, não progredindo.

- Starvation: Ocorre quando uma thread não é capaz de conseguir o acesso a um recurso compartilhado e, com isso, não progredindo.

- Suspension: Ocorre quando uma thread suspende ou fica em espera indefinidamente.

Com os trabalhos encontrados sobre taxonomia de defeitos foi feita uma análise buscando identificar as relações entre eles. Para isso, foram observadas as citações que cada trabalho faz para os outros trabalhos pertencentes ao grupo de trabalhos encontrados. $\mathrm{O}$ resultado dessa análise pode ser observada na Figura 3.2, na qual os retângulos representam os trabalhos encontrados e as setas indicam que o trabalho de onde a seta parte serviu de referência para os trabalhos os quais as setas apontam. 


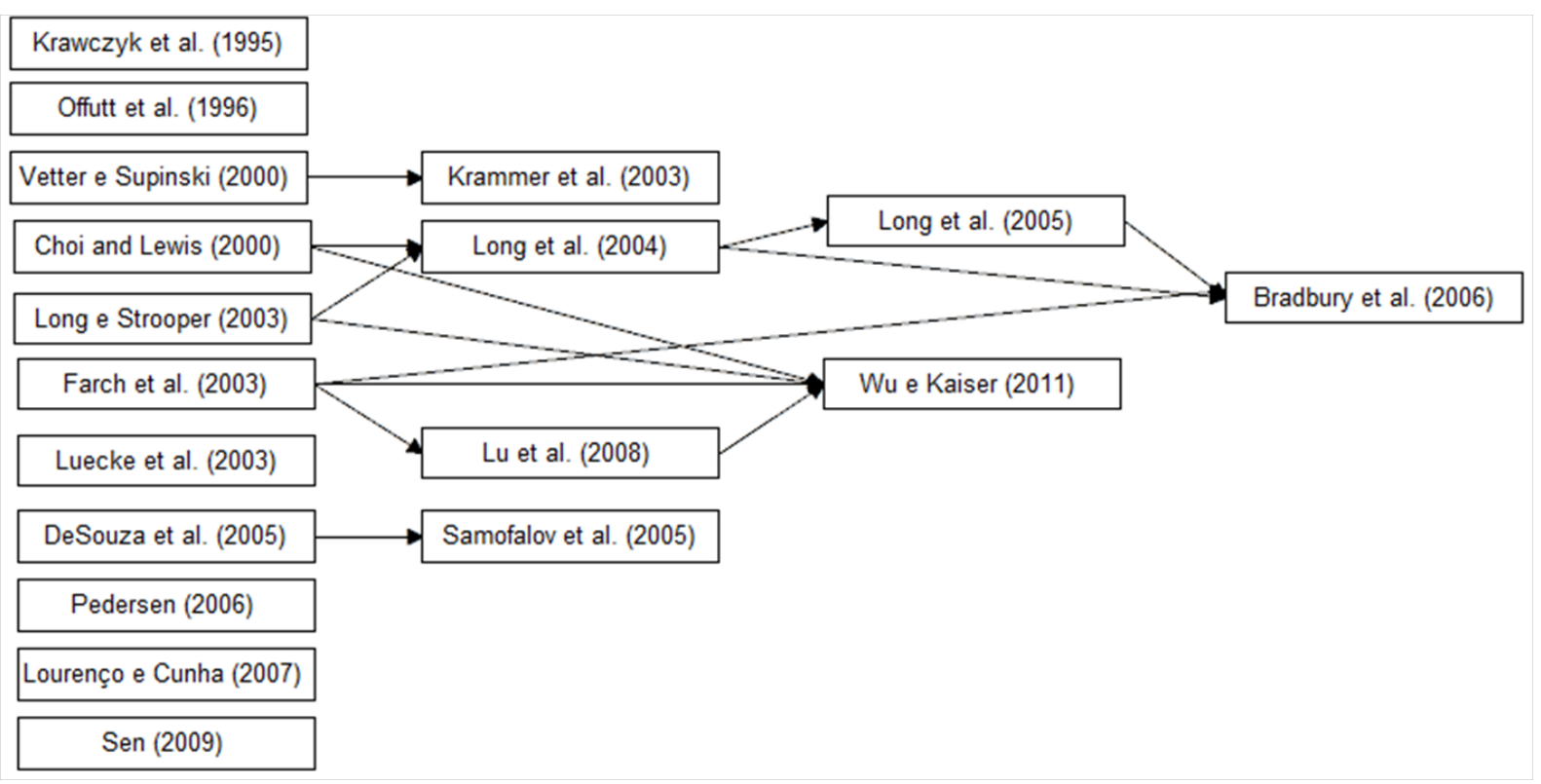

Figura 3.2: Relacionamento entre os trabalhos encontrados.

\subsubsection{Operadores de Mutação}

Na literatura podem ser encontrados diversos trabalhos que apresentam a proposta de operadores de mutação para serem aplicados em programas concorrentes, porém nem todos apresentam de que maneira o problema do não determinismo é tratado na execução dos mutantes. Offutt et al. (1996) propõem a definição de operadores de mutação para programas Ada. Com relação a tarefas concorrentes, os autores definem 3 operadores de mutação:

1. Modificação da declaração ENTRY.

2. Substituição da declaração $A C C E P T$.

3. Substituição alternativa de SELECT.

Levando em consideração o trabalho de Offutt et al. (1996), Silva-Barradas (1998) propõe a aplicação do critério teste de mutação para programas concorrentes em Ada. O autor divide os operadores de mutação em duas classes: Operadores de mutação para declarações e Operadores de Mutação para Expressões Condicionais. Os operadores de mutação pertencentes à primeira classe são aplicados aos construtores da linguagem que são usados para controlar o comportamento concorrente do programa em Ada. Nessa classe estão os seguintes operadores:

- DEL_CALL: Exclui uma entrada ou uma ação de chamada protegida.

- DEL_ACCEPT: Exclui uma declaração de accept. 
- CH_ENTRY: Substitui o nome de uma entrada ou ação de proteção com o nome de outra entrada/ação de proteção com um perfil que tenha a mesma especificação que a original.

- CH_TSK_REF: Substitui uma referência de tarefa por uma referência que seja da mesma família modificando a parte discriminante.

- DEK_ELSE_NULL: Exclui um else null; alternativo.

- DEL_OR_TERM: Exclui um or terminate alternativo.

- CH_PARM: Muda valores dos parâmetros em uma entrada ou ação de chamada protegida.

- DELL_ACC_STATS: Substitui declarações pertencentes ao corpo de uma entrada de permissão de entrada ou de ação protegida com NULL.

A segunda classe de operadores de mutação é aplicada em protetores (em seletivas accept/call), barreiras (em ações protegidas), declarações filiais que diretamente controlam a execução de chamadas de entradas ou declarações que permitem entradas. Também são aplicadas em cláusulas when de declarações exit. Nessa classe estão os seguintes operadores:

- ADD_NOT: Adiciona o operador not.

- CH_AND_OR: Substitui and por or e vice-versa.

- CH_REL_OP: Substitui um operador relacional $(>,<,=,>=,<=, /=)$ por outro operador relacional.

- CH_COND_FALSE: Substitui uma expressão condicional por uma constante FALSE.

Delamaro et al. (2001) definem um conjunto de operadores de mutação para testar aspectos de concorrência e sincronização da linguagem Java. Os autores argumentam que os operadores de mutação cobrem a maioria dos aspectos relacionados à concorrência e sincronização e são também de baixo custo (geram um número pequeno de mutantes). Foram identificadas as principais estruturas relacionadas à concorrência e definidos operadores de mutação para execução dessas estruturas. Os operadores de mutação foram criados com base em quatro grupos de estruturas relacionadas à concorrência em Java. Esses grupos são:

1. Código de bloqueio de monitor.

2. Métodos relacionados à manipulação do wait set. 
3. Uso de métodos síncronos.

4. Uso de métodos relacionados à sincronização e concorrência.

Ghosh (2002) apresenta uma proposta de operadores de mutação para programas concorrentes orientados a objetos em Java. O foco da abordagem está concentrado nos casos nos quais o acesso a dados compartilhados precisa ser protegido, mas não é. O modelo de falhas assume que os programadores podem não usar a construção synchronized quando há a necessidade. O autor traz duas abordagens diferentes, em que na mais simples só é realizada a criação de um mutante que remove a palavra synchronized do programa original. A abordagem baseada no grafo de conflito tem como base o trabalho de Yang et al. (1998). A abordagem sugere a criação de um grafo de fluxo para cada thread e inclui arestas de interação entre as threads. Baseado nas duas formas de sincronização em Java, há três tipos de combinação que podem ser representados no grafo: método com método, bloco com bloco e método com bloco. O mecanismo funciona com a invocação do driver de teste que invoca métodos no código do mutante seguindo uma sequência de métodos. O estado e a saída do mutante são capturados e comparados com o Oráculo usando um comparador. O autor não apresenta como esse mecanismo é executado e nem como é tratado o não determinismo.

Giacometti et al. (2003) apresentam uma proposta inicial para a aplicação do teste de mutação para programas em ambiente de passagem de mensagens, considerando o ambiente PVM (Parallel Virtual Machine). Diferentemente dos outros trabalhos, este apresenta a definição de operadores de mutação levando em consideração todo um padrão de programação concorrente pré-definido, enquanto os outros definem operadores de mutação apenas para algumas funções que permitem a programação concorrente para tais linguagens. Resumindo, o padrão PVM é bem mais específico e abrangente para programação concorrente, possuindo um número maior de funções do que outras linguagens como Ada e Java que tratam pequenos aspectos da programação concorrente. Os autores indicam a necessidade de tratar o não determinismo no contexto de PVM, a exemplo do trabalho de Silva-Barradas (1998). Os operadores de mutação definidos pelos autores procuram modelar os seguintes tipos de erros: Erro no fluxo de dados entre processos; Erro no empacotamento de mensagens e Erro na sincronização e no paralelismo das tarefas. Como resultado, os autores chegaram à definição dos seguintes operadores:

- ReplArgPVM: Substituição de parâmetros nas chamadas de função PVM.

- IncrDecrArgPVM: Incremento/decremento de parâmetros nas chamadas de funções PVM.

- ReplArgbyArg: Operador de troca na ordem dos parâmetros nas chamadas de funções PVM. 
- InsUnaArgPVM: Inclusão de operadores unários nos parâmetros das chamadas de funções PVM.

- ReplCallPVM: Operadores de troca de função PVM.

- DelSndPVM: Remoção de função PVM de envio de mensagens.

- DelRcvPVM: Remoção de função PVM de recebimento de mensagens.

- DelFinTask: Remoção de finalizações de tarefas paralelas.

- ReplKill: Substituição de pvm_kill por pvm_exit.

- ReplHalt: Substituição de pvm_halt por pvm_exit.

- ReplExit: Substituição de pvm_exit por pvm_halt.

- ReplRcv: Substituição do modelo de comunicação do comando receive.

- ReplProbe: Substituição de pvm_recv por pvm_probe.

- DelSync: Remoção da Sincronização dos processos.

- ReplPkData: Substituição de funções para empacotar/desempacotar mensagens.

Bradbury et al. (2006) propõem a criação de operadores de mutação para programas desenvolvidos em Java (J2SE 5.0). Os autores utilizam como base para a criação dos operadores um modelo de erros previamente definido por Farchi et al. (2003) e adicionam alguns padrões de erros para programas concorrentes em Java. A partir deste modelo, os autores apresentam cinco categorias de operadores de mutação para Java relacionados à concorrência:

1. Modificar parâmetros de métodos concorrentes,

2. Modificar a ocorrência de chamadas a métodos concorrentes (removendo, substituindo e trocando),

3. Modificar palavras-chave (adicionando e removendo),

4. Mudar objetos concorrentes e

5. Modificar região crítica (deslocando, expandindo, diminuindo e dividindo).

Sen (2009) define sete operadores de mutação divididos em duas categorias. A primeira categoria abrange os operadores de mutação criados a partir da modificação de operadores. Nesta categoria encontram-se os seguintes operadores: 
- Modify Function Timeout.

- Modify Concurrency Construct Count.

A segunda categoria engloba os operadores de mutação criados a partir da remoção, substituição e troca de operadores de concorrência. Nesta categoria encontram-se os seguintes operadores:

- Remove Concurrency Construct.

- Replace Timed Construct with Untimed Construct.

- Exchange Lock/Permit Acquisition.

- Exchange Function Call with Another.

- Exchange one Concurrency Construct Instance with Another.

Jagannath et al. (2010) definem operadores de mutação para programas desenvolvidos utilizando o modelo de programação orientado a atores. Um programa desenvolvido com essa abordagem consiste em um conjunto de objetos concorrentes que se comunicam por meio de troca de mensagens. Para desenvolver programas nesse modelo é necessário utilizar linguagens de programação e bibliotecas como ActorFoundry, Axum, Erlang, Kilim, Scala e Singularity. Um ator é um objeto concorrente autônomo com suas próprias threads de controle que se comunicam usando passagem de mensagens. Para responder uma mensagem recebida, os atores podem enviar uma mensagem para outros atores, criar novos atores e/ou atualizar o estado local. Os autores dividiram os operadores em 3 categorias:

- Mensagem

$R S R$ - Remove Send/Receive.

MMP - Modify Message Parameter.

RMP - Reorder Message Parameters.

MMN - Modify Message Name.

MMR - Modify Message Recipient.

CRT - Change (message) Reference Type.

CST - Change (message) Synchronization Type.

- Restrição

$R C$ - Remove Constraint.

MC - Modify Constraint. 
- Criação/Deleção

RCD - Remove Creation/Deletion.

MCP - Modify Creation Parameter.

$R C P$ - Reorder Creation Parameters.

Wu e Kaiser (2011) apresentam uma abordagem onde são aplicados operadores de mutação de segunda ordem os quais geram erros de concorrência não representados pelos operadores de primeira ordem. Os autores apresentam 6 operadores para Java que são:

1. RKSN+RSSN Remove synchronized Keyword and a Statement from Synchronized Method.

2. AKST+MASN Add static Keyword and Modify Argument with Constant to Synchronized Method.

3. RKSN+MASN Remove synchronized Keyword and Modify Argument with Constant.

4. RSNB+RSSB Remove synchronized Block and a Statement from Synchronized Block.

5. MOSB $+R S S B$ Modify synchronized Object and Remove a Statement from Synchronized Block.

6. MOSB+MVSB Modify synchronized Object and Move Statement(s) Out of Synchronized Block.

\subsubsection{Procedimentos para a Aplicação do Teste de Mutação}

Carver (1993) foi o primeiro a propor uma abordagem para a aplicação do teste de mutação em programas concorrentes. Para isso, o autor utiliza duas outras abordagens de teste em programas concorrentes: MET (Multiple Execution Testing) e DET (Deterministic Execution Testing). A abordagem MET consiste em, a partir de uma entrada $X$, executar o programa diversas vezes e examinar o resultado de cada execução. Caso uma das execuções apresentar um resultado diferente do esperado, há um defeito no programa que necessita ser corrigido. O problema dessa técnica é que não há como garantir que todas as sequências de sincronização foram executadas, sendo que o programa pode apresentar uma resposta diferente da esperada (incorreta) ao executar uma sequência de sincronização diferente das executadas no teste. A abordagem DET apresentada nos trabalhos de Tai (1985), Tai (1986) e Tai et al. (1989) é definida a partir da seleção de um conjunto de teste, no qual cada caso de teste é formado por uma entrada $X$ e uma sequência de sincronização $S$. Para cada caso de teste é forçada a execução da entrada $X$ com a sequência $S$ e, então, 
é observado o resultado. Caso o resultado da execução forçada for diferente do esperado, foi encontrado um defeito no programa. O problema dessa técnica está em encontrar todas as sequências de sincronização que podem ser exercitadas pelo programa em teste e determinar sua executabilidade.

A partir da união dessas duas abordagens, Carver (1993) desenvolveu o procedimento chamado DEMT (Deterministic Execution Mutation Testing) para a execução determinística dos mutantes. Neste procedimento, primeiramente são geradas sequências de sincronizações aleatórias por meio da aplicação da abordagem MET no programa em teste $P$. Caso seja encontrado um resultado diferente do esperado, o programa contém um defeito e precisa ser corrigido. Caso contrário, o próximo passo é gerar os mutantes e aplicar a execução determinística em cada um dos mutantes gerados. Para isso, são selecionados casos de teste formados por uma entrada $X$ e uma sequência de sincronização $S$. Assim, os mutantes devem ser executados pelo par $(X, S)$. Um mutante é considerado morto caso não consiga executar a sequência de sincronização $S$ ou apresente um resultado diferente da apresentada pelo programa em teste com o mesmo par $(X, S)$. Os passos desse procedimento são apresentados na Figura 3.3.

gerar mutantes $\left(\mathrm{M}_{1}, \mathrm{M}_{2}, \ldots, \mathrm{M}_{\mathrm{n}}\right)$ a partir de $\mathrm{P}$; repita \{

aplicar teste não determinístico para executar aleatoriamente $\mathrm{P}$ com a entrada $\mathrm{x}$; armazenar a sync-seq $\mathrm{S}_{\mathrm{P}}$ gerada pela execução e a saída de $\mathrm{P}$ com x, output-x-P; analisar quais das condições ocorrem:

(a) $\mathrm{S}_{\mathrm{P}}$ é válida e output-X-P é correta;

(b) $\mathrm{S}_{\mathrm{P}}$ é válida e output-x-P é incorreta;

(c) $\mathrm{S}_{\mathrm{P}}$ é inválida e output-X-P é correta;

(d) $\mathrm{S}_{\mathrm{P}}$ é inválida e output-X-P é incorreta; se (b), (c) ou (d) então

localizar e corrigir o defeito de $\mathrm{P}$; aplicar teste determinístico, forçando a execução de $\mathrm{P} \operatorname{com}\left(\mathrm{x}, \mathrm{S}_{\mathrm{P}}\right)$ senão para avaliar se o comportamento de P corrigido está correto;

para cada mutante $\mathrm{M}_{\mathrm{i}}, \mathrm{i}<=\mathrm{n}$, faça aplicar teste determinístico, forçando a execução de Mi com (x, $\left.\mathrm{S}_{\mathrm{P}}\right)$ e produzindo a saída output-x-Mi; se $S_{P}$ é não executável para Mi ou output-x-P $>$ output-x-Mi então

fim-se; marcar mutante Mi como morto (ou distinguido);

\} até escore de mutação atingir valor desejado;

Figura 3.3: Procedimento DEMT.

Embora a abordagem MET reduza o esforço necessário para selecionar sequências de sincronização para teste, pode não ser possível matar alguns mutantes. Em alguns casos, para matar um mutante, seria necessário exercitar uma sequência $S$ que é executável para 
o mutante, mas não executável para o programa $P$. No entanto, segundo o procedimento proposto, somente as sequências $S$ executáveis do $P$ podem ser exercitadas usando MET. Os autores sugerem selecionar casos de teste, representados por $I N \_S Y N(X, S)$, mesmo que $S$ seja não executável para $P$. Para isso, é necessário determinar o resultado esperado para a execução forçada de $P \operatorname{com}(X, S)$. O resultado esperado inclui a expectativa de $S$ ser executável, a condição de finalização do $P$ e a saída esperada.

A expectativa de $S$ ser executável e a condição de finalização da execução forçada de $P \operatorname{com}(X, S)$ pode ser descrita usando uma dessas 4 tuplas: (fea,nt), (fea, at), (inf, nt) ou (inf,at). Nessas tuplas "fea" e "inf" significam executável (feasible) e não executável (infeasible) respectivamente e " $n t$ " e "at" significam "finalização normal" e "finalização anormal" respectivamente. Com isso, os autores chegam ao procedimento DEMT usando DET com casos de teste $I N \_S Y N$ selecionados. Os mutantes morrem caso a tupla difira com relação à executabilidade, condição de término ou saída.

De um modo geral, esta abordagem é eficiente quanto à execução dos mutantes deterministicamente, fazendo com que o mutante percorra a mesma sequência de sincronização do programa original, porém traz o problema da abordagem DET, na qual encontrar as sequências de sincronização é um problema, uma vez que não se pode ter certeza que todas as sequências de sincronização do programa em teste foram executadas.

Normalmente, calcular o conjunto de todas as saídas para um programa concorrente é demorado e gera alto custo computacional. No caso do procedimento DEMT, com a utilização da abordagem MET é criado um conjunto $\Omega$ que é a aproximação do conjunto de todas as saídas do programa concorrente. Porém, ao criar esse conjunto, é possível que uma execução de um mutante $M$ com um caso de teste $t$ resulte em uma saída que não esteja no conjunto $\Omega$, mas que faz parte do conjunto de todas as saídas, fazendo que o mutante seja morto incorretamente.

Outro procedimento para tratar o não determinismo durante a aplicação do teste de mutação em programas concorrentes foi desenvolvido por Offutt et al. (1996), no qual os autores executam a técnica de teste primeiramente executando o programa original $N$ vezes com o mesmo caso de teste $t$ para criar $N$ saídas $O_{i}$, sendo que $i$ vai de 1 a $N$. O conjunto $\Omega=O_{1}, O_{2}, \ldots, O_{N}$ é o conjunto de saídas executáveis possíveis. Em seguida, executa o mutante $m$ com o caso de teste $t$ para criar a saída $O(m, t)$. Se $O(m, t) \in \Omega$, então o mutante continua vivo, caso contrário, ele é morto. Sabe-se que o conjunto $\Omega$ se aproxima do verdadeiro conjunto de saídas executáveis do programa dependendo do valor de $N$. Para conseguir o conjunto de saídas executáveis verdadeiro é necessário executar o programa várias vezes. O valor de $N$ pode ser estimado por alguns pontos durante o teste:

- Determinado pelo sistema de mutação como uma constante para todos os programas. 
- Definido pelo testador para cada aplicação.

- Estimado pelo sistema de mutação, executando o programa original repetidamente até que, em um pequeno número de execuções, nenhum resultado novo seja retornado.

Como pode ser observado, esse procedimento difere-se do apresentado por Carver (1993), uma vez que nesse procedimento o mutante não é executado deterministicamente, sendo apenas observada a sua saída e comparada com o conjunto $\Omega$. Ao realizar esse procedimento, observa-se o mesmo problema do procedimento DEMT com relação ao conjunto $\Omega$, fazendo com que o mutante possa ser morto incorretamente. Além disso, outro problema similar encontrado nesse procedimento está relacionado a possibilidade do mutante continuar vivo por acaso. Isso pode acontecer quando um caso de teste pode matar um mutante, mas não o faz por causa da execução não determinística que faz com que a função que sofreu a mutação não seja executada. Por fim, outro problema é a impossibilidade de reproduzir a análise, uma vez que diferentes ambientes podem gerar diferentes conjuntos $\Omega$, fazendo com que os mutantes mortos usando o conjunto $\Omega$ original podem permanecer vivos utilizando um novo conjunto $\Omega$ e vice-versa. Esses problemas ocorrem porque não são levadas em consideração as sequências de sincronização exercitadas durante a execução dos casos de teste.

Um outro procedimento, definido por Silva-Barradas (1998) foi desenvolvido com o objetivo de resolver os problemas apresentados pelas abordagens MET e DET durante o teste de mutação para programas concorrentes. O procedimento criado pelo autor é dividido em duas fases. Na primeira fase é realizada a execução do programa $P$ com cada dado de teste $t$, gravando o comportamento de $P$, formado pela túpla $(t, s e q, o)$, na qual seq é a sequência de sincronização e $o$ a saída obtida, formando um conjunto de comportamentos $\Psi$. Em seguida, é gerado o conjunto de mutantes e, então, cada mutante é forçado a executar os comportamentos do conjunto $\Psi$. O mutante é morto caso não consiga reproduzir a sequência de sincronização ou apresente um resultado $o^{\prime}$ diferente do $o$ gravado. A segunda fase, dado um conjunto de mutantes que permanecem vivos, para cada mutante é identificado um par $(t, s e q)$, em que $t$ pertence ao conjunto de casos de teste e seq exercita a função que sofreu a mutação no programa. Em seguida, é realizada a execução do programa $P$ com o par identificado e é gravada a saída. Após isso, é realizada a execução do mutante e observado o resultado. O mutante é morto caso os resultados difiram.

Como pode ser observado, esse procedimento não utiliza MET para criar um conjunto $\Omega$, com isso, o problema de matar um mutante incorretamente não ocorre. Além disso, ao utilizar a geração de comportamentos que exercitem a mutação criada no programa, 
utilizando a execução determinística resolve o problema de deixar o mutante vivo por acaso, uma vez que o caso de teste vai exercitar a mutação inserida no programa.

Choi e Srinivasan (1998) desenvolveram uma ferramenta chamada DejaVu, que possui como função realizar a gravação e reprodução da execução de um programa multithread escrito em Java. A abordagem utilizada pela DejaVu para realizar a captura da sequência de execução das threads é baseada em um relógio global como, por exemplo, o time stamp para a aplicação toda e um relógio local para cada thread.

Delamaro (2004) apresenta uma abordagem para reproduzir a execução de um programa concorrente utilizando instrumentação. Esta abordagem baseia-se na técnica de record and playback, na qual são registradas a entrada e a saída da execução de um programa e, usando esse dados, é realizada a reprodução do mesmo programa. Na abordagem apresentada pelo autor, um programa $P$ é instrumentado com o intuito de gravar a sequência de sincronização na primeira execução e seguir essa sequência de sincronização gravada na re-execução do programa. A instrumentação é realizada em duas etapas distintas. A primeira é realizada para gravar a sequência de sincronização, na qual identifica-se quando um bloco sincronizado é executado. A fase de reprodução requer uma instrumentação diferente. É importante notar que antes de uma thread entrar em um ponto sincronizado é necessário checar na sequência de sincronização se o próximo evento é o que deve ser executado.

Sen e Abadir (2010) apresentam como ocorre a execução do teste no contexto de aplicações concorrentes desenvolvidas em SystemC. Assim como em Tai (1985), cria-se um programa $P^{\prime}$ que possui todos os mutantes, sendo que apenas uma mutação é executada por vez. Para a simulação de $P^{\prime}$ com o caso de teste $t$, os autores utilizam como referência o trabalho de Helmstetter et al. (2006), no qual é apresentado um método para explorar o conjunto de sequências válidas para um programa em SystemC dada uma entrada. Esse método utiliza a redução de ordem parcial dinâmica, a qual maximiza a cobertura e mantém o número de testes o menor possível, permitindo assim explorar todos as sequências possíveis com um dado conjunto de testes. Para a verificação se o caso de teste $t$ é capaz de matar o mutante $P^{\prime}$ é verificado se há uma saída da execução do mutante que não está presente de todas as possíveis saídas de $t$ com o programa original $P$.

\subsection{Ferramenta de Teste ValiMPI}

A implementação deste projeto de mestrado levou em consideração as funcionalidades disponíveis na ferramenta de teste ValiMPI, uma vez que esta ferramenta. Desse modo, essa ferramenta é detalhada nesta seção. A ferramenta ValiMPI implementa o conjunto de critérios de teste estrutural estabelecidos por Vergilio et al. (2005). Atualmente os cri- 
térios que estão implementados na ferramenta são: Todos-Nós, Todos-Nós-r, Todos-Nós-s, Todas-Arestas, Todas-Arestas-s, Todos-c-Usos, Todos-p-Usos e Todos-s-Usos.

A arquitetura da ferramenta é composta por cinco módulos: Vali-Inst, Vali-Exec, Vali-Elem, Vali-Sync e Vali-Eval. A Figura 3.4 mostra um grafo com o fluxo de trabalho da ferramenta ValiMPI.

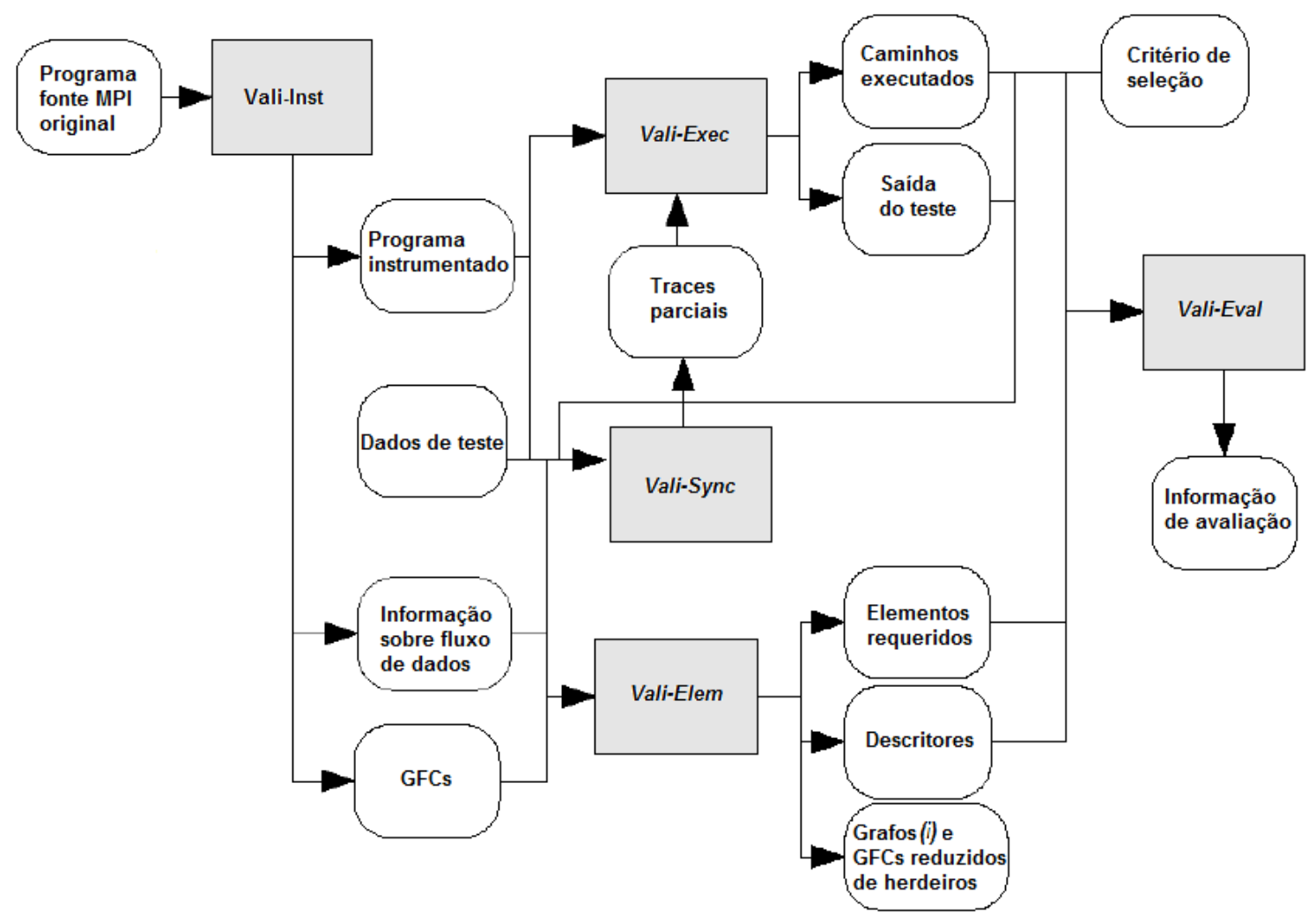

Figura 3.4: Fluxo de trabalho da ValiMPI. (Hausen, 2005)

O módulo Vali-Inst é o módulo responsável por gerar o GFCP (Grafo de Fluxo de Controle Paralelo) e informações sobre o fluxo de dados do programa, como também o programa instrumentado. Nesse programa são adicionados comandos especiais que não mudam a semântica, mas registram informação de rastro (trace). A tarefa de instrumentação propriamente dita é feita pela IDeL (Simão et al., 2003). A IDeL, instanciada para a gramática da linguagem $\mathrm{C}$, recebe o código fonte do programa MPI juntamente com a descrição semântica da instrumentação. No programa instrumentado algumas declarações são inseridas diferindo-o do programa original, como exemplos, a inserção de check-point que identifica o rastro de execução, substituição de funções como MPI_Send, MPI_Isend, MPI_Recv e MPI_Irecv por ValiMPI_Send, ValiMPI_Isend, ValiMPI_Recv e ValiMPI_Irecv. Como resultado do Vali-Inst são gerados os seguintes itens: programa instrumentado, informações sobre o fluxo de dados e grafos de fluxo de controle. 
O módulo Vali-Elem utiliza as informações geradas pelo Vali-Inst e gera os elementos requeridos para os critérios de teste implementados pela ValiMPI. Esses elementos requeridos representam as informações que precisam ser executadas (exercitadas/testadas) no código concorrente. Esse módulo recebe como entrada os GFCs, as informações de fluxo de dados e a distribuição das funções em teste entre os processos, gerando como saída os elementos requeridos pelos critérios baseados em fluxo de controle e fluxo de dados. Nesse módulo também são gerados descritores dos elementos requeridos, para isso é utilizado o grafo reduzido de herdeiros e o grafo $(i)$, usado pela ferramenta de teste Poketool (Chaim, 1991).

O módulo Vali-Exec executa os dados de teste fornecidos pelo usuário tendo como base o programa instrumentado. Como resultado, tem-se a saída do teste e os caminhos executados no programa instrumentado. Este módulo armazena as entradas, as saídas geradas, o número de processos paralelos, o traço de execução de cada função por processo e a sequência de execução para cada processo. Os caminhos executados gerados por esse módulo são utilizados como entrada para o módulo Vali-Sync. A execução controlada garante que duas execuções do programa paralelo com a mesma entrada produzirão os mesmos caminhos e as mesmas sequências de sincronização.

O módulo Vali-Sync implementa o teste de alcançabilidade proposto por Lei e Carver (2006). As variantes são geradas a partir da execução de um caso de teste, utilizando como entrada os arquivos de sincronizações executadas e traces gerados pelo módulo Vali-Exec. Com essas informações, identificam-se as possíveis variantes, tomando como base o algoritmo proposto por Lei e Carver (2006). Com a geração de traces parciais, a execução controlada das variantes pode ser realizada. Esses traces parciais contêm as sincronizações que devem ser executadas deterministicamente. As demais sincronizações são executadas não deterministicamente.

O módulo Vali-Eval avalia a cobertura dos casos de teste em relação aos critérios de teste selecionados. Esse módulo usa os caminhos executados para cada dado de teste para verificar quais elementos requeridos (para um critério de teste) são exercitados.

\subsection{Considerações Finais}

Neste capítulo foram apresentados conceitos sobre teste de software. Foram descritos os conceitos principais e a terminologia sobre teste de software. Em seguida foram apresentadas as três principais técnicas de teste de software, dando ênfase no teste baseado em defeitos, mais especificamente no critério teste de mutação por possuir maior importância no contexto deste trabalho. 
A aplicação do teste para o contexto de programas concorrentes foi apresentada, descrevendo os trabalhos relacionados, com ênfase nos trabalhos sobre teste de mutação. A ferramenta de teste ValiMPI foi descrita, a qual foi utilizada para apoiar a implementação do teste de mutação para programas em MPI. Esses trabalhos forneceram subsídios para o desenvolvimento deste trabalho.

Vários trabalhos para teste em programas concorrentes podem ser encontrados na literatura, porém há poucos trabalhos que podem ser aplicados a programas concorrentes que utilizam o padrão MPI. No próximo capítulo são apresentados os operadores de mutação definidos para programas em MPI e a abordagem definida para a análise do comportamento dos mutantes. 


푼

\section{Teste de Mutação para Programas em}

MPI

\subsection{Considerações Iniciais}

Neste capítulo são apresentados os operadores de mutação definidos para MPI e a abordagem que será aplicada para a execução dos mutantes. A Seção 4.2 descreve detalhadamente os operadores de mutação definidos para MPI. Na Seção 4.3 é presentada uma tabela comparativa entre os operadores definidos e os operadores existentes para programas na linguagem C. Na Seção 4.4 é feito um mapeamento dos operadores de mutação na taxonomia de defeitos definida por DeSouza et al. (2005). A Seção 4.5 apresenta dois procedimentos para a análise comportamental dos mutantes. Por fim, a Seção 4.6 apresenta as considerações finais deste capítulo.

\subsection{Operadores de Mutação para MPI}

Como visto no capítulo anterior, houveram definições de operadores de mutação para outros ambientes de programação paralela como, por exemplo, PVM, porém pelas diferenças entres esses ambientes e o padrão MPI, novos operadores de mutação são necessários para tratar concorrência e sincronização nesse ambiente. 
Outro aspecto motivador para a definição de operadores de mutação para MPI vem da possibilidade da confusão que o programador pode cometer ao desenvolver os programas em MPI, visto que há várias funções com sintaxe parecida, porém com semântica e objetivo diferentes. Além disso, algumas funções possuem um grande número de argumentos o que pode fazer com que o programador confunda-se na hora em que estiver programando. Com isso, erros de troca envolvendo argumentos podem ser identificados com o teste de mutação.

Para a definição dos operadores foram considerados os aspectos de comunicação two-sided (na qual há a necessidade de que em ambos os processos haja a especificação da comunicação) entre processos, podendo ser tanto comunicação ponto a ponto quanto comunicação coletiva. A estrutura das chamadas de funções MPI e suas definições de funcionamento podem ser encontradas no documento oficial do padrão MPI-2 (Forum, 1997).

Inicialmente, foi realizado um estudo sobre como operadores de mutação foram definidos para outras linguagens de programação que apresentam aspectos concorrentes, observando como a definição dos operadores foi conduzida. Após o estudo dos trabalhos relacionados, observou-se que o trabalho de Giacometti et al. (2003) é o que mais se assemelha ao projeto que está em desenvolvimento. Isso se deve ao fato do padrão de programação concorrente PVM (Parallel Virtual Machine), trabalhado pelos autores, possuir semelhança com o padrão MPI no que diz respeito ao paradigma de troca de mensagens.

Tradicionalmente, não existe uma maneira direta de definir operadores de mutação para uma dada linguagem. Em geral, os operadores de mutação são projetados tendo por base a experiência no uso da linguagem e a partir do conhecimento sobre os enganos mais comuns cometidos durante a sua utilização. Para a criação dos operadores de mutação para MPI, utilizou-se a taxonomia de erros criada por DeSouza et al. (2005), na qual os autores propõem uma classificação para os erros cometidos por programadores quando estão programando em MPI. Os operadores foram definidos com base nos erros apresentados na taxonomia e, em especial, considerou-se o trabalho de Giacometti et al. (2003). Na sequência, novos operadores foram definidos, considerando aspectos intrínsecos do MPI.

\subsubsection{Constantes Requeridas}

O conjunto de constantes requeridas, definido por Delamaro (1997), contém valores especiais que são relevantes para alguns tipos primitivos de dados na linguagem $\mathrm{C}$ e operações associadas a esses tipos. As constantes requeridas são utilizadas no operador ReplArg (Substituição em parâmetros na chamada de função), no qual as constantes requeridas são utilizadas nos argumentos das funções. A Tabela 4.1 apresenta as constantes requeridas para cada tipo de dados. 
Tabela 4.1: Conjunto de constantes requeridas (Delamaro, 1997).

\begin{tabular}{|l|l|}
\hline Tipo de variável & Constantes requeridas \\
\hline $\begin{array}{l}\text { signed integer } \\
\text { signed char } \\
\text { signed long }\end{array}$ & $-1,1,0$, MAXINT, MININT \\
\hline $\begin{array}{l}\text { unsigned integer } \\
\text { unsigned char } \\
\text { unsidned long } \\
\text { enum }\end{array}$ & $-1,1,0$, MAXUNSIGNED \\
\hline $\begin{array}{l}\text { float } \\
\text { double }\end{array}$ & $-1.0,1.0,0.0,-0.0$ \\
\hline $\begin{array}{l}\text { As constantes MAXINT, MININT e MAXUNSIGNED correspondem respectiva- } \\
\text { mente ao maior inteiro positivo, ao inteiro mais negativo e ao maior inteiro sem } \\
\text { sinal. Esses valores são dependentes de máquina e de tipos de dados. }\end{array}$ \\
\hline
\end{tabular}

\subsubsection{Operadores de Mutação}

Esta seção apresenta a definição dos operadores de mutação para programas desenvolvidos utilizando o padrão MPI. Primeiramente, é apresentada uma explicação de cada um dos operadores definidos e qual é o seu objetivo. Após a definição, é apresentado um exemplo de como a mutação irá ocorrer no programa.

Os operadores de mutação foram divididos em 3 categorias: Coletiva, Ponto a ponto e Todas. As categorias foram organizadas levando em consideração o tipo de função MPI na qual os operadores são aplicados. A primeira categoria, "Coletiva", apresenta operadores de mutação que são aplicados em funções que realizam comunicação coletiva. A segunda categoria, "Ponto a ponto", contém operadores de mutação que podem ser aplicados em funções que realizam comunicação ponto a ponto subdividida em operadores aplicados às funções de send, receive e outras. Por fim, a categoria "Todas" mostra os operadores que podem ser aplicados tanto para as funções coletivas quanto para as funções ponto a ponto (Silva et al., 2012b).

Os operadores de mutação divididos em categorias podem ser vistos na Tabela 4.2 na qual a coluna da esquerda apresenta as categorias e sub-categorias e a coluna da direita apresenta os operadores de mutação.

A seguir, cada operador de mutação definido para MPI é apresentado. Primeiramente é feita uma breve descrição do funcionamento do operador e, em seguida, é apresentado um exemplo para ilustrar a aplicação do operador. 
Tabela 4.2: Operadores de mutação para programas em MPI.

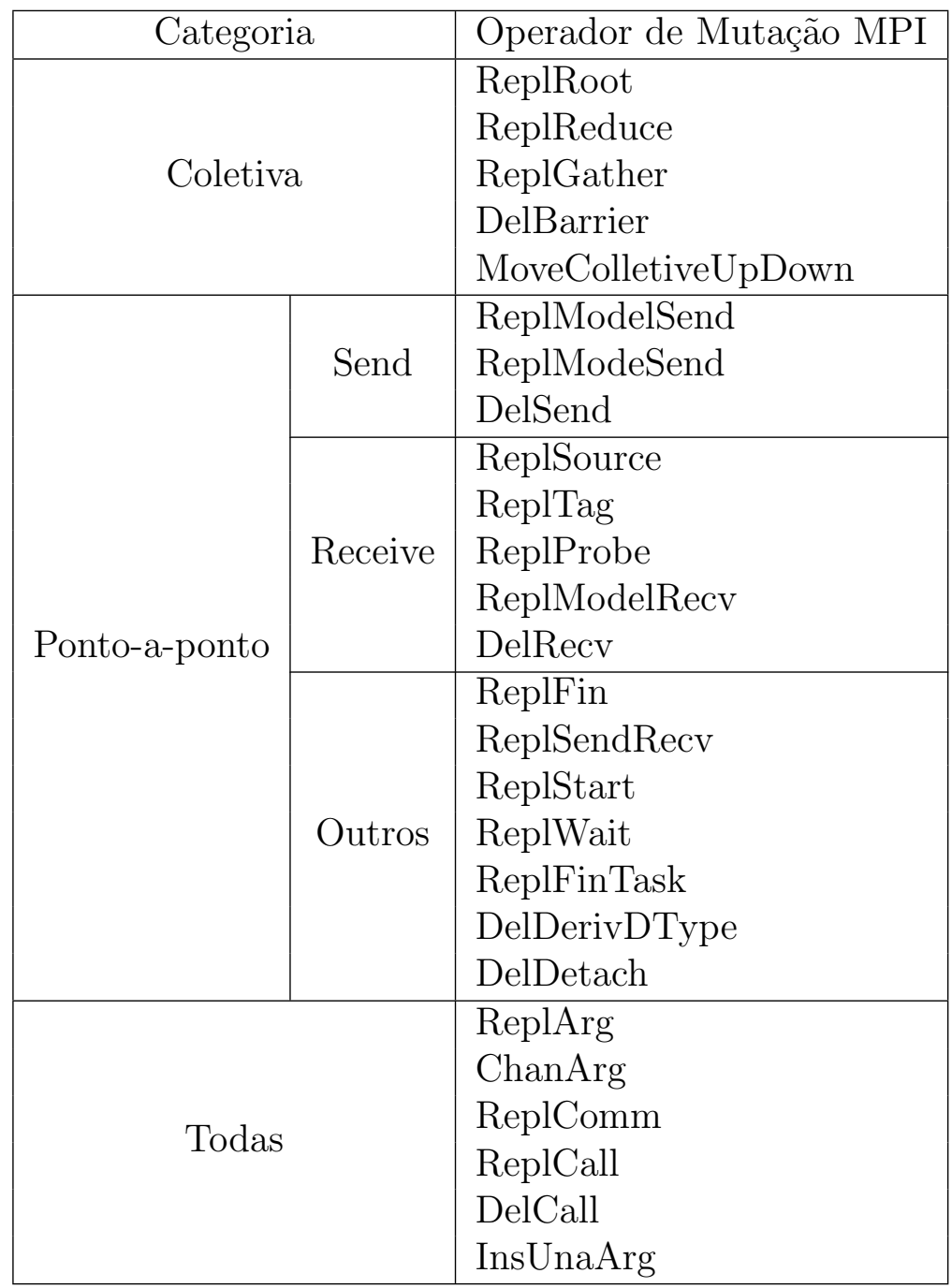

\subsubsection{Operadores de Mutação para Funções Coletivas}

RepIRoot - Substituição do parâmetro root em chamada de função coletiva: Esse operador tem como objetivo mudar o valor do parâmetro root em algumas chamadas a funções coletivas. Esse parâmetro especifica o processo principal da comunicação, geralmente o destino das mensagens. A cada ocorrência de uma operação coletiva que use o parâmetro root será criado um mutante com o valor de root para cada um dos processos. Por exemplo, uma execução com 3 processos ficaria da seguinte forma:

Original: MPI_Reduce (\&sendbuf, \&recvbuf, count, datatype, MPI_MAX, 0, comm); Mutante1: MPI_Reduce (\&sendbuf, \&recvbuf, count, datatype, MPI_MAX, 1, comm); Mutante2: MPI_Reduce (\&sendbuf, \&recvbuf, count, datatype, MPI_MAX, 2, comm);

Pode-se observar que o sexto parâmetro que indica o root, ou seja, o processo para qual o valor resultante da operação de redução é enviado, foi alterado para 1 e 2 nos Mutante1 e Mutante2 respectivamente, considerando três processos existentes (Processo 0, Processo 
1 e Processo 2). Aplicando esse operador pode-se identificar erros nos quais há processos que recebem dados que não serão processados e processos que apresentam erros por não possuir dados que deveriam ser recebidos por meio dessa função.

ReplReduce - Substituição da função de redução: Esse operador tem como função realizar a substituição entre as chamadas das funções MPI_Reduce, MPI_Allreduce e MPI_Reduce_scatter. Em toda ocorrência de uma dessas funções será criado um mutante para cada uma das outras, e tem-se por exemplo:

Original: MPI_Reduce (\&sendbuf, \&recvbuf, count, datatype, op, root, comm);

Mutante1: MPI_Allreduce (\&sendbuf, \&recvbuf, count, datatype, op, comm); Mutante2: MPI_Reduce_scatter (\&sendbuf, \&recvbuf, \&recvcnts, datatype, op, comm);

Pode-se observar que no Mutante1 a função inserida foi a MPI_Allreduce, enquanto que no Mutante2 a função inserida foi a MPI_Reduce_scatter. Utilizando esse operador, erros relacionados aos dados enviados podem ocorrem como, por exemplo, ao utilizar a função MPI_Reduce_scatter, que envia uma parte de um vetor para cada processo, quando a função a ser utilizada é a MPI_Allreduce, que envia o vetor todo.

ReplGather - Substituição da função de coleta: Esse operador tem como função realizar a substituição entre as chamadas da função MPI_Gather, função MPI_Gatherv, MPI_Allgather e MPI_Allgatherv. Em toda ocorrência de uma dessas funções será criado um mutante para cada uma das outras. Um exemplo é mostrado a seguir:

Original: MPI_Gather (\&sendbuf, sendcnt, sendtype, \&recvbuf, recvcount, recvtype, root, comm);

Mutante1: MPI_Allgather (\&sendbuf, sendcnt, sendtype, \&recvbuf, recvcount, recvtype, comm);

Mutante2: MPI_Gatherv (\&sendbuf, sendcnt, sendtype, \&recvbuf, recvcnts, displs, recvtype, root, comm);

Mutante3: MPI_Allgatherv (\&sendbuf, sendcnt, sendtype, \&recvbuf, recvcnts, displs, recvtype, comm);

Pode-se observar que no Mutante1 a função inserida foi a MPI_Allgather. Já no Mutante2, a função inserida foi a MPI-Gatherv e, por fim, a função inserida no Mutante3 foi a MPI_Allgatherv. Ao aplicar esse operador, dados podem ser perdidos, uma vez que as funções Gatherv podem enviar mensagens de tamanhos diferentes, o que não ocorre nas funções Gather. Além disso, quando substituída a função que envia o resultado da operação de união para todos os processos por uma que envie o resultado somente para um processo, alguns processos apresentarão erros com relação aos dados que não possuem. 
DelBarrier - Remoção da função de barreira: Esse operador tem como objetivo remover toda a ocorrência de uma chamada a uma função de sincronização MPI_Barrier, como no seguinte exemplo:

Original: MPI_Barrier (comm);

Mutante1:

Pode-se observar que o Mutante1 não apresenta a função MPI_Barrier. Com a ausência de uma função de barreira, a sincronização entre os processos fica comprometida, podendo ocorrer erros de perda de mensagens, acesso a dados quando isso não poderia ocorrer, sobrescrita de dados, entre outros.

MoveColletiveUpDown - Mover operações coletivas para cima ou para baixo: Esse operador tem como finalidade mover operações coletivas algumas linhas para cima ou para baixo da linha onde ela originalmente está. Com isso, espera-se modelar os erros de sincronização e comunicação. Isso pode ocorrer porque, uma vez que as operações não estão no lugar esperado, podem ser executadas instruções que não deveriam ser ou instruções importantes para a execução correta da função coletiva não são executadas. A Figura 4.1 apresenta um exemplo de um programa que usa a função MPI_Barrier para realizar a sincronização dos processos. A Figura 4.2 apresenta o programa mutante no qual a função de sincronização está dentro do escopo do processo de rank 0 .

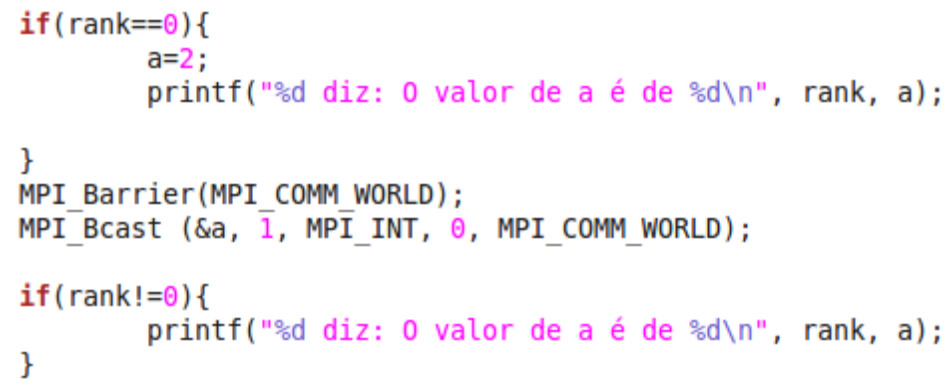

Figura 4.1: Programa original.

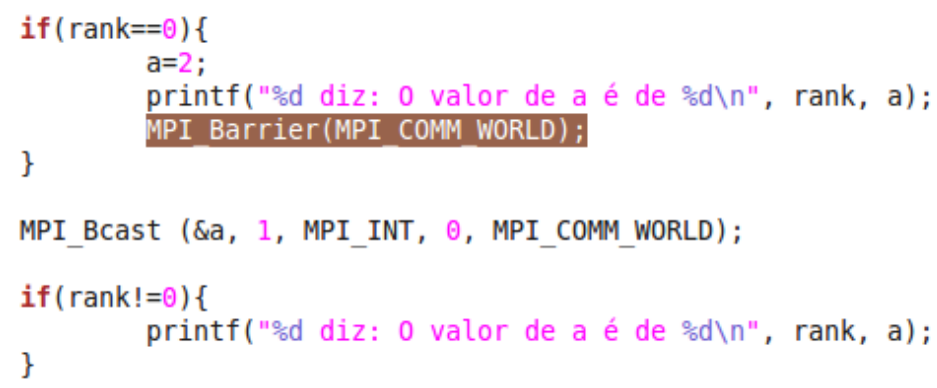

Figura 4.2: Programa mutante. 
Pode-se observar que a função MPI_Barrier no programa mutante foi retirada do lugar onde estava e foi inserida algumas linhas acima do seu lugar de origem. Dessa forma, o processo 0 vai ficar esperando que todos os processos do comunicador cheguem até a barreira, mas eles não vão, uma vez que a função ficou dentro da condição de if.

\subsubsection{Operadores de Mutação para Funções Ponto a ponto}

RepIModelSend - Substituição do modelo da função de envio: Esse operador tem como objetivo realizar a substituição da chamada de função de envio de mensagem por sua respectiva versão no outro modelo. As funções de envio de mensagens ponto-a-ponto no modelo bloqueante são: MPI_Send (padrão), MPI_Ssend (síncrono), MPI_Bsend (bufferizado) e $M P I_{-} R$ send (imediato). As funções no modelo não bloqueante são respectivamente: MPI_Isend (padrão), MPI_Issend (síncrono), MPI_Ibsend (bufferizado) e MPI_Irsend (imediato). A cada ocorrência de uma chamada a uma função de envio de mensagem, será criado um mutante com a versão da função no outro modelo e tem-se como exemplo:

Original: MPI_Send (\&sndbuf, count, dtype, dest, tag, comm);

Mutante1: MPI_ISend (\&sndbuf, count, dtype, dest, tag, comm, \&request);

Pode-se observar que no Mutante1 a função inserida foi a MPI_Isend que representa o modelo não bloqueante da função MPI_Send. A aplicação deste operador pode acarretar em problemas com as mensagens enviadas. Isso pode ocorrer caso um send passe do modelo bloqueante para o não bloqueante, fazendo com que algumas mensagens possam ser sobrescritas no buffer.

RepIModeSend - Substituição do modo de comunicação da função de envio: Esse operador possui a finalidade de modificar o modo utilizado na comunicação entre os processos. Uma comunicação pode ser feita por meio de quatro modos diferentes: Padrão, Síncrono, Imediato e Bufferizado, tanto para comunicação bloqueante, para comunicação não bloqueante e para comunicação persistente. A cada ocorrência de uma chamada a uma função ponto a ponto são criados três mutantes que apresentam os três outros modos de comunicação. Caso esse operador seja aplicado em uma função de envio bloqueante (MPI_Send) pode-se realizar a troca por três modelos de comunicação. Com isso, tem-se como exemplo:

Original: MPI_Send (\&sndbuf, count, dtype, dest, tag, comm);

Mutante1: MPI_Ssend (\&sndbuf, count, dtype, dest, tag, comm);

Mutante2: MPI_Rsend (\&sndbuf, count, dtype, dest, tag, comm);

Mutante3: MPI_Bsend (\&sndbuf, count, dtype, dest, tag, comm); 
Pode-se observar que no Mutante1 a função inserida foi a $M P I_{-} S$ send que representa a versão síncrona da função original. O Mutante2 apresenta a função $M P I_{-}$Rsend que representa a versão imediata da função original. Por fim, o Mutante3 apresenta a função MPI_Bsend que representa a versão bufferizada da função original. Ao aplicar esse operador, erros de deadlock podem ocorrem na aplicação. Em um caso no qual um processo $A$ envia uma mensagem por meio de um send bloqueante para um processo $B$ utilizando um receive bloqueante. Ao trocar o send bloqueante por um send imediato no processo $A$, a mensagem pode ser perdida e o processo $B$ fica travado esperando a mensagem que foi perdida.

DelSend - Remoção de função de envio de mensagens: Esse operador tem como objetivo remover uma função de envio de mensagem. A cada ocorrência de uma função de envio de mensagem será criado um mutante que não possuirá esta chamada. Esse operador pode também ser aplicado a funções de envio de mensagens persistentes, porém, nesse caso, a função a ser deletada será a função MPI_Start que tem como objetivo iniciar uma comunicação persistente. Por exemplo, ao aplicar esse operador à função MPI_Send tem-se:

Original: MPI_Send (\&sndbuf, count, dtype, dest, tag, comm);

Mutante1:

Pode-se observar que o Mutante1 não apresenta a função MPI_Send. Ao aplicar esse operador pode-se encontrar erros de deadlock, pois uma vez que um send é retirado, um receive bloqueante pode ficar esperando pelo send que nunca vai ser executado. Além disso, caso o receive seja não bloqueante, irá receber dados incorretos presentes no espaço de memória no qual deveria estar a mensagem enviada pelo send que não existe mais.

RepISource - Substituição do parâmetro source: Esse operador tem como objetivo realizar a substituição do parâmetro $M P I_{-} A N Y_{-} S O U R C E$ por outro source utilizado no programa e vice-versa. A constante $M P I_{-} A N Y_{-} S O U R C E$ é utilizada nas funções de recebimento de mensagens como um wild card ou coringa, que tem como função possibilitar que a função possa receber a mensagem de qualquer processo que envie uma mensagem. Com isso, tem-se como exemplo:

Original: MPI_Recv (\&recvbuf, count, dtype, source, tag, comm, status);

Mutante1: MPI_Recv (\&recvbuf, count, dtype, MPI_ANY_SOURCE, tag, comm, status);

Pode-se observar que o quarto parâmetro que representa o source, ou seja, o número do processo que enviou a mensagem, foi substituído pela constante MPI_ANY_SOURCE. 
A aplicação desse operador pode simular erros de deadlock. Supondo que existem dois receives, um não bloqueante que recebe uma mensagem do Processo 1 e um bloqueante que recebe uma mensagem do Processo 2 e esses dois receives estão nessa ordem (não bloqueante, bloqueante). Ao realizar a mutação, é criado um programa no qual o primeiro receive pode receber de qualquer processo (MPI_ANY_SOURCE). Ao executar esse mutante, o primeiro receive recebe a mensagem do Processo 2 que deveria se recebido pelo segundo receive. Com isso, o segundo receive (bloqueante) vai ficar bloqueado esperando a mensagem que foi recebida pelo primeiro receive (não bloqueante). Outro caso é quando há dois receives, um não bloqueante que recebe uma mensagem de qualquer processo (MPI_ANY_SOURCE) e um bloqueante que recebe uma mensagem do Processo 2 e esses dois receives estão nessa ordem (não bloqueante, bloqueante). Ao realizar a mutação, é criado um programa no qual o primeiro receive recebe a mensagem do Processo 2 e o segundo receive também recebe a mensagem do Processo 2. Ao executar esse programa, o primeiro receive vai receber a mensagem e o segundo receive vai ficar bloqueado esperando a mensagem que já foi recebida pelo receive anterior.

ReplTag - Substituição do parâmetro tag: Esse operador tem como objetivo realizar a substituição do parâmetro $M P I_{-} A N Y_{-} T A G$ por outra tag e vice-versa. O parâmetro tag é uma variável do tipo inteiro que é utilizada para distinguir mensagens enviadas de um mesmo processo. A constante $M P I_{-} A N Y_{-} T A G$ é utilizada nas funções de recebimento de mensagens como um wild card ou coringa, que tem como função possibilitar que a função possa receber uma mensagem com qualquer tag. Com isso, tem-se como exemplo:

Original: MPI_Recv (\&recvbuf, count, dtype, source, MPI_ANY_TAG, comm, status); Mutante1: MPI_Recv (\&recvbuf, count, dtype, source, tag1, comm, status);

Pode-se observar que o quinto parâmetro que representa a tag, ou seja, uma etiqueta que identifica a mensagem, foi substituído pela constante MPI_ANY_TAG. Ao aplicar esse operador pode-se simular erros de deadlock, pois uma vez que substituindo o parâmetro MPI_ANY_TAG por outra tag utilizada no programa, o deadlock pode ocorrer, pois um receive bloqueante pode ficar esperando a mensagem do send, porém esta mensagem já foi recebida por outro receive. Já quando ocorre a troca de uma tag por MPI_ANY_TAG, o erro pode ocorrer porque um receive bloqueante pode ficar esperando a mensagem do send, porém esta mensagem já foi recebida por outro receive.

RepIProbe - Substituição da função de checagem por função de recebimento: Esse operador tem como função realizar a substituição da função de recebimento de mensagem por uma função de checagem de recebimento de mensagem. A cada ocorrência de uma chamada a recebimento de mensagens MPI_Recv (bloqueante) ou MPI_Irecv (não 
bloqueante) será criado um mutante com a chamada à função correspondente ao modelo de envio, ou seja, MPI_Probe (bloqueante) e MPI_Iprobe (não bloqueante). Com isso, tem-se como exemplo:

Original: MPI_Recv (\&recvbuf, count, dtype, source, tag, comm, \&status);

Mutante1: MPI_Probe (source, tag, comm, \&status);

Pode-se observar que no Mutante1 a função MPI_Recv foi substituída pela função MPI_Probe. A aplicação desse operador pode causar erros de dados, uma vez que a função MPI_Probe tem uma estrutura parecida com o receive e objetivo co-relacionado sendo facilmente confundida pelo usuário, fazendo com que a mensagem não seja recebida. Erros com relação aos dados podem ocorrer caso haja um send não bloqueante esperando uma mensagem que não é enviada. Com isso, o send irá receber dados incorretos e pode apresentar um resultado diferente do esperado. Além disso, erros envolvendo deadlock podem ocorrer uma vez que um receive é retirado, um send bloqueante pode ficar esperando pela execução do receive que nunca será executado.

RepIModelRecv - Substituição do modelo da função de recebimento: Esse operador tem como objetivo realizar a substituição da chamada de função de recebimento de mensagem por sua respectiva versão no outro modelo. A função de recebimento de mensagens ponto a ponto no modelo bloqueante é MPLRecv e a função no modelo não bloqueante é MPI_Irecv. A cada ocorrência de uma chamada a uma função de recebimento de mensagem, será criado um mutante com a versão da função no outro modelo. Com isso, tem-se como exemplo:

Original: MPI_Recv (\&recvbuf, count, dtype, source, tag, comm, \&status); Mutante1: MPI_Irecv (\&recvbuf, count, dtype, source, tag, comm, \&status, \&request);

Pode-se observar que no Mutante1 a função inserida foi a MPI_Irecv que representa o modelo não bloqueante da função MPI_Recv. A aplicação desse operador pode simular erros de sincronização pois uma vez que um receive muda do modo bloqueante para o não bloqueante, o recebimento da mensagem pode não ter sido completado e dados incorretos podem ser utilizados.

DelRecv - Remoção de função de recebimento de mensagens: Esse operador tem como objetivo realizar a retirada de uma função de recebimento de mensagem. A cada ocorrência de uma função de recebimento de mensagem será criado um mutante que não possuirá esta chamada. Esse operador pode também ser aplicado a funções de recebimento de mensagens persistentes, porém, nesse caso, a função a ser deletada será a função 
MPI_Start que tem como objetivo iniciar uma comunicação persistente. Por exemplo, tem-se esse operador aplicado à função MPI_Recv:

Original: MPI_Recv (\&recvbuf, count, dtype, source, tag, comm, \&status);

Mutante1:

Pode-se observar que o Mutante1 não apresenta a função MPI_Recv. A aplicação desse operador pode causar erros de dados, pois uma vez que um receive é retirado, os dados que deveriam ser recebidos não estão disponíveis. Além disso, um send bloqueante ou síncrono pode ficar bloqueado causando um deadlock.

ReplFin - Substituição da função de finalização: Esse operador possui a finalidade de substituir uma chamada da função MPI_Finalize por uma MPI_Abort e vice-versa. A função MPI_Finalize tem como objetivo finalizar o ambiente paralelo MPI e após essa chamada de função, nenhuma outra chamada a funções MPI pode ser realizada. A função MPI_Abort tem como objetivo finalizar todos os processos pertencentes a um comunicador. Com isso, tem-se como exemplo:

\section{Original: MPI_Finalize (); \\ Mutante1: $\boldsymbol{M P I} \boldsymbol{A}$ bort (comm);}

Pode-se observar que no Mutante1 a função MPI_Finalize foi substituída pela função $M P I_{-}$Abort. Com isso, apenas um conjunto de processos presentes em um comunicador serão finalizados e não ao ambiente MPI todo, como ocorre com a função MPI_Finalize.

RepISendRecv - Substituição da função MPI_Sendrecv: Esse operador tem como finalidade realizar a substituição da chamada a função $M P I \_S e n d r e c v$ por funções similares como MPI_Sendrecv_replace, todos os modos de send e receive além de probe. Em cada ocorrência de uma chamada a esta função será criado um mutante para a função de MPI_Sendrecv_replace, de MPI_Recv, de MPI_Probe e para cada um dos modos de send. Com isso, tem-se como exemplo:

Original: MPI_Sendrecv (\&sendbuf, sendcount, sendtype, dest, sendtag, \&recvbuf, recvcount, recvtype, source, recvtag, comm, \&status);

Mutante1: MPI_Sendrecv_replace (\&sendbuf, sendcount, sendtype, dest, sendtag, source, recvtag, comm, \&status);

Mutante2: MPI_Send (\&sndbuf, sendcount, sendtype, dest, sendtag, comm);

Mutante3: MPI_Ssend (\&sndbuf, sendcount, sendtype, dest, sendtag, comm);

Mutante4: MPI_Bsend (\&sndbuf, sendcount, sendtype, dest, sendtag, comm);

Mutante5: MPI_Rsend (\&sndbuf, sendcount, sendtype, dest, sendtag, comm); 
Mutante6: MPI_Recv (\&recvbuf, recvcount, recvtype, source, recvtag, comm, \&status);

Mutante7: MPI_Probe (source, recvtag, comm, \&status);

Pode-se observar que o Mutante1 apresenta a função MPI_Sendrecv_replace, o Mutante2 apresenta a função MPI_Send, o Mutante3 apresenta a função MPI_Ssend, o Mutante4 apresenta a função MPI_Bsend, o Mutante5 apresenta a função MPI_Rsend, o Mutante6 apresenta a função MPI_Recv e o Mutante7 apresenta a função MPI_Probe. A aplicação desse operador pode causar erros de deadlock, pois uma vez que um sendrecv é substituído por um send, por exemplo, um send pode ficar bloqueado esperando a confirmação de um receive que não existe. Isso também pode acontecer quando o sendrecv é substituído por um receive, pois um receive pode ficar esperando por um send que não existe mais. Além disso, erros envolvendo dados podem ocorrer quando, por exemplo, o sendrecv é substituído por um receive, então um receive não bloqueante poderá utilizar dados errados, uma vez que a mensagem correta não foi enviada.

\section{RepIStart - Substituição da função de inicialização de comunicação persistente:} Esse operador tem como objetivo realizar a substituição da função MPI_Start por MPI_Startall e vice-versa. A cada ocorrência de uma dessas funções será criado um mutante com a outra função. Por exemplo:

Original: MPI_Startall (count, array_of_requests);

Mutante1: MPI_Start (\&request);

Pode-se observar que no Mutante1 a função chamada foi a MPI_Start que realiza a inicialização de apenas uma comunicação persistente. Neste caso, várias outras funções representadas pelos request presentes no conjunto de requests não serão executadas, gerando erros de comunicação entre os processos.

RepIWait - Substituição da função de espera de requisição: Esse operador tem como objetivo realizar a substituição entre as funções de espera de requisições (MPI_Wait, MPI_Waitall, MPI_Waitany e MPI_Waitsome). A cada ocorrência de uma dessas funções, será criado um mutante para cada uma das outras funções. Por exemplo:

Original: MPI_Wait (\&request, \&status);

Mutante1: MPI_Waitall (count, array_of_requests, array_of_statuses);

Mutante2: MPI_Waitany (count, array_of_requests, \&index, \&status);

Mutante3: MPI_Waitsome (incount, array_of_requests, \&outcount, array_of_indices, array_of_statuses); 
Pode-se observar que no Mutante1 a função utilizada é a MPI_Waitall. O Mutante2 apresenta a função MPI_Waitany. Por fim, o Mutante3 apresenta a função MPI_Waitsome. A aplicação desse operador pode causar erros de dados uma vez que ao trocar um waitall por wait, uma função de receive pode receber dados incorretos caso o send correspondente não tenha sido executado.

DelFinTask - Remoção de finalização de tarefas paralelas: Esse operador possui o objetivo de remover uma função de finalização de uma tarefa paralela. As funções que poderão ser eliminadas são a MPI_Finalize e MPI_Abort. A cada ocorrência de uma função de finalização de tarefas paralelas será criado um mutante que não possuirá esta chamada. Com isso, tem-se como exemplo:

\section{Original: $M P I_{-}$Abort (comm);}

Mutante1:

Pode-se observar que o Mutante1 não apresenta a função MPI_Abort. A aplicação desse operador pode gerar erros de deadlock, pois uma vez que sem a função de finalização o processo ficará executando, causando deadlock.

DelDerivDType - Remoção da função de criação de tipos derivados de dados: Esse operador tem como objetivo remover toda a ocorrência de uma chamada a uma função de criação de tipo derivados de dados. Em MPI, as funções que realizam a criação de dados são: MPI_Type_contiguous, MPI_Type_vector, MPI_Type_struct, MPI_Type_indexed, MPI_Type_hvector, MPI_Type_hindexed. Com isso, tem-se como exemplo:

\section{Original: MPI_Type_contiguous (count, oldtype, \&newtype); \\ Mutante1:}

Pode-se observar que o Mutante1 não apresenta a função MPI_Type_contiguous. A aplicação desse operador pode causar erros de dados, pois sem a função, não há alocação de memória para os tipos derivados de dados criados.

DelDetach - Remoção da função de desalocar memória: Esse operador tem como objetivo excluir a função que realiza a desalocação de memória. A cada ocorrência da função MPI_Buffer_detach e da função MPI_Request_free será criado um mutante sem estas funções. Com isso, tem-se como exemplo:

\section{Original: MPI_Buffer_detach (\&buffer, size);}

Mutante1: 
Pode-se observar que o Mutante1 não apresenta a função MPI_Buffer_detach. A aplicação desse operador pode gerar erros de falta de memória uma vez que sem essa função, erros por causa da falta da desalocação de memória podem ocorrer.

\subsubsection{Operadores de Mutação para Todas as Funções MPI}

RepIArg - Substituição em parâmetros na chamada de função: Esse operador possui como finalidade realizar a substituição de cada parâmetro das chamadas de funções MPI. Esse operador realiza três tipos de substituição. O primeiro tipo realiza a substituição de um parâmetro (variável ou constante) por todas as variáveis e constantes do programa. O segundo tipo realiza a substituição de um parâmetro (variável ou constante) por todas as constantes em MPI. O terceiro tipo realiza a substituição de um parâmetro (variável ou constante) por constantes requeridas. Durante a substituição, caso os parâmetros forem de tipos diferentes, será realizada uma conversão explícita de tipos de dados (cast), que faz com que o compilador trate uma variável como se fosse do tipo especificado. Suponha que esse operador seja aplicado em uma função de envio bloqueante (MPI_Send). A partir disso podemos realizar a substituição entre os seis parâmetros, podendo eles ser constantes ou variáveis dentro da chamada da função. Além disso, podem-se aplicar as constantes requeridas e as constantes do MPI, por exemplo:

Original: MPI_Send (\&sndbuf, count, dtype, dest, tag, comm);

Mutante1: MPI_Send (\&count, count, dtype, dest, tag, comm);

Mutante2: MPI_Send (\&sndbuf, -1, dtype, dest, tag, comm);

Mutante3: MPI_Send (\&sndbuf, MPI_DISTRIBUTE_DFLT_DARG, dtype, dest, tag, comm);

Pode-se observar que o Mutante1 teve o parâmetro sndbuf substituído pelo parâmetro count, o Mutante2 teve o parâmetro count substituído pela constante requerida - 1 e o Mutante3 teve o parâmetro count substituído pela constante MPI MPI_DISTRIBUTE_DFLT_DARG. A aplicação desse operador pode causar erros de dados, pois o tamanho de uma mensagem pode ser inserido erroneamente, por exemplo.

ChanArg - Troca em parâmetros na chamada de função: Esse operador tem como função realizar a troca entre variáveis e/ou constantes entre si na chamada de função. Suponha que esse operador seja aplicado em uma função de envio bloqueante (MPI_Send). A partir disso podemos realizar a troca entre as variáveis. Caso os parâmetros forem de tipos diferentes será aplicada a função de cast que faz com que o compilador trate uma variável como se fosse do tipo especificado. Com isso, tem-se como exemplo:

Original: MPI_Send (\&sndbuf, count, dtype, dest, tag, comm); 
Mutante1: MPI_Send (\&count, sndbuf, dtype, dest, tag, comm);

Mutante2: MPI_Send (\&dest, count, dtype, sndbuf, tag, comm);

Mutante3: MPI_Send (\&tag, count, dtype, dest, sndbuf, comm);

Pode-se observar que o Mutante1 teve os parâmetros sndbuf e count trocados entre si. Já o Mutante2 teve os parâmetros sndbuf e dest trocados entre si. Por fim, o Mutante3 teve os parâmetros sndbuf e tag trocados entre si. A aplicação desse operador pode causar erros de dados, pois o tamanho de uma mensagem pode ser inserido erroneamente, por exemplo.

RepIComm - Substituição de comunicador na chamada de função: Esse operador tem como finalidade realizar a substituição do comunicador pelos demais inter e intra-comunicadores presentes no programa. Um comunicador define um grupo de processos que podem comunicar ente si. A seguir é mostrado um exemplo da utilização desse operador.

Original: MPI_Send (\&sndbuf, count, dtype, dest, tag, MPI_COMM_WORLD);

Mutante1: MPI_Send (\&sndbuf, count, dtype, dest, tag, comm1);

Pode-se observar que no Mutante1 o sexto parâmetro que representa o comunicador foi substituído pelo comunicador comm1. A aplicação desse operador pode causar erros de dados, pois funções que deveriam ser executadas em um determinado grupo de processos não acontecem.

RepICall - Substituição de função: Esse operador tem como objetivo realizar a substituição de chamada a uma função MPI pelas demais chamadas de funções MPI existentes na aplicação. A cada ocorrência de uma função, esta será substituída por outra. Com isso, tem-se como exemplo:

Original: MPI_Send (\&sndbuf, count, dtype, dest, tag, MPI_COMM_WORLD);

Mutante1: MPI_Comm_size (comm, size);

Pode-se observar que no Mutante1 a chamada à função MPI_Send foi substituída pela chamada à função MPI_Comm_size. A aplicação desse operador pode causar erros de deadlock dependendo da ordem em que as funções se encontrarão no programa mutante.

DelCall - Remoção de chamada à função: Esse operador tem como objetivo remover uma chamada a uma função MPI. A cada ocorrência de uma função MPI, será criado um mutante que não possuirá esta chamada. Com isso, tem-se como exemplo: 
Original: MPI_Start (\&request);

Mutante1:

Pode-se observar que o Mutante1 não apresenta a função MPI_Start. A aplicação desse operador pode causar erros de deadlock dependendo de qual função não está presente no programa mutante.

\section{InsUnaArg - Inclusão de operadores unários nos parâmetros nas chamadas de função:}

Esse operador tem como finalidade a inclusão de operadores unários nos parâmetros nas chamadas de função. Os operadores unários são: '-', '--', ‘++' e '!'. Os operadores '--' e '++' podem aparecer antes ou depois de cada variável de tipo numérico. Suponha que esse operador seja aplicado em uma função de envio bloqueante (MPI_Send). A partir disso podemos realizar a troca entre as três variáveis do tipo int (cont, dest e tag). Com isso temos:

Original: MPI_Send (\&sndbuf, count, dtype, dest, tag, comm); Mutante1: MPI_Send (\&sndbuf, - count, dtype, dest, tag, comm); Mutante2: MPI_Send (\&sndbuf, count-1, dtype, dest, tag, comm); Mutante3: MPI_Send (\&sndbuf, count+1, dtype, dest, tag, comm);

Pode-se observar que no Mutante1 foi inserido um operador '-' na frente do parâmetro count. Observe que no Mutante2 o parâmetro count foi diminuído em uma unidade. Por fim, no Mutante3 o parâmetro count foi aumentado em uma unidade. A aplicação desse operador pode causar erros de dados, uma vez que aumentando ou diminuindo o tamanho de uma mensagem, erros nos dados enviados podem ocorrer.

\subsection{Comparação dos Operadores para MPI com os Defi- nidos para $\mathrm{C}$}

Esta seção tem como objetivo mostrar a relação dos operadores de mutação para MPI, anteriormente apresentados, com os operadores de mutação para C definidos por Agrawal et al. (1989), apresentada na Tabela 4.3. O caracter - significa que não há correspondência para o operador. A partir disso, pode-se observar que alguns operadores definidos aqui para MPI são total ou parcialmente cobertos pelos operadores de mutação definidos para programas desenvolvidos na linguagem C. Porém, como se está observando aspectos de comunicação e sincronização dos processos concorrentes da aplicação, há a necessidade de utilizar os operadores de mutação definidos. 
Tabela 4.3: Operadores de mutação para o padrão MPI e sua correspondência para com os operadores para a linguagem $\mathrm{C}$.

\begin{tabular}{|c|c|c|}
\hline \multicolumn{3}{|c|}{ Funções Coletivas } \\
\hline MPI & Descrição & $\mathrm{C}$ \\
\hline ReplRoot & Substituição do root & Vsrr \\
\hline ReplReduce & Substituição da função de redução & - \\
\hline ReplGather & Substituição da função de coleta & - \\
\hline DelBarrier & Remoção da função de barreira & SSDL \\
\hline MoveCollecUpDown & Mover funções para cima/ baixo & - \\
\hline \multicolumn{3}{|c|}{ Funções Ponto a ponto } \\
\hline MPI & Descrição & $\mathrm{C}$ \\
\hline ReplModelSend & Substituição do modelo de send & - \\
\hline ReplModeSend & Substituição do modo de send & - \\
\hline DelSend & Remoção de função send & SSDL \\
\hline ReplSource & Substituição do parâmetro source & Vsrr \\
\hline ReplTag & Substituição do parâmetro tag & Vsrr \\
\hline ReplProbe & Substituição de probe com receive & - \\
\hline ReplModelRecv & Substituição do modelo de receive & - \\
\hline DelRecv & Remoção de função de receive & SSDL \\
\hline ReplFin & Substituição da função de finalização & - \\
\hline ReplSendRecv & Substituição da função Sendrecv & - \\
\hline ReplStart & Substituição da função de inicialização & - \\
\hline ReplWait & Substituição da função de espera & - \\
\hline ReplFinTask & Remoção de finalização de tarefas & - \\
\hline DelDerivDType & Remoção de tipos derivados de dados & SSDL \\
\hline DelDetach & Remoção da função de desalocar memória & SSDL \\
\hline \multicolumn{3}{|c|}{ Todas as Funções } \\
\hline MPI & Descrição & $\mathrm{C}$ \\
\hline ReplArg & Substituição em parâmetros & $\begin{array}{c}\text { Vsrr, CRCR } \\
\text { Cccr, Ccsr }\end{array}$ \\
\hline ChanArg & Troca em parâmetros & Vsrr \\
\hline ReplComm & Substituição de comunicador & Vsrr \\
\hline ReplCall & Substituição de função & - \\
\hline DelCall & Remoção de chamada à função & SSDL \\
\hline InsUnaArg & Inclusão de operadores unários & Ouor \\
\hline
\end{tabular}

\subsection{Classificação dos Operadores}

A taxonomia de erros apresentada por DeSouza et al. (2005) divide os erros cometidos pelos programadores ao desenvolverem programas em MPI em três categorias principais: 1) erros de sincronização (deadlocks ou condição de disputa), 2) erros de incompatibilidade e 3) erros de recursos. Um deadlock em MPI ocorre quando um conjunto de operações de mensagem cria dependências entre elas que podem nunca serem satisfeitas. Uma operação de mensagem cria uma dependência quando o padrão MPI permite à implementação blo- 
quear até que uma operação ocorra (ou seja iniciada) em outros processos. Por exemplo, uma operação MPI_Ssend cria uma dependência do transmissor no receptor quando é realizada uma operação bloqueante que não pode retornar até que o receive correspondente seja executado.

Uma vez que o padrão permite que o $M P I_{-}$Send retorne a execução antes de executar o receive correspondente usando sends não bloqueantes, algumas implementações podem fazer com que o programa termine a execução por causa de um deadlock. Se um programa MPI é não determinístico por haver a ocorrência de wildcard receives ou receives coringa, uma aplicação pode gerar um deadlock e em outra ocasião não, dependendo de quais mensagens a implementação seleciona para os wildcard receives. Chama-se isso de deadlocks dependentes de tempo. Um deadlock padrão não possui dependências não determinísticas. Isso é bom para encontrar e consertar mesmo se a aplicação terminar devido ao tempo da aplicação ou com alguma implementação MPI.

Um exemplo de condição de disputa é aquela onde a aplicação pode mudar o conteúdo do buffer antes deste ser completamente enviado. Isso é chamado de condição de disputa de interface porque trabalha com a interface entre o processo e a chamada dela à rotina de comunicação MPI. Uma condição de disputa interprocessos refere-se a dois processos tentando enviar a mesma mensagem lógica. A semântica MPI sempre resolve as condições de disputa, então o programa não suspende, mas o resultado pode ser inesperado.

Incompatibilidade pode ser a troca de parâmetros que pode ser encontrada só olhando a chamada. Alternativamente pode ser a troca entre um send e um receive no tipo de chamada de passagem de mensagem, o tipo dos argumentos ou o tamanho da mensagem. Por fim, existem ainda os erros envolvendo recursos. Esses recursos podem ser recursos MPI, como os tipos derivados de dados ou comunicadores, assim como podem ser recursos presentes na aplicação, como ponteiros. Os erros de inicialização pode ocorrer quando, por exemplo, que um ponteiro não seja inicializado porque os dados não foram alocados. Outro erro pode ocorrer caso os dados simplesmente não sejam inicializados. No final da execução, todos os recursos devem ser desalocados. Algumas vezes, recursos MPI podem ser esgotados e aplicações devem desalocar todos os recursos assim que for possível.

Uma análise foi feita nos operadores de mutação com o intuito de verificar se todas as categorias presentes na taxonomia de DeSouza et al. (2005) eram contempladas. Após a análise realizada, chegou-se à conclusão que quase todos os erros propostos pela taxonomia foram representados por pelo menos um operador de mutação. A Figura 4.3 apresenta os operadores de mutação na primeira coluna e as categorias de erros nas quais esse operador é significativo na segunda coluna, sendo que cada letra representa uma categoria da taxonomia que segue a seguinte ordem:

- A- Sincronização - Deadlock - Padrão 
- B- Sincronização - Deadlock - Dependente do tempo

- C- Sincronização - Condição de disputa - Interface

- D- Sincronização - Condição de disputa - Entre processos

- E- Incompatibilidade - Tipo de chamada

- F- Incompatibilidade - Argumentos

- G- Incompatibilidade - Tamanho

- H- Recursos - Alocação

- I- Recursos - Inicialização

- J- Recursos - Desalocação

\begin{tabular}{|l|l|}
\hline Operador de mutação & \multicolumn{1}{|c|}{ Categoria } \\
\hline ReplRoot & F \\
\hline ReplReduce & E \\
\hline ReplGather & E \\
\hline DelBarrier & D \\
\hline MoveColletiveUpDown & A, D \\
\hline ReplModelSend & C \\
\hline RepIModeSend & A, B \\
\hline DelSend & A, D \\
\hline ReplSource & B \\
\hline ReplTag & B \\
\hline RepIProbe & A, D, E \\
\hline ReplModelRecv & C \\
\hline DelRecv & A, D \\
\hline
\end{tabular}

\begin{tabular}{|l|l|}
\hline \multicolumn{1}{|c|}{ Operador de mutação } & \multicolumn{1}{|c|}{ Categoria } \\
\hline ReplFin & E \\
\hline RepISendRecv & A, D, E \\
\hline RepIStart & A, D, E \\
\hline RepIWait & A, D, E \\
\hline DelFinTask & A \\
\hline DelDerivDType & H \\
\hline DelDetach & J \\
\hline ReplArg & F, G \\
\hline ChanArg & F, G \\
\hline RepIComm & F \\
\hline RepICall & A, B, C, D, E, J \\
\hline DelCall & A, B, D, J \\
\hline InsUnaArg & G \\
\hline
\end{tabular}

Figura 4.3: Classificação dos operadores seguindo a taxonomia de DeSouza et al. (2005).

Como pode ser observado, a única categoria que não é contemplada pelos operadores é a categoria I- Recursos - Inicialização. Isso ocorreu porque o padrão MPI não possui nenhuma função que realize a inicialização de variáveis. Isso é feito por meio da linguagem de programação que se está utilizando. Para que essa categoria de erro seja contemplada por algum operador de mutação é necessário aplicar operadores definidos para a linguagem de programação utilizada para desenvolver o programa. 


\subsection{Procedimento para a Análise Comportamental de Mu- tantes}

Após a definição dos operadores de mutação para programas em MPI, faz-se necessária a criação de um procedimento que defina como o processo de teste deve ser conduzido. Esse procedimento precisa tratar o não determinismo que é inerente aos programas concorrentes. Levando em consideração os trabalhos que utilizam as abordagens MET (Multiple Execution Testing) e DET (Deterministic Execution Testing) para a aplicação do teste de mutação em programas concorrentes, foram criados dois procedimentos que podem ser utilizados, ambos utilizando a abordagem do teste de alcançabilidade (reachability testing) desenvolvido por Lei e Carver (2006). O teste de alcançabilidade obtém todas as sincronizações executáveis a partir de uma dada execução inicial. Seu objetivo é reduzir o número de sincronizações redundantes, gerando as possíveis combinações de sincronização. Diferentemente das abordagens anteriores, o teste de alcançabilidade determina, durante a execução, quais sincronizações são possíveis de ocorrer em uma nova execução. A técnica de teste baseado em prefixo é empregada para executar o programa deterministicamente até certo ponto e após esse ponto permitir a execução não determinística. As sequências de sincronização (sync-sequences) são derivadas automaticamente e on-the-fly, sem construir nenhum modelo estático. A abordagem funciona da seguinte forma. A partir de uma execução inicial, gerada de maneira não determinística, uma sequência de sincronização inicial $Q 0$ é produzida. Com base em $Q 0$, identificam-se "condições de disputa" entre pares de sincronizações e essas condições de disputa dão origem às variantes de $Q 0$. As variantes são prefixos de $Q 0$ com uma ou mais sincronizações modificadas. Essas variantes são utilizadas para realizar execuções controladas baseadas em prefixo com a mesma entrada, exercitando as sincronizações da variante. Com isso, novas sequências de sincronização $Q i$ são geradas de modo a gerar todas as variações a partir de $Q 0$ e, a partir delas, todas as sincronizações possíveis para uma entrada de teste $t$.

\subsubsection{Procedimento DEMT adaptado}

O procedimento DEMT (Deterministic Execution Mutation Testing) adaptado emprega as abordagens DET (Deterministic Execution Testing) e teste de alcançabilidade para a análise comportamental de programas concorrentes, adaptando o procedimento de Carver (1993). Nessa adaptação (Figura 4.4), o teste de alcançabilidade é empregado para gerar todas as sequências de sincronização a partir de uma entrada de teste X. Novas entradas de teste são adicionadas à medida que é necessário melhorar o escore de mutação. Após isso, é utilizado o teste determinístico para forçar a execução de cada mutante com 
cada uma das sequências de sincronização executadas no programa original (Silva et al., 2012a). Isso é importante porque é possível avaliar os mutantes com todas as sequências de sincronização possíveis para o programa original e, com isso, todas as possibilidades são cobertas. Um mutante é considerado como morto caso ele não consiga executar a sequência de sincronização ou apresente um resultado diferente do obtido com a execução do programa original.

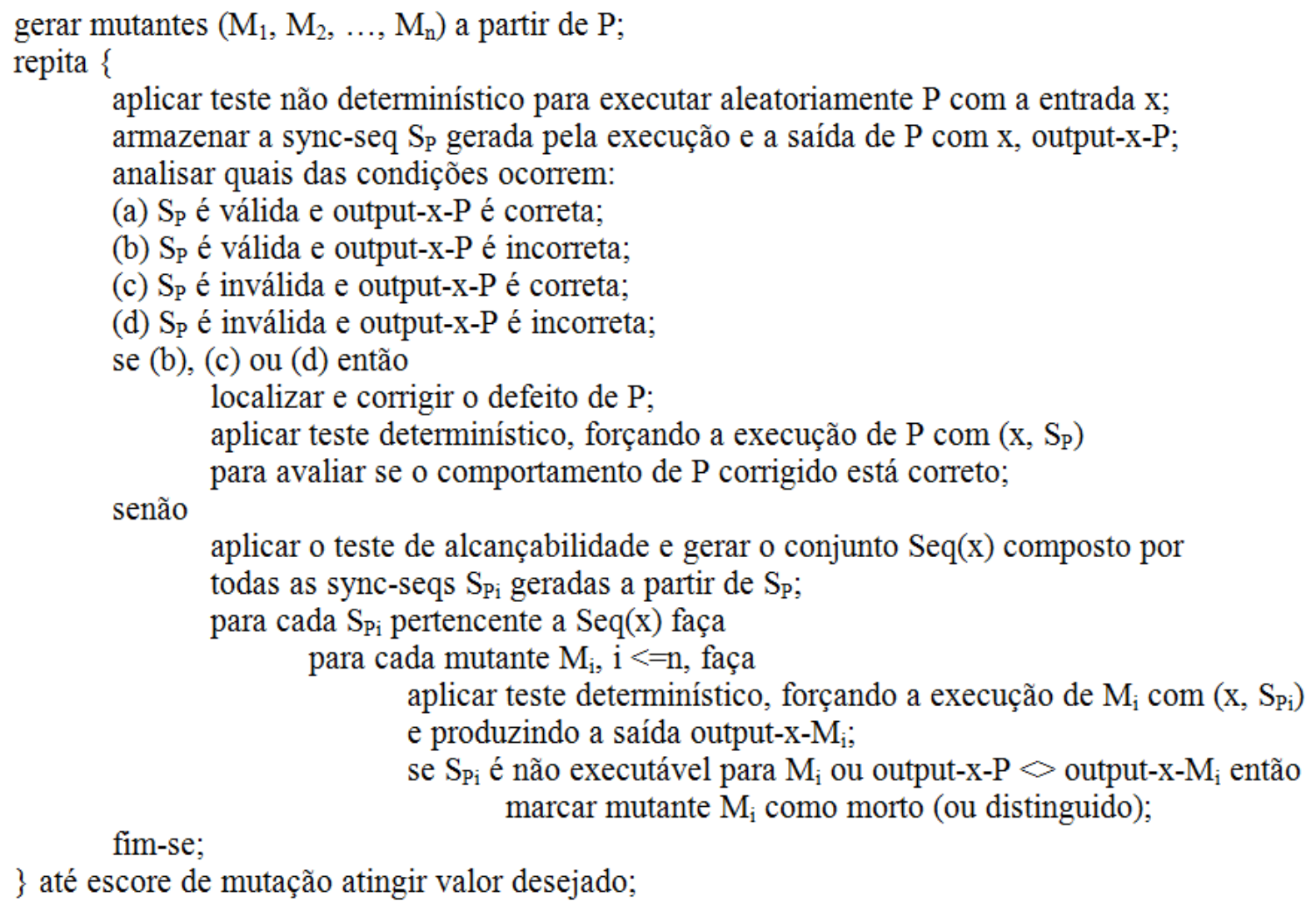

Figura 4.4: Procedimento DEMT adaptado.

Como pode ser observado, nesse procedimento não é utilizada a abordagem MET. Como alternativa, foi utilizada a abordagem do teste de alcançabilidade, que gera todas as sequências de sincronização para um determinado dado de teste. Com isso, o problema de matar um mutante incorretamente não ocorre, uma vez que se tem o conjunto de todas as saídas do programa original para um determinado dado de teste. O problema de matar o mutante incorretamente foi resolvido ao utilizar a abordagem determinística para executar os mutantes.

Porém, esse procedimento traz alguns problemas:

- A identificação de mutantes error-revealing pode ser dificultada. Um mutante é dito ser error-revealing se para qualquer caso de teste $t$ tal que $P(t)$ seja diferente $M(t)$ pudermos concluir que $\mathrm{P}(\mathrm{t})$ não está de acordo com o resultado esperado, ou seja, 
$M$ revela a presença de um defeito. Em programas sequenciais, um defeito presente na versão original do programa é revelado ao elaborar-se um caso de teste que seja capaz de distinguir o comportamento de um mutante error-revealing e a versão do programa original em teste. Nesse caso, observa-se a saída do programa original e pode-se concluir que a mesma é diferente do esperado. Nesse procedimento, isso não é possível, uma vez que os mutantes são executados deterministicamente e não livremente, sendo que o mutante é forçado a seguir a mesma sequência de sincronização do programa original, sendo morto caso isso não seja possível.

- Mesmo obtendo todas as possíveis sequências de sincronização por meio do teste de alcançabilidade, pode não ser possível matar alguns mutantes. Para matar um mutante seria necessário exercitar uma sequência $S$ que é executável para o mutante, mas não executável para o programa $P$, mesmo problema encontrado e resolvido no procedimento de Carver (1993).

- O problema principal dessa técnica está no fato de forçar os mutantes a reproduzir a execução do programa original, fazendo com que os mutantes sejam mortos com mais facilidade. Esse problema é observado, pois os mutantes não são executados livremente, uma vez que a abordagem do teste determinístico é utilizado para executar os mutantes. A maior parte dos mutantes morre por não conseguir exercitar a sequência de sincronização realizada pelo programa original. Isso ocorre pois os mutantes foram criados levando em consideração os aspectos de comunicação e sincronização dos programas concorrentes.

\subsubsection{Procedimento MET adaptado}

O procedimento apresentado por Offutt et al. (1996) utiliza a abordagem MET para encontrar um conjunto $\Omega$ que seja o mais próximo do conjunto de todas as saídas de um programa $P$ com um caso de teste $t$. Porém, a utilização de MET com essa finalidade causa um custo computacional grande, além de ser demorado e não ter a garantia de que todas as saídas serão obtidas. Para resolver esse problema, sugere-se a utilização do teste de alcançabilidade, no qual se tem todas as saídas e, com isso, não é mais necessária a avaliação da sequência de sincronização e a sua reprodução pelos mutantes.

A partir disso, foi criado um outro procedimento que segue o procedimento definido por Offutt et al. (1996). Neste novo procedimento (Figura 4.5), o teste de alcançabilidade é empregado para gerar todas as sequências de sincronização a partir de uma entrada de teste $X$. Em seguida, cada mutante é executado com o caso de teste e a saída é observada e comparada com o conjunto de saídas obtidas pelas execuções do caso de teste 
no programa. O mutante é considerado como morto caso o resultado apresentado não esteja contido no conjunto das saídas do programa original.

O problema encontrado nesse procedimento é com relação aos mutantes que permanecem vivos por acaso. Isso ocorre uma vez que, executando os mutantes livremente, há a possibilidade de que em nenhuma execução seja exercitada a mutação inserida por consequência do não determinismo. Para resolver esse problema, duas abordagens podem ser utilizadas. A primeira delas é utilizar o teste de alcançabilidade para gerar todo o conjunto de saídas possíveis para cada um dos mutantes que permaneceram vivos após a aplicação do teste. Com isso, é possível comparar o conjunto de saídas do mutante com o conjunto de saídas do programa original e caso o mutante apresente uma saída que não esteja no conjunto de saídas do programa original, ele pode ser considerado como morto. A segunda abordagem consiste em aplicar MET nos mutantes sobreviventes visando obter sequências de sincronização diferentes. Com isso, pode-se obter resultados diferentes e, assim, considerar o mutante como morto ou vivo.

gerar mutantes $\left(\mathrm{M}_{1}, \mathrm{M}_{2}, \ldots, \mathrm{M}_{\mathrm{n}}\right)$ a partir de $\mathrm{P}$; repita \{

aplicar teste não determinístico para executar aleatoriamente $\mathrm{P}$ com a entrada $\mathrm{x}$; armazenar a sync-seq $S_{P}$ gerada pela execução e a saída de $\mathrm{P}$ com x, output-x-P; analisar quais das condições ocorrem:

(a) $S_{\mathrm{P}}$ é válida e output-x-P é correta;

(b) Sp é válida e output-x-P é incorreta;

(c) $\mathrm{S}_{\mathrm{p}}$ é inválida e output-x-P é correta;

(d) $S_{p}$ é inválida e output-x-P é incorreta;

se (b), (c) ou (d) então

localizar e corrigir o defeito de $\mathrm{P}$; aplicar teste determinístico, forçando a execução de $\mathrm{P} \operatorname{com}\left(\mathrm{x}, \mathrm{S}_{\mathrm{P}}\right)$

senão para avaliar se o comportamento de $\mathrm{P}$ corrigido está correto;

aplicar o teste de alcançabilidade e gerar o conjunto $\operatorname{Seq}(\mathrm{x})$ composto por todas as sync-seqs $\mathrm{S}_{\mathrm{p}}$ geradas a partir de $\mathrm{S}_{\mathrm{p}}$; para cada mutante $\mathrm{M}_{\mathrm{i}}, \mathrm{i}<=$ n, faça

aplicar teste não determinístico para executar aleatoriamente $\mathrm{M}_{\mathrm{i}} \operatorname{com}$ a entrada $\mathrm{x}$, produzindo a saída output-x- $\mathrm{M}_{\mathrm{i}}$;

se output-x- $\mathrm{M}_{\mathrm{i}}$ não estiver contido no conjunto de output-x-P então marcar mutante $\mathrm{M}_{\mathrm{i}}$ como morto (ou distinguido);

senão

caso o ponto de mutação não estiver sido exercitado, aplicar MET para

fim-se; encontrar outras sync-seqs que possam executar o ponto de mutação;

\} até escore de mutação atingir valor desejado;

Figura 4.5: Procedimento MET modificado.

Neste trabalho foi adotada a segunda abordagem, na qual se tem a aplicação de MET nos mutantes que permanecem vivos após a primeira execução. Essa abordagem foi adotada visto que é a menos custosa em relação à outra e o testador é quem determina quantas 
vezes o mutante deve ser re-executado. A Figura 4.5 apresenta o procedimento completo definido para a análise comportamental dos mutantes.

\subsection{Considerações Finais}

Neste capítulo foram abordadas as diferentes etapas para a aplicação do teste de mutação para programas MPI. Primeiramente foram apresentados os operadores de mutação definidos, apresentando a definição e uma simples aplicação para cada operador. Em seguida, foi apresentada uma comparação dos operadores definidos com os operadores de mutação para a linguagem C. Após isso, foi feita a classificação dos operadores com relação à taxonomia de defeitos escolhida como base para a criação dos operadores. Por fim, foi apresentado um procedimento para a análise comportamental dos mutantes.

No próximo capítulo é apresentada a ferramenta ValiMPI_Mut desenvolvida com o objetivo de ser uma prova dos conceitos apresentados neste capítulo. É apresentada a arquitetura da ferramenta que foi desenvolvida usando uma arquitetura de referência. Além disso, é apresentada a interface da ferramenta, apresentado as principais funcionalidades. 


\section{Ferramenta de Apoio ao Teste de}

Mutação

\subsection{Considerações Iniciais}

Para que a atividade de teste, em geral, seja conduzida de forma satisfatória e com qualidade, ferramentas de apoio são necessárias. É comum que as ferramentas de teste apresentem funcionalidades similares como, por exemplo, selecionar o artefato a ser testado, selecionar quais critérios de teste aplicar, gerar casos de teste, avaliar os resultados e gerar relatórios da atividade. Visando apoiar o desenvolvimento dessas ferramentas, arquiteturas de referência vêm sendo desenvolvidas. Segundo Müller e Tichy (2001), uma arquitetura de referência captura a essência da arquitetura de um conjunto de sistemas. Arquiteturas de referência apresentam alguns benefícios como apresentar léxico e taxonomia comuns, visão arquitetural comum e a modularização que ajuda a dividir esforços. Além disso, arquitetura de referência provê uma eficiência na criação de produtos por meio do compartilhamento de padrões e da gerência de sinergia (Cloutier et al., 2010). Dentro do domínio de teste de software, tem-se como exemplo a RefTEST (Reference Architecture for Testing Tools), definida por Nakagawa et al. (2007). Projetada com base em arquiteturas e ferramentas de teste de software já existentes, esta arquitetura de referência tem sido empregada para o desenvolvimento de novas ferramentas de teste como pode ser visto em Nakagawa et al. (2009) e Ferrari et al. (2010). 
Os resultados obtidos nos trabalhos citados indicam que é promissor utilizar uma arquitetura de referência como apoio. Considerando os benefícios de utilizar uma arquitetura de referência para auxiliar o projeto e definição de ferramentas de apoio, neste capítulo apresentam-se os resultados obtidos com a utilização da arquitetura de referência RefTEST para a definição da arquitetura de uma ferramenta de apoio ao teste de mutação para programas concorrentes desenvolvidos em MPI.

Porém, sabe-se que os testes em programas concorrentes não ocorrem da mesma forma como em programas sequenciais, uma vez que possuem aspectos como o não determinismo que devem ser tratados durante a aplicação do teste. Com isso, alguns aspectos devem ser levados em consideração no momento do projeto da ferramenta, uma vez que a arquitetura de referência RefTEST foi desenvolvida tomando como base apenas ferramentas de teste para programas sequenciais.

Este capítulo apresenta a ferramenta ValiMPI_Mut e um exemplo de sua aplicação. A Seção 5.2 apresenta a arquitetura da ferramenta, assim como os requisitos funcionais e os diagramas de classes dos módulos da ferramenta. A Seção 5.3 descreve um exemplo de uso da ferramenta para a criação de uma sessão de teste. Por fim, a Seção 5.4 apresenta as considerações finais deste capítulo.

\subsection{Arquitetura da Ferramenta ValiMPI_Mut}

A ferramenta ValiMPL_Mut foi construída para apoiar a aplicação do teste de mutação para programas concorrentes em MPI. A arquitetura da ValiMPI_Mut (Silva et al., 2013) é apresentada na Figura 5.1. Esta arquitetura, assim como ocorre com a RefTEST, utiliza os conceitos do padrão MVC (Model-View-Controller). A partir disso, na camada de apresentação pode-se observar a representação da visão e do controle, onde estão as comunicações com a interface e as regras de negócio. Já na camada de aplicação pode ser visto o modelo, onde se encontram as funções gerais, como a classe de persistência que será necessária para a comunicação com a camada de persistência, a base de dados, além das funções necessárias para gerar as possíveis sequências de sincronização presentes no programa em teste. No modelo também encontra-se o núcleo da ferramenta, que consiste nas atividades fundamentais da ferramenta que foram mapeados para que a implementação do critério teste de mutação pudesse ser aplicado. Para que isso pudesse ocorrer, o conceito "Critério de Teste" foi especializado para "Teste de Mutação", o conceito "Artefato de Teste" foi especializado para "Código Original" e o conceito "Requisito de Teste" foi especializado para "Mutantes". O conceito "Caso de Teste" não foi especializado, pois este não muda conforme o critério, permanecendo o mesmo para qualquer critério de teste. 


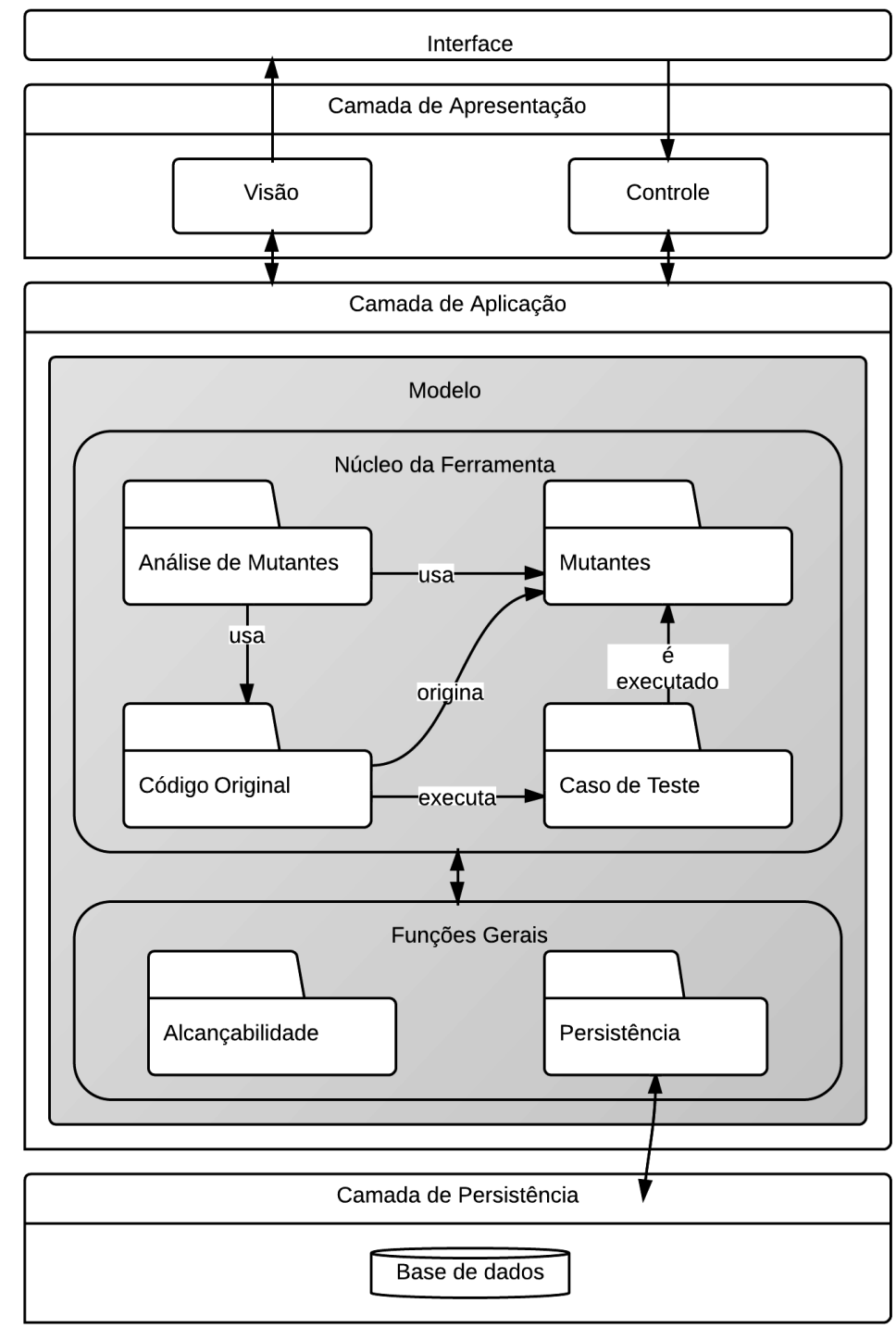

Figura 5.1: Arquitetura da ferramenta ValiMPI_Mut.

Com base nas especializações realizadas, foi criado um diagrama de classe no qual podem ser vistas as funcionalidades de cada um dos conceitos presentes no módulo base da arquitetura de referência. Na Figura 5.2 é apresentado o conjunto de classes que gerenciam o Artefato de Teste, que é o programa que será testado. Nesse diagrama, a classe "Projeto" compreende o projeto que será criado para que a ferramenta possa realizar os testes. É essa classe que contém todos os dados do projeto, como o código original, o conjunto de casos de teste e o conjunto de mutantes. A classe "Codigo" compreende o código fonte que será testado. A classe "ValiInst" e a classe "ValiCc" tem como função fazer uma chamada para a execução, respectivamente, dos módulos Vali_inst e Vali_cc da ferramenta ValiMPI, gerando uma versão instrumentada e executável do código. A classe "ProjetoRN" possui a regra de negócio que atuará sobre as classes "Projeto" e "Codigo". As funcionalidades presentes nessas classes partiram dos requisitos apresentados na Tabela 5.1, os quais, foram derivados da arquitetura de referência RefTEST. Na primeira coluna 
estão os requisitos especificados e a segunda coluna representa a função implementada na ferramenta.

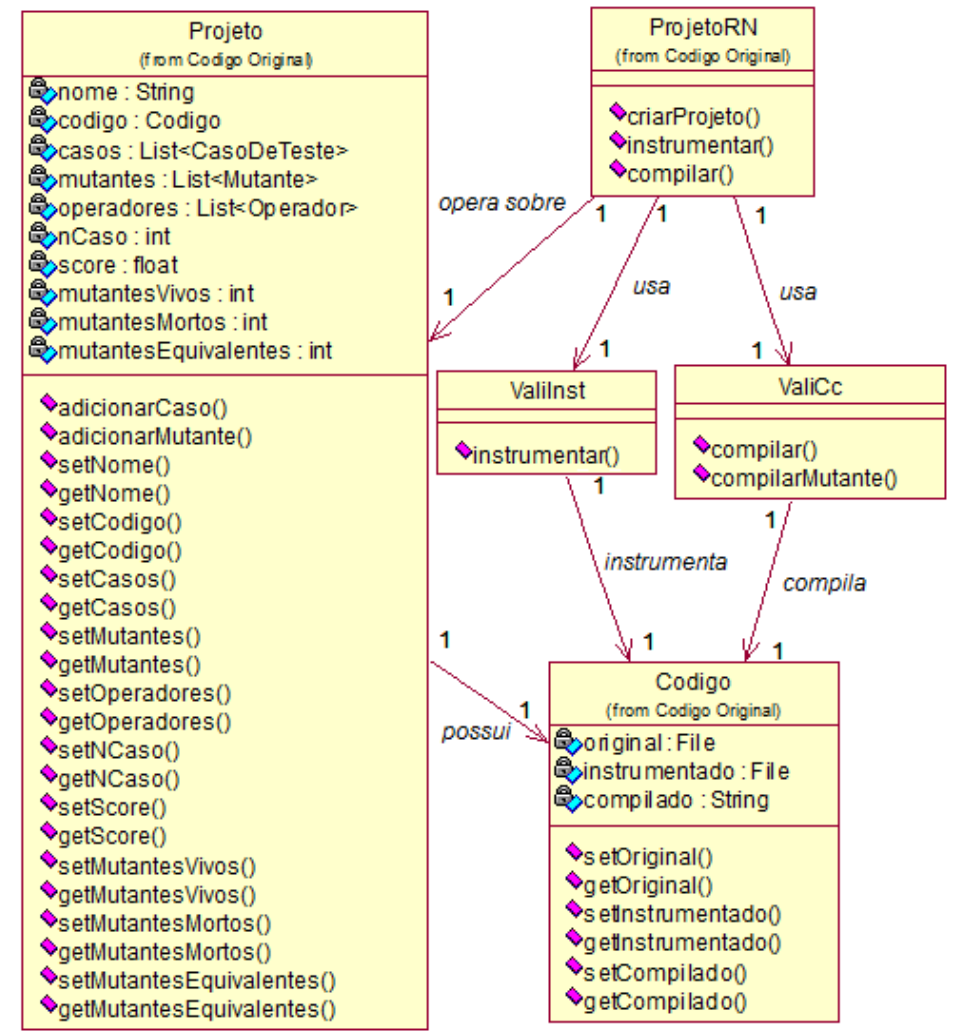

Figura 5.2: Diagrama de classes do módulo "Código Original".

Tabela 5.1: Funcionalidades do módulo "Código Original".

\begin{tabular}{ll}
\hline Requisito funcional & Função \\
\hline Cria uma sessão de teste & ProjetoRN.criarProjeto() \\
Exclui uma sessão de teste & Não aplicável \\
Recupera uma sessão de teste & Não aplicável \\
Adquire artefato a ser testado & Projeto.setCodigo() \\
Trata o artefato a ser testado & ValiInst.instrumentar() \\
Fornece relatório de execução do artefato a ser testado & Não aplicável \\
Exclui artefato a ser testado & Não aplicável \\
Inclui drivers e stubs & Não aplicável \\
Permite a visualização de drivers e stubs & Não aplicável \\
Permite a visualização de artefato & Codigo.getOriginal() \\
Compila o código & ValiCc.compilar()
\end{tabular}

Na Figura 5.3 observa-se a classe que tem como objetivo gerenciar os casos de teste. A classe "CasoDeTeste" tem como objetivo guardar as informações sobre um determinado caso de teste. Como a ferramenta foi desenvolvida para o teste de programas concorrentes, 
a classe "Sequencia" tem como objetivo guardar as informações sobre uma determinada sequência de sincronização da execução de um caso de teste. A classe "CasoRN" opera funções sobre o caso de teste. A classe "ValiExec" tem como objetivo fazer a execução do módulo vali_exec da ferramenta ValiMPI para executar um caso de teste. As funcionalidades presentes nas classes partiram dos requisitos apresentados na Tabela 5.2.

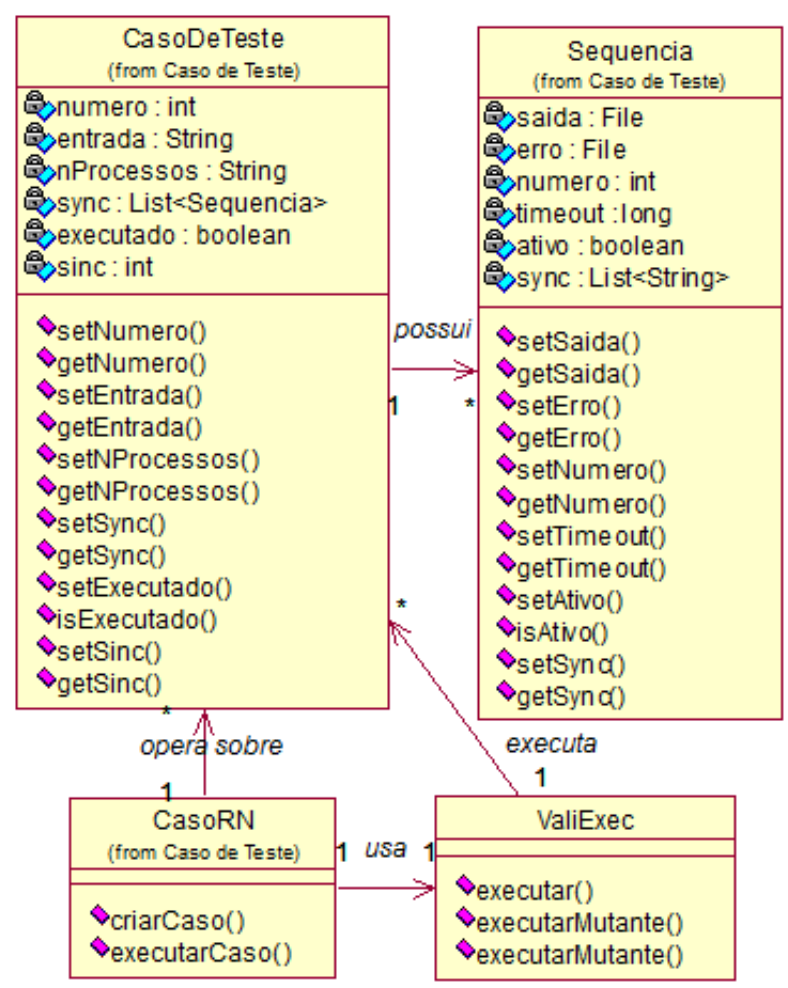

Figura 5.3: Diagrama de classes do módulo "Caso de Teste".

Tabela 5.2: Funcionalidades do módulo "Caso de Teste".

\begin{tabular}{ll}
\hline Requisito funcional & Função \\
\hline Importa casos de teste & Não aplicável \\
Inclui casos de teste manualmente & CasoDeTeste.criarCaso() \\
Gera casos de teste automaticamente & Não aplicável \\
Minimiza conjunto de casos de teste & Não aplicável \\
Habilita casos de teste & Não aplicável \\
Desabilita casos de teste & Não aplicável \\
Exporta casos de teste & Não aplicável \\
Fornece relatório de casos de teste & Não aplicável \\
Editar um caso de teste & Não aplicável \\
Informa sobre o número total de casos de teste & Projeto.getNCaso() \\
Remove casos de teste & Não aplicável \\
Permite a visualização de casos de teste & Projeto.getCasos()
\end{tabular}


Na Figura 5.4 são apresentadas as classes que têm como função gerenciar os requisitos de teste, ou seja, os mutantes que serão utilizados durante a aplicação do critério. A classe "Mutante" tem como objetivo guardar as informações de um determinado mutante. A classe "Operador" é uma classe abstrata, sendo que a partir dela são criadas outras classes para cada um dos operadores de mutação a serem implementados, como por exemplo as classes "ReplModeSend" e "ReplModelSend" não presentes no diagrama. A classe "ValiExec" tem como objetivo executar os mutantes. As funcionalidades presentes nas classes partiram dos requisitos apresentados na Tabela 5.3.

Na Figura 5.5 observa-se as classes que têm como objetivo gerenciar o critério Teste de Mutação. A classe "Analisador" tem como função realizar o cálculo do escore de mutação, além de calcular o número de mutantes vivos, mortos e equivalentes. As funcionalidades presentes na classe partiram dos requisitos apresentados na Tabela 5.4 que foram propostas na arquitetura de referência RefTEST.

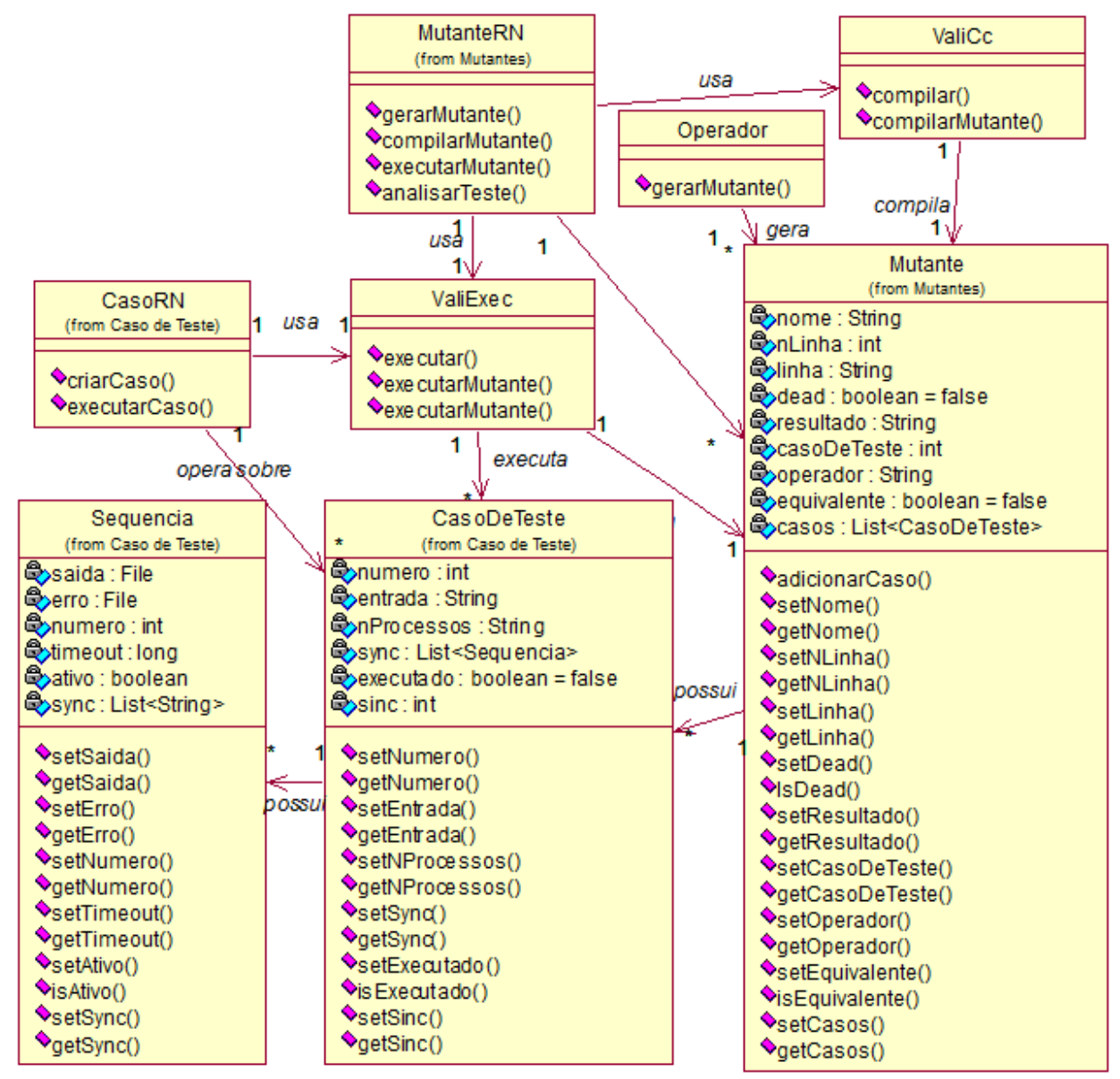

Figura 5.4: Diagrama de classes do módulo "Mutantes". 
Tabela 5.3: Funcionalidades do módulo "Mutantes".

\begin{tabular}{ll}
\hline Requisito funcional & Função \\
\hline Importa requisitos de teste & Não aplicável \\
Gera requisitos de teste & MutanteRN.gerarMutante() \\
Seleciona requisitos de teste & Não aplicável \\
Tira seleção de requisitos de teste & Não aplicável \\
Marca requisito como não-executável & Mutante.setEquivalente() \\
Desmarca requisito de teste & Mutante.setEquivalente() \\
Executa requisitos com casos de teste & ValiExec.executarMutante() \\
Coleta trace de execução dos requisitos & Mutante.adicionarCaso() \\
Fornece relatório de requisitos de teste & Não aplicável \\
Permite a visualização de requisitos de teste & Mutante.getLinha() \\
Exclui requisito de teste & Não aplicável \\
Compilar requisito & ValiCc.compilarMut()
\end{tabular}

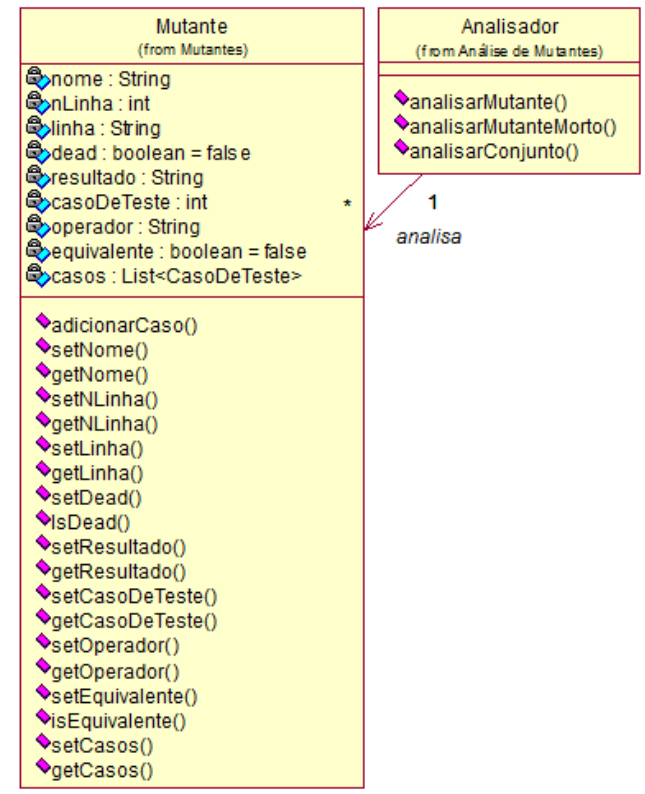

Figura 5.5: Diagrama de classes do módulo "Teste de Mutação".

Tabela 5.4: Funcionalidades do módulo "Teste de Mutação".

\begin{tabular}{ll}
\hline Requisito funcional & Função \\
\hline Estabelece critério de adequação do teste & Não aplicável \\
Calcula cobertura do teste & Analisador.analisarConjunto() \\
Fornece relatório de falhas do teste & Não aplicável \\
Permite a análise estática da execução & Não aplicável \\
Informa o total de requisitos analisados & Projeto.getMutantes() \\
Informa requisitos não cobertos & Projeto.getMutantesVivos() \\
Informa requisitos cobertos & Projeto.getMutantesMortos() \\
Informa requisitos não-executáveis & Projeto.getMutantesEquivalentes() \\
\hline
\end{tabular}




\subsection{Exemplo de Uso da Ferramenta}

Nesta seção é ilustrado o desenvolvimento de uma sessão de teste simples utilizando a ferramenta de teste desenvolvida. Usa-se para isso o programa GCD, que calcula o maior divisor comum entre três números fornecidos, usando quatro processos concorrentes. $\mathrm{O}$ processo mestre $\left(p^{0}\right)$ recebe os três valores $x, y, z$ e chama os três processos escravos $\left(p^{1}\right.$, $p^{2}$ e $p^{3}$ ). O processo $p^{0}$ envia $x$ e $y$ para $p^{1}$ e $y$ e $z$ para $p^{2}$. Os dois processos escravos recebem os valores, encontram o máximo divisor comum entre os dois valores e enviam o resultado para o processo mestre. Se um dos valores retornados for 1 , então $p^{3}$ é finalizado. Caso contrário, esses valores são enviados para $p^{3}$ que calcula o máximo divisor comum final, retornando o resultado para $p^{0}$. O programa é invocado passando 4 parâmetros, sendo o primeiro o número de processos e, em seguida, 3 números.

A Figura 5.6 apresenta a tela inicial da ferramenta, na qual se pode ver os menus com as opções da ferramenta. Para criar o projeto é necessário acessar o Menu "Arquivo" e então a opção "Novo projeto". Com isso, é aberta a janela apresentada na Figura 5.7, na qual insere-se o nome do projeto e, então, clica-se no botão buscar, com a finalidade de procurar o arquivo do programa que será testado, como mostra a Figura 5.8. Ao clicar no botão "Abrir", o programa selecionado é instrumentado, compilado e os arquivos para a criação do grafo de fluxo de controle são criados, como mostrado na Figura 5.9.

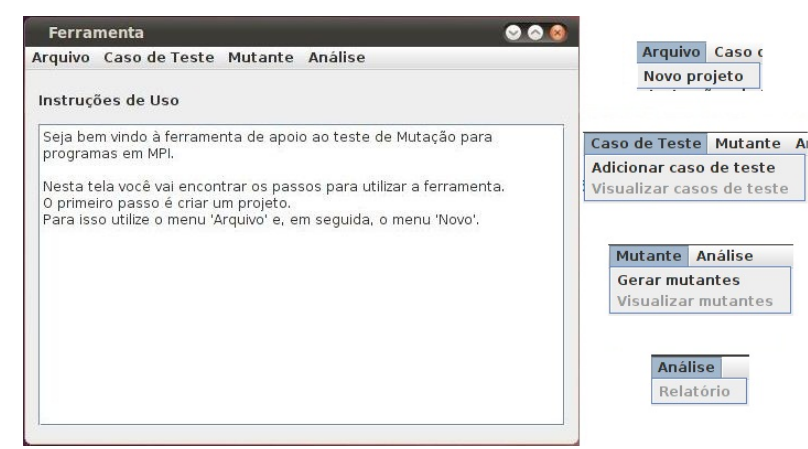

Figura 5.6: Tela inicial e opções do menu.

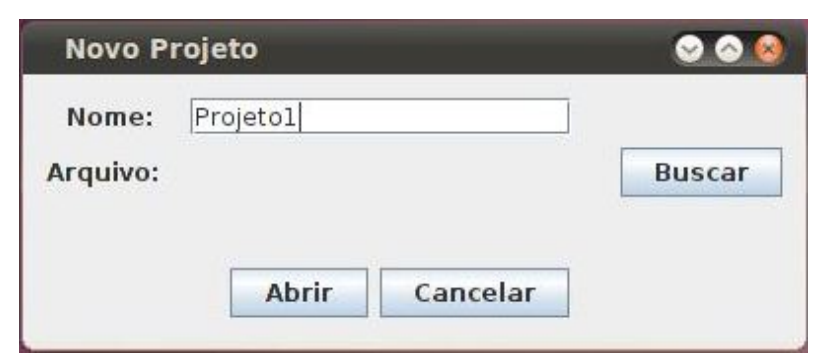

Figura 5.7: Tela para criar um novo projeto. 


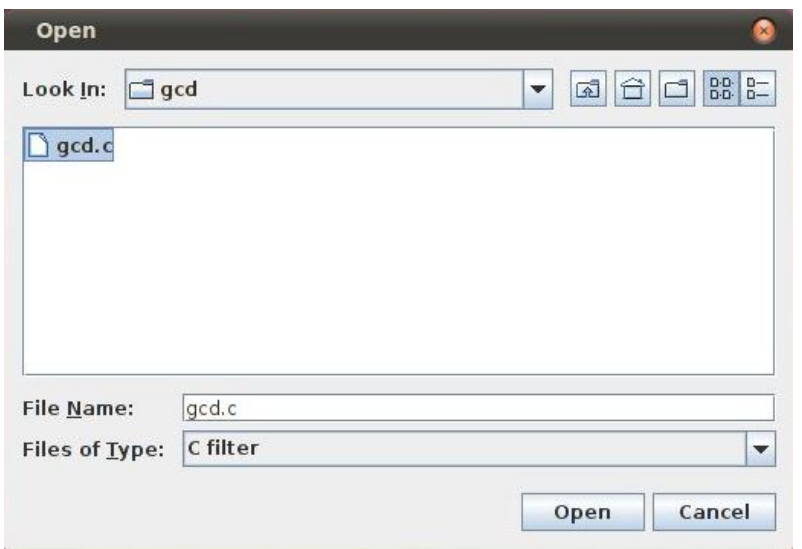

Figura 5.8: Tela para adicionar um código a ser testado.
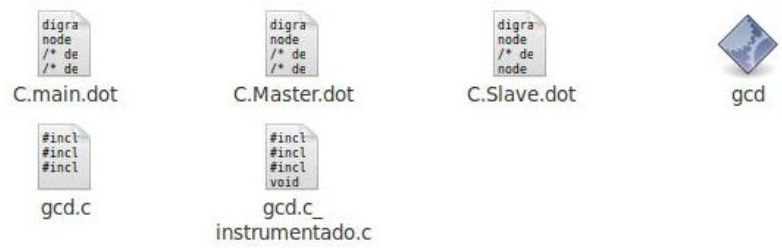

Figura 5.9: Arquivos gerados quando um novo projeto de teste é criado.

Para adicionar um caso de teste é necessário acessar o menu "Caso de Teste" e clicar na opção "Adicionar Caso de Teste". A Figura 5.10 apresenta a tela onde é realizada a inserção dos dados que compõem o caso de teste. Nesta tela é inserido o número de processos e os parâmetros de entrada. Ao adicionar o caso de teste, ele é executado e, através do módulo da vali_sync da ferramenta ValiMPI, é possível aplicar o teste de alcançabilidade, podendo, assim, encontrar todas as sequências de sincronização do programa em teste para o caso de teste inserido.

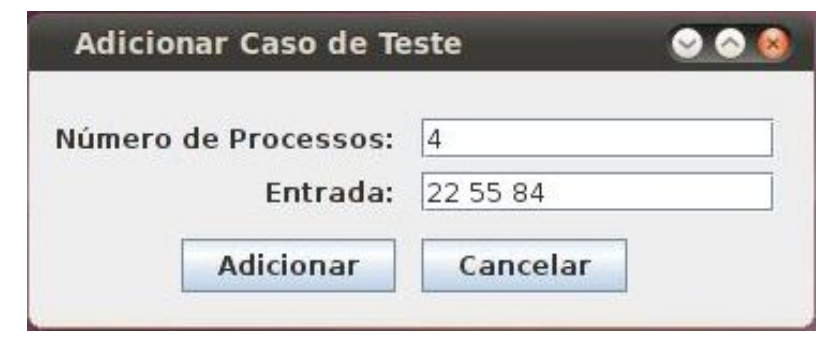

Figura 5.10: Tela para adicionar um caso de teste.

Durante a execução dos casos de teste, será criado um diretório para cada um dos casos de teste, onde serão armazenados os dados da execução, como mostrado na Figura 5.11. Basicamente, esses arquivos contém as informações do caso de teste, como argumentos de entrada, nome do programa, informações sobre as sequências de sincronização de cada processo, a saída, possíveis mensagens de erro e os arquivos para gerar os grafos de fluxo de controle de cada um dos processos. Após a execução dos casos de teste, no menu 
"Visualizar Casos de Teste" é possível observar a entrada do caso de teste (Figura 5.12) e as saídas para cada sincronização executada (Figura 5.13).

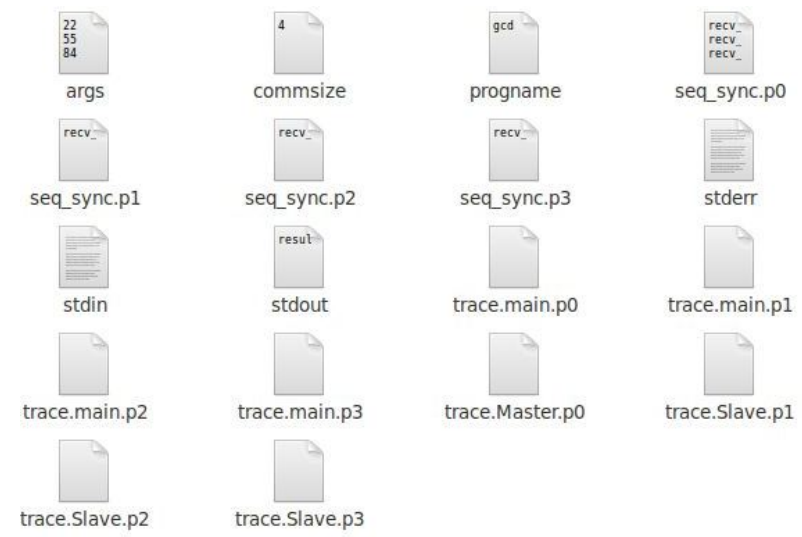

Figura 5.11: Arquivos gerados a partir da execução do caso de teste 1.

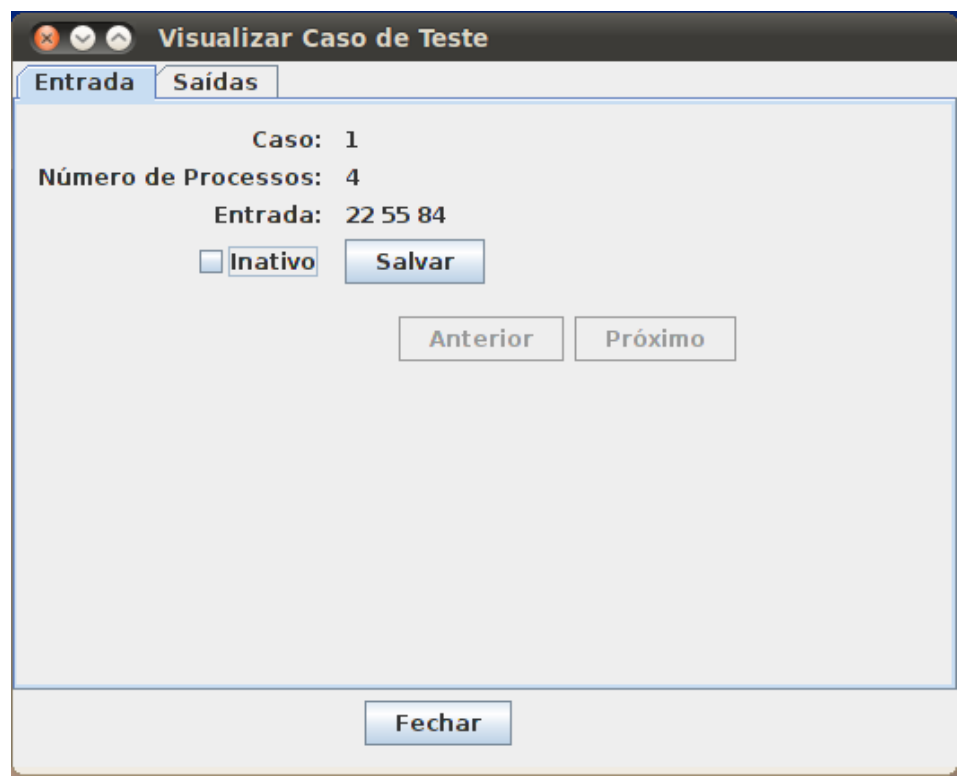

Figura 5.12: Aba para visualizar as entradas dos casos de teste.

Para criar mutantes é necessário acessar o menu "Gerar Mutantes" e a tela mostrada na Figura 5.14 será apresentada. Nesta tela, o usuário poderá escolher qual operador de mutação será aplicado ao programa em teste. Os operadores de mutação implementados inicialmente foram: ReplModelSend, DelSend, ReplModelRecv e DelRecv. Com isso, será criado um diretório chamado "mutantes" onde serão inseridos os mutantes. Para visualizar os mutantes é necessário acessar o menu "Visualizar Mutante" e será apresentada a tela mostrada na Figura 5.15. Nesta tela é apresentado o código do programa original e o código do mutante instrumentado. Além disso, na aba "Informações" são observadas informações sobre esse mutante, como mostra a Figura 5.16. Caso o mutante tenha 


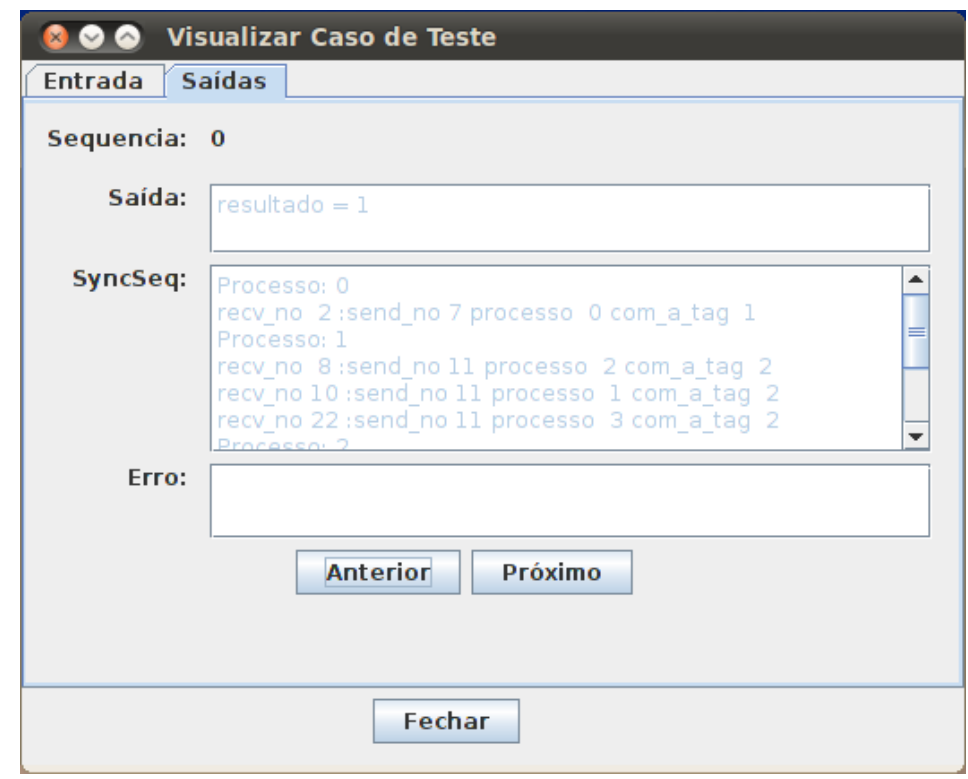

Figura 5.13: Aba para visualizar as saídas dos casos de teste.

passado por um caso de teste e ainda permaneça vivo, as informações sobre as sequências de sincronização executadas são mostradas, como visto na Figura 5.17

Seguindo o procedimento de execução de mutantes definido, para alguns mutantes é necessária a aplicação da abordagem MET com a finalidade de encontrar novas sequências de sincronização para os mutantes vivos. Para re-executar um mutante é necessário escolher o caso de teste a ser re-executado, usando os botões "Anterior" e "Próximo" e clicar no botão "Re-execução".

Para acessar as informações sobre os mutantes é necessário acessar o menu "Relatório", o qual contém as informações sobre o teste como, total de mutantes, mutantes vivos, mutantes mortos e o score de mutação, como mostra a Figura 5.18.

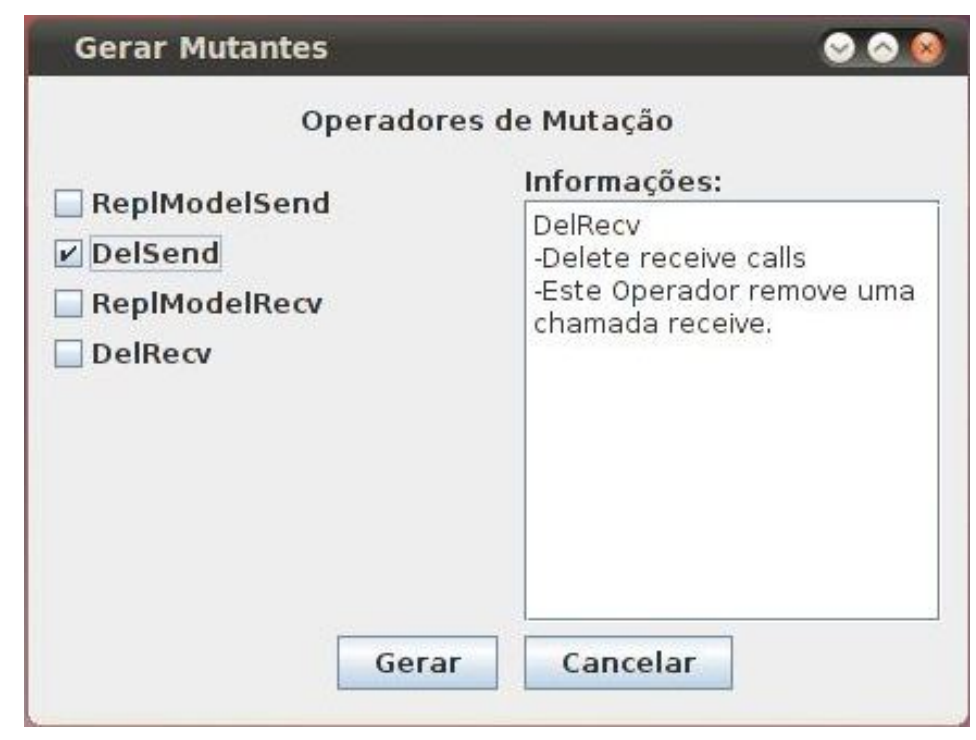

Figura 5.14: Tela para criar mutantes. 


\section{CAPÍTULO 5. FERRAMENTA DE APOIO AO TESTE DE MUTAÇÃO}

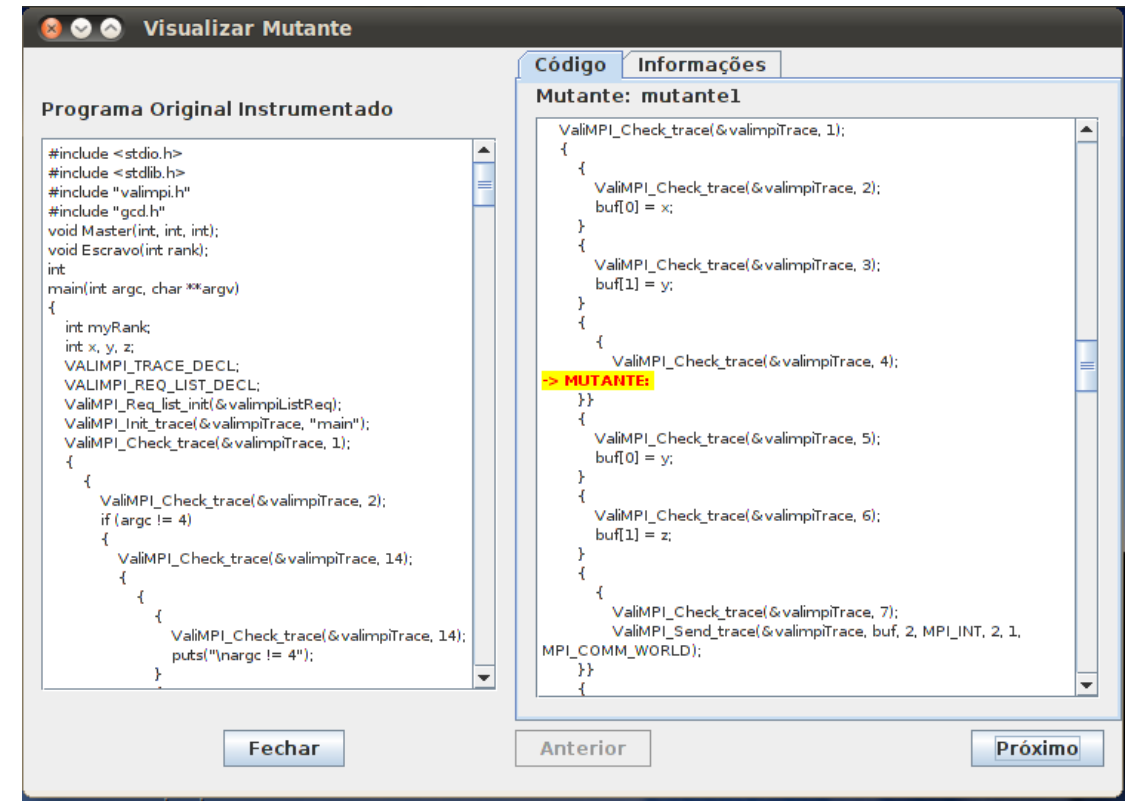

Figura 5.15: Tela para visualizar mutante.

\subsection{Considerações Finais}

Nesta seção foi apresentada uma visão geral da ferramenta de teste desenvolvida para apoiar o teste de mutação em programas MPI. Primeiramente foi apresentada a arquitetura da ferramenta, que foi definida a partir da instanciação da RefTEST para o teste de mutação. Em seguida foi apresentada de maneira ampla a utilização da ferramenta para criar uma sessão de teste utilizando o programa GCD como exemplo. No próximo capítulo serão apresentadas as conclusões deste trabalho. 


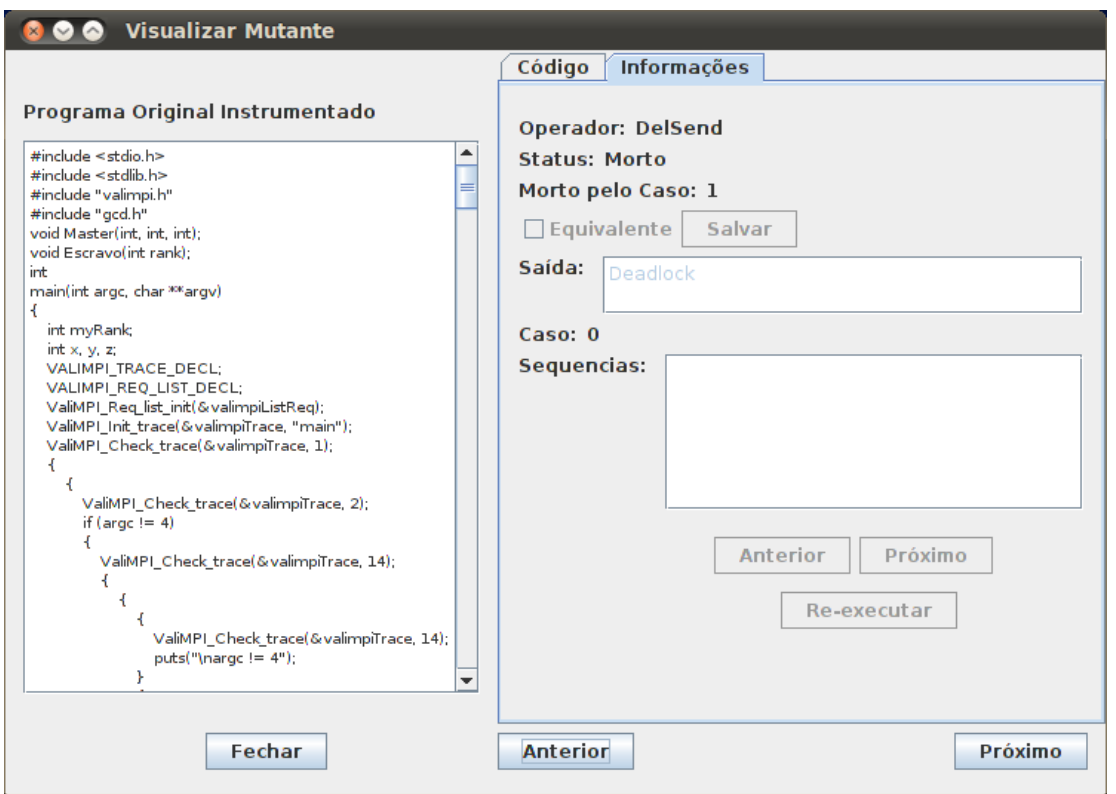

Figura 5.16: Informações sobre o resultado da execução de um mutante morto.

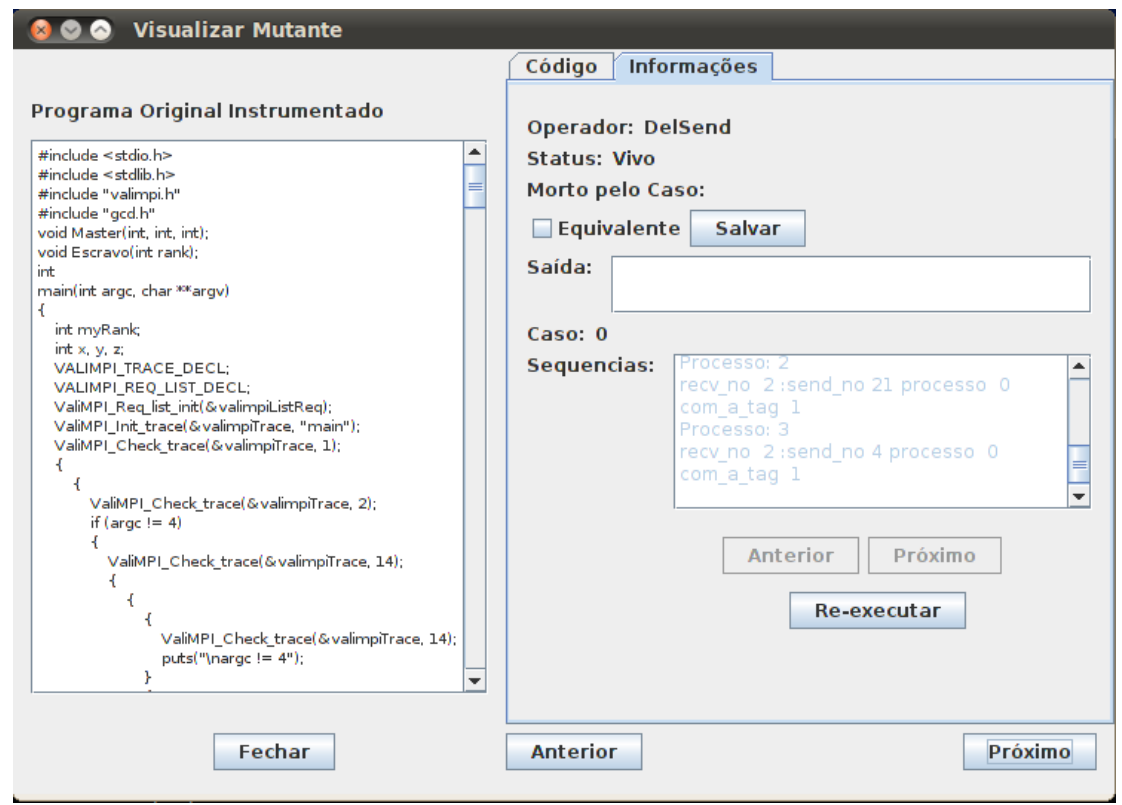

Figura 5.17: Informações sobre um mutante vivo.

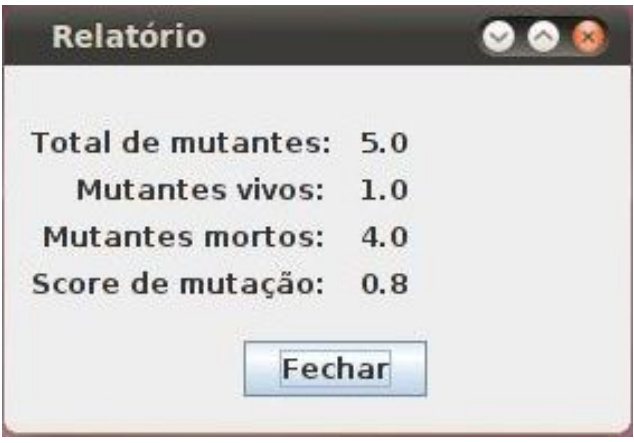

Figura 5.18: Informações sobre a aplicação do teste de mutação 



\subsection{Caracterização da Pesquisa Realizada}

Programas concorrentes possuem características que os diferem de programas sequenciais como comunicação, sincronização, paralelismo e concorrência. Essas características estão presentes na maioria dos programas concorrentes e precisam ser consideradas durante a atividade de teste. Para auxiliar o desenvolvedor durante o desenvolvimento do softwares concorrentes foram criados diversos ambientes de desenvolvimento como PVM e MPI, específicos para desenvolvimento de programas que utilizam o paradigma de comunicação de passagem de mensagens. O padrão MPI (Message Passing Interface), que é o utilizado neste trabalho, surgiu como uma tentativa de padronização dos ambientes de passagem de mensagem através de uma especificação para o desenvolvimento de aplicações paralelas.

No contexto de programas concorrentes, a atividade de teste de software apresenta-se como desafiadora, uma vez que características como o não determinismo dos programas concorrentes faz com que novas técnicas de testes sejam criadas ou técnicas usadas em programas sequenciais sejam adaptadas para esse contexto.

Este trabalho de mestrado teve como objetivo a definição do teste de mutação para programas concorrentes com memória distribuída, desenvolvidos em MPI, na linguagem C. Durante o desenvolvimento do projeto, foi realizada uma revisão na literatura com a finalidade de encontrar trabalhos que pudessem contribuir para o desenvolvimento de critérios de teste para programas concorrentes, dando maior atenção aos trabalhos que 
abordavam o teste de mutação aplicado a este tipo de programa e trabalhos relacionados com a classificação de defeitos nesse contexto.

Atualmente, o teste de mutação vem se destacando como um critério bastante eficaz para revelar defeitos, apesar do custo de aplicação do mesmo. Foram estudados os trabalhos que apresentavam alguma contribuição no contexto de criação e aplicação do critério de teste de mutação para programas concorrentes independentemente da linguagem de programação no qual os programas foram implementados. Observou-se principalmente o aspecto de criação dos operadores e como a execução dos mutantes era realizada, pois o aspecto do não determinismo é um desafio a ser explorado, uma vez que a execução de um mesmo programa com a mesma entrada pode gerar resultados diferentes, dependendo da sequência de sincronização dos processos.

Para a criação dos mutantes houve a necessidade de identificar quais eram os erros típicos que são cometidos pelos desenvolvedores durante a implementação do programa. Por esse motivo, houve a necessidade de estudar os trabalhos que abordavam a definição de uma taxonomia de erros para programas concorrentes, independente da linguagem de programação ou do ambiente utilizado.

Em seguida, foi realizada a definição dos operadores de mutação para programas concorrentes com memória distribuída, desenvolvidos em MPI, na linguagem C. Levou-se em consideração os aspectos de comunicação presente no padrão MPI, sendo a comunicação sendo ponto a ponto ou coletiva.

Após isso, foi feita uma revisão bibliográfica com o objetivo de identificar trabalhos onde era explorada a execução do teste de mutação e como foi tratada a questão do não determinismo na execução dos programas concorrentes. A partir disso, foi definido um procedimento para a aplicação do teste de mutação e como tratar o não determinismo inerente a esse tipo de programação.

Por fim, foi desenvolvida uma ferramenta para apoiar a aplicação do teste de mutação em programas em MPI, utilizando o procedimento definido. A partir da arquitetura de referência RefTEST, foi criada a arquitetura da ferramenta ValiMPL_Mut. Em seguida, foi apresentada uma breve utilização da ferramenta para a criação de uma sessão de teste.

\subsection{Contribuições}

Podem-se destacar como principais contribuições deste trabalho:

1. Definição de um conjunto de operadores de mutação para programas concorrentes implementados em MPI, enfatizando a comunicação e a sincronização entre os processos. 
2. Definição de um procedimento eficiente para a análise comportamental dos mutantes.

3. Criação de uma ferramenta de apoio para o teste de mutação para programas concorrentes escritos em MPI.

\subsection{Dificuldades e Limitações}

Durante a execução do trabalho, algumas dificuldades ocorreram. A primeira dificuldade foi em encontrar uma taxonomia de erros/ defeitos que fosse significativa para programas concorrentes em MPI. Para resolver esses problema, foi utilizada a taxonomia de DeSouza et al. (2005). Um problema encontrado neste trabalho foi a falta de exemplos reais desses defeitos em códigos em MPI.

Durante a definição do procedimento para a execução dos mutantes, houve um problema com relação a quais abordagens utilizar (MET, DET e teste de alcançabilidade) e quando utilizar. Primeiramente foi desenvolvida uma abordagem (DEMT adaptada), porém, em seguida foi visto que ela possuía alguns problemas como a dificuldade de identificar mutantes error-revealing, a não execução livre dos mutantes e a facilidade com que os mutantes eram mortos, visto que eles eram forçados a executar a sequência de sincronização do programa origina. Após identificados esses problemas, a definição de um novo procedimento foi realizada (MET adaptada) na qual esses problemas não ocorrem.

Durante o desenvolvimento da ferramenta, houve alguns problemas com relação ao uso da ferramenta ValiMPI. Primeiramente foi necessário identificar qual versão da ValiMPI era a que mais atendia as necessidades. Foi necessário entender como alguns scripts funcionam e quais são as suas limitações para conseguir utilizar-los corretamente.

\subsection{Trabalhos Futuros}

Durante o desenvolvimento deste projeto, apenas alguns operadores de mutação definidos foram implementados. Como trabalho futuro, seria importante a implementação de todos os operadores definidos. Outro ponto importante a ser considerado como trabalho futuro está em validar esses operadores para verificar a aplicabilidade e importância de cada operador.

Além disso, seria interessante fazer um experimento para comparar o procedimento criado usando MET para identificar diferentes sequências de sincronização dos mutantes em relação ao mesmo procedimento usando o teste de alcançabilidade para encontrar 
todas as sequências de sincronização do mutante vivo. Com isso, pode-se avaliar questões de custo e eficácia em cada um dos procedimentos. 


\section{Referências}

Acree, A. T.; Budd, T. A.; DeMillo, R. A.; Lipton, R. J.; Sayward, F. G. Mutation analysis. technical report git-ics-79/08. Relatório Técnico, Georgia Institute of Technology, Atlanta, GA, USA, 1979.

Acree, Jr., A. T. On mutation. Tese de Doutoramento, Atlanta, GA, USA, 1980.

Agrawal, H.; Demillo, R. A.; Hathaway, R.; Hsu, W.; Hsu, W.; Krauser, E. W.; Martin, R. J.; Mathur, A. P.; Spafford, E. H. Design of mutant operators for the C programming language. Relatório Técnico, Software Engineering Reserch Center, Purdue Institute, 1989.

Almasi, G. S.; Gottlieb, A. Highly parallel computing. Redwood City, CA, USA: Benjamin-Cummings Publishing Co., Inc., 1989.

Andrews, G. Foundations of Multithreaded, Parallel, and Distributed Programming. Addison-Wesley, 2001.

Barbosa, E. F.; Vincenzi, A. M. R.; Maldonado, J. C. Uma contribuição para a determinação de um conjunto essencial de operadores de mutação no teste de programas $\mathrm{C}$. In: XII Simpósio Brasileiro de Engenharia de Software, Maringá, PR, BR, 1998, p. $103-120$.

Ben-Ari, M. Principles of concurrent and distributed programming. Upper Saddle River, NJ, USA: Prentice-Hall, Inc., 1990.

Bradbury, J. S.; Cordy, J. R.; Dingel, J. Mutation operators for concurrent Java (J2SE 5.0). In: Proceedings of the Second Workshop on Mutation Analysis, Washington, DC, USA: IEEE Computer Society, 2006, p. 11-20. 
Budd, T. A. Mutation analysis: Ideas, example, problems and prospects. Computer Program Testing, 1981.

Carver, R. Mutation-based testing of concurrent programs. In: Proceedings of Test Conference, 1993, p. 845-853.

Chaim, M. L. Poke-tool - uma ferramenta para suporte ao teste estrutural de programas baseado em análise de fluxo de dados. Dissertação de mestrado, DCA/FEEC/UNICAMP, 1991.

Choi, B.; DeMillo, R.; Krauser, E.; Martin, R.; Mathur, A.; Offutt, A.; Pan, H.; Spafford, E. The mothra tool set (software testing). In: Proceedings of the Twenty-Second Annual Hawaii International Conference on System Sciences, 1989, p. 275 -284.

Choi, J.-D.; Srinivasan, H. Deterministic replay of Java multithreaded applications. In: Proceedings of the SIGMETRICS symposium on Parallel and distributed tools, ACM, 1998, p. 48-59.

Choi, S.-E.; Lewis, E. C. A study of common pitfalls in simple multi-threaded programs. SIGCSE Bull., v. 32, p. 325-329, 2000.

Cloutier, R.; Muller, G.; Verma, D.; Nilchiani, R.; Hole, E.; Bone, M. The concept of reference architectures. In: Systems Engineering, 2010, p. 14-27.

Coulouris, G.; Dollimore, J.; Kindberg, T. Sistemas distribuídos: Conceitos e projeto. 4. ed. Bookman Companhia Editora, 2007.

Delamaro, M.; Maldonado, J.; Pezzè, M.; Vincenzi, A. Mutant operators for testing concurrent Java programs. In: XV Simpósio Brasileiro de Engenharia de Software, 2001.

Delamaro, M. E. Proteum: Um ambiente de teste baseado na análise de mutantes. Dissertação de mestrado, São Carlos, SP, BR, 1993.

Delamaro, M. E. Mutação de interface: Um critério de adequação interprocedural para o teste de integração. Tese de Doutoramento, São Carlos, SP, BR, 1997.

Delamaro, M. E. Using instrumentation to reproduce the execution of Java concurrent programs. In: Simpósio Brasileiro de Qualidade de Software, 2004.

Delamaro, M. E.; Maldonado, J. C.; M., J. Conceitos básicos. In: Maldonado, J. C.; M., J.; Delamaro, M. E., eds. Introdução ao Teste de Software, v. 1, Elsevier Editora Ltda, 2007. 
DeMillo, R. A.; Lipton, R. J.; Sayward, F. G. Hints on test data selection: Help for the practicing programmer. Computer, v. 11, p. 34-41, 1978.

DeSouza, J.; Kuhn, B.; de Supinski, B. R.; Samofalov, V.; Zheltov, S.; Bratanov, S. Automated, scalable debugging of MPI programs with intel message checker. In: Proceedings of the second international workshop on Software engineering for high performance computing system applications, New York, NY, USA: ACM, 2005, p. 78-82.

Fabbri, S. C. P. F.; Maldonado, J. C.; Masiero, P. C.; Delamaro, M. E. Proteum/FSM: A tool to support finite state machine validation based on mutation testing. In: Proceedings of the 19th International Conference of the Chilean Computer Science Society, Washington, DC, USA: IEEE Computer Society, 1999a, p. 96-.

Fabbri, S. C. P. F.; Maldonado, J. C.; Masiero, P. C.; Delamaro, M. E.; Wong, E. Mutation testing applied to validate specifications based on petri nets. In: Proceedings of the IFIP TC6 Eighth International Conference on Formal Description Techniques VIII, London, UK, UK: Chapman \& Hall, Ltd., 1996, p. 329-337.

Fabbri, S. C. P. F.; Maldonado, J. C.; Sugeta, T.; Masiero, P. C. Mutation testing applied to validate specifications based on statecharts. In: Proceedings of the 10th International Symposium on Software Reliability Engineering, Washington, DC, USA: IEEE Computer Society, 1999b, p. 210-.

Farchi, E.; Nir, Y.; Ur, S. Concurrent bug patterns and how to test them. In: Proceedings of the 17th International Symposium on Parallel and Distributed Processing, Washington, DC, USA: IEEE Computer Society, 2003.

Ferrari, F. C. A contribution to the fault-based testing of aspect-orientd software. Tese de Doutoramento, São Carlos, SP, BR, 2010.

Ferrari, F. C.; Nakagawa, E. Y.; Rashid, A.; Maldonado, J. C. Automating the mutation testing of aspect-oriented java programs. In: 5th International Workshop on Automation of Software Test, Cape Town, 2010, p. 51-58.

Flynn, M. J. Some computer organizations and their effectiveness. IEEE Transactions on Computers, v. C-21, p. 948-960, 1972.

Forum, M. P. MPI: A message-passing interface standard. Relatório Técnico, Knoxville, TN, USA, 1995.

Forum, M. P. MPI-2: Extensions to the message-passing interface. Relatório Técnico, Knoxville, TN, USA, 1997. 
Forum, M. P. MPI: A message-passing interface standard version 3.0. Relatório Técnico, Knoxville, TN, USA, 2012.

Ghosh, S. Towards measurement of testability of concurrent object-oriented programs using fault insertion: a preliminary investigation. In: Source Code Analysis and Manipulation, 2002. Proceedings. Second IEEE International Workshop on, 2002, p. 17-25.

Giacometti, C.; Souza, S. R. S.; Souza, P. S. L. Teste de mutação para a validação de aplicações concorrentes usando PVM. In: REIC. Revista Eletrônica de Iniciação científica, 2003.

Grama, A.; Gupta, A.; Karypis, G.; Kumar, V. Introduction to parallel computing. 2. ed. Redwood City, CA, USA: Benjamin-Cummings Publishing Co., Inc., 2003.

Gropp, W.; Lusk, E. Goals guiding design: PVM and MPI. In: Cluster Computing, 2002. Proceedings. 2002 IEEE International Conference on, 2002, p. 257-265.

Gropp, W.; Lusk, E.; Skjellum, A. Using MPI: Portable parallel programming with the message-passing interface. MIT PressScientific And Engineering Computation Series, 1999.

Hausen, A. C. ValiMPI: uma ferramenta de teste estrutural para programas paralelos em ambiente de passagem de mensagem. Mestrado em informática, Universidade Federal do Paraná(UFPR), 2005.

Helmstetter, C.; Maraninchi, F.; Maillet-Contoz, L.; Moy, M. Automatic generation of schedulings for improving the test coverage of systems-on-a-chip. In: Proceedings of the Formal Methods in Computer Aided Design, Washington, DC, USA: IEEE Computer Society, 2006, p. 171-178.

Hyde, D. C. Introduction to the programming language occam. 1995.

Disponível em http://www.eg. bucknell.edu/ cs366/occam.pdf

IEEE Ieee standard glossary of software engineering terminology. IEEE Std 610.12-1990, p. 1, 1990.

Jagannath, V.; Gligoric, M.; Lauterburg, S.; Marinov, D.; Agha, G. Mutation operators for actor systems. In: Proceedings of the 2010 Third International Conference on Software Testing, Verification, and Validation Workshops, Washington, DC, USA, 2010, p. $157-162$. 
Kim, S.; Clark, J. A.; McDermid, J. A. The rigorous generation of Java mutation operators using HAZOP. 12th International Conference on Software \& Systems Engineering and their Applications, 1999.

Koscianski, A.; Soares, M. S. Qualidade de software: aprenda as metodologias e técnicas mais modernas para o desenvolvimento de software. 2 ed. São Paulo, SP, BR: Novatec Editora, 2007.

Krammer, B.; Bidmon, K.; Müller, M. S.; Resch, M. M. MARMOT: An MPI analysis and checking tool. In: Parallel Computing, 2003.

Krawczyk, H.; Wiszniewski, B.; Mork, P. Classification of software defects in parallel programs. HPCTI Progress Report 1, faculty of Eletronics, Technical University of Gdansk, 1995.

Lei, Y.; Carver, R. H. Reachability testing of concurrent programs. IEEE Trans. Softw. Eng., v. 32, p. 382-403, 2006.

Li, Y. Remote procedure call (csc6320 survey paper). 2000.

Disponível em www.cs.gsu.edu/ cscyip/csc8320/rpcD/rpc.doc

Long, B.; Duke, R.; Goldson, D.; Strooper, P.; Wildman, L. Mutation-based exploration of a method for verifying concurrent Java components. 2004.

Long, B.; Strooper, P. A classification of concurrency failures in Java components. In: Proceedings of the 17th International Symposium on Parallel and Distributed Processing, Washington, DC, USA: IEEE Computer Society, 2003.

Long, B.; Strooper, P.; Wildman, L. A method for verifying concurrent Java components based on an analysis of concurrency failures: Research articles. Concurr. Comput.: Pract. Exper., 2005.

Lourenço, J.; Cunha, G. Testing patterns for software transactional memory engines. In: Proceedings of the 2007 ACM workshop on Parallel and distributed systems: testing and debugging, New York, NY, USA: ACM, 2007, p. 36-42.

Lu, S.; Park, S.; Seo, E.; Zhou, Y. Learning from mistakes: a comprehensive study on real world concurrency bug characteristics. In: Proceedings of the 13th international conference on Architectural support for programming languages and operating systems, New York, NY, USA: ACM, 2008, p. 329-339. 
Luecke, G. R.; Chen, H.; Coyle, J.; Hoekstra, J.; Kraeva, M.; Zou, Y. MPI-CHECK: a tool for checking Fortran 90 MPI programs. Concurrency and Computation: Practice and Experience, v. 15, n. 2, p. 93-100, 2003.

Lutz, M. Programming python - powerful object-oriented programming. 4. ed. O'Reilly Media, 2011.

Maldonado, J. C. Critérios potenciais usos: Uma contribuição ao teste estrutural de software. Tese de Doutoramento, Campinas, SP, BR, 1991.

McCabe, T. J. A complexity measure. In: Proceedings of the 2nd international conference on Software engineering, Los Alamitos, CA, USA: IEEE Computer Society Press, 1976.

Müller, M. M.; Tichy, W. F. Case study: Extreme programming in a university environment. In: In Proceedings of the 23rd International Conference on Software Engineering, 2001, p. 537-544.

Myers, G. J.; Sandler, C.; Badgett, T. The art of software testing. 3rd ed. Wiley Publishing, 2011.

Nakagawa, E. Y.; Sasaki, M. M. F.; Maldonado, J. C. An aspect-oriented framework for software documentation: An example on testing. In: XII Iberoamerican Conference on Requirements Engineering and Software Environments, Medellín, 2009, p. 225-238.

Nakagawa, E. Y.; Simão, A. S.; Ferrari, F.; Maldonado, J. C. Towards a reference architecture for software testing tools. In: Proc. of the 19th Int. Conf. on Software Engineering and Knowledge Engineering, Boston, USA, 2007.

Offutt, A. J.; Rothermel, G.; Zapf, C. An experimental evaluation of selective mutation. In: Proceedings of the 15th international conference on Software Engineering, Los Alamitos, CA, USA: IEEE Computer Society Press, 1993, p. 100-107.

Offutt, A. J.; Voas, J.; Payne, J. Mutation operators for Ada. Relatório Técnico, 1996.

Pacheco, P. S. Parallel programming with MPI. San Francisco, CA, USA: Morgan Kaufmann Publishers Inc., 1997.

Pedersen, J. B. Classification of programming errors in parallel message passing systems. In: $C P A, 2006$, p. 363-376.

Pezzè, M.; Young, M. Teste e análise de software: processos, princípios e técnicas. 1 ed. Porto Alegre, RS, BR: Bookman, 2008. 
Pressman, R. Software engineering: A practitioner's approach. 7 ed. New York, NY, USA: McGraw-Hill, Inc., 2010.

Quinn, M. J. Parallel programming in C with MPI and OpenMP. McGraw-Hill Education Group, 2003.

Rapps, S.; Weyuker, E. J. Selecting software test data using data flow information. IEEE Trans. Softw. Eng., v. 11, p. 367-375, 1985.

Roscoe, A. W.; Hoare, C. A. R.; Bird, R. The theory and practice of concurrency. Upper Saddle River, NJ, USA: Prentice Hall PTR, 1997.

Samofalov, V.; Krukov, V.; Kuhn, B.; Zheltov, S.; Konovalov, A.; DeSouza, J. Parallel computing: Current and future issues of high-end computing. Proceedings of the International Conference, 2005.

Sarmanho, F. S.; Souza, P. S.; Souza, S. R.; Simão, A. S. Structural testing for semaphore-based multithread programs. In: Proceedings of the 8th international conference on Computational Science, Berlin, Heidelberg: Springer-Verlag, 2008, p. 337-346.

Scott, L. R.; Clark, T.; Bagheri, B. Scientific parallel computing. Princeton, NJ, USA: Princeton University Press, 2005.

Sen, A. Mutation operators for concurrent SystemC designs. In: Proceedings of the 2009 10th International Workshop on Microprocessor Test and Verification, Washington, DC, USA: IEEE Computer Society, 2009, p. 27-31.

Sen, A.; Abadir, M. Coverage metrics for verification of concurrent systemc designs using mutation testing. In: High Level Design Validation and Test Workshop, 2010, p. $75-81$.

Silva, R. A.; Souza, S. R. S.; Souza, P. S. L. Execução determinística de programas concorrentes durante o teste de mutação. In: 6th Brazilian Workshop on Systematic and Automated Software Testing, 2012a.

Silva, R. A.; Souza, S. R. S.; Souza, P. S. L. Mutation testing for concurrent programs in MPI. In: 13th Latin American Test Workshop, 2012b, p. 69-74.

Silva, R. A.; Souza, S. R. S.; Souza, P. S. L. Utilizando uma arquitetura de referência para apoiar o desenvolvimento de uma ferramenta de teste de programas concorrentes. In: $10^{\circ}$ Congresso Internacional de Gestão da Tecnologia e Sistemas de Informação, 2013. 
Silva-Barradas, S. Mutation analysis of concurrent software. PhD dissertation, Dottorato di Ricerca in Ingegneria Informatica e Automatica, Politecnico di Milano, 1998.

Simão, A. S.; Souza, S. R. S.; Maldonado, J. C. A family of coverage testing criteria for coloured petri nets. In: XVII Simpósio Brasileiro de Engenharia de Software, 2003, p. $209-224$.

Sommerville, I. Engenharia de software. 8 ed. Pearson Education - Br, 2007.

Souza, S. R. S.; Souza, P. S. L.; Machado, M. C. C.; Camillo, M. S.; Simao, A. S.; Zaluska, E. Using coverage and reachability testing to improve concurrent program testing quality. In: 23rd International Conference on Software Engineering and Knowledge Engineering, 2011, p. 207-212.

Souza, S. R. S.; Vergilio, S. R.; Souza, P. S. L. Teste de programas concorrentes. In: Maldonado, J. C.; M., J.; Delamaro, M. E., eds. Introdução ao Teste de Software, v. 1, Elsevier Editora Ltda, 2007.

Souza, S. R. S.; Vergilio, S. R.; Souza, P. S. L.; Simão, A. S.; Hausen, A. C. Structural testing criteria for message-passing parallel programs. Concurr. Comput.: Pract. Exper., v. 20, p. 1893-1916, 2008.

Stallings, W. Arquitetura e organização de computadores. $5^{\circ}$ ed. PRENTICE HALL BRASIL, 2010.

Tai, K.; Carver, R.; Obaid, E. Deterministic execution debugging of concurrent Ada programs. In: Proceedings of the Computer Software and Applications Conference, 1989, p. $102-109$.

Tai, K. C. On testing concurrent programs. In: Proceedings of COMPSAC, 1985, p. $510-517$.

Tai, K.-C. An approach to testing concurrent Ada programs. In: Proceedings of the third annual Washington Ada symposium on Ada: Ada use in focus : practical lessons in perspective, New York, NY, USA: ACM, 1986, p. 253-264.

Tanenbaum, A. S. Organização estruturada de computadores. 5. ed. Sao Paulo, Brazil: Prentice Hall, 2007.

Taylor, R.; Levine, D.; Kelly, C. Structural testing of concurrent programs. Software Engineering, IEEE Transactions on, v. 18, n. 3, p. 206-215, 1992. 
Vergilio, S. R.; Souza, S. R. S.; Souza, P. S. L. Coverage testing criteria for message-passing parallel programs. In: 6th IEEE Latin American Test Workshop (LATW), 2005, p. 161-166.

Vetter, J. S.; Supinski, B. R. Dynamic software testing of mpi applications with umpire. In: Proceedings of the 2000 ACM/IEEE conference on Supercomputing, Washington, DC, USA: IEEE Computer Society, 2000.

Wawrzyniak, R. Systems-on-a-chip: A brave new world. In: Semico Research Corporation Report SC101-1-99, 1999.

Wilkinson, B.; Allen, M. Parallel programming: techniques and applications using networked workstations and parallel computers. Upper Saddle River, NJ, USA: Prentice-Hall, Inc., 1999.

Wu, G.; Kaiser, L. Constructing subtle concurrency bugs using synchronization-centric second-order mutation operators. In: SEKE, Knowledge Systems Institute Graduate School, 2011, p. 244-249.

Yang, C.-S. D.; Souter, A. L.; Pollock, L. L. All-du-path coverage for parallel programs. In: Proceedings of the 1998 ACM SIGSOFT international symposium on Software testing and analysis, New York, NY, USA: ACM, 1998, p. 153-162.

Yang, R.-D.; Chung, C.-G. Path analysis testing of concurrent programs. Inf. Softw. Technol., v. 34, p. 43-56, 1992. 